Leitlinien

Z Rheumatol $2020 \cdot 79$ (Suppl 1):S1-S38 https://doi.org/10.1007/s00393-020-00775-6

(c) Deutsche Gesellschaft für Rheumatologie e.V. Published by Springer Medizin Verlag $\mathrm{GmbH}$. All rights reserved 2020

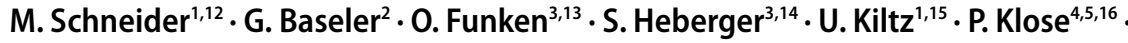

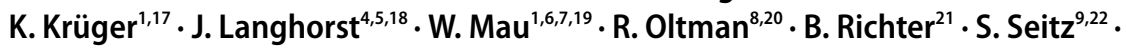
P. Sewerin ${ }^{1,12} \cdot$ R. Tholen ${ }^{10} \cdot$ C. Weseloh ${ }^{1} \cdot$ M. Witthöft ${ }^{1,23} \cdot$ C. Specker ${ }^{1,24}$

'Deutsche Gesellschaft für Rheumatologie e. V., Berlin, Deutschland; ${ }^{2}$ Deutsche Rheuma-Liga Bundesverband e.V., Bonn, Deutschland; ${ }^{3}$ Deutsche Gesellschaft für Allgemein- und Familienmedizin, Berlin, Deutschland; ${ }^{4}$ Gesellschaft für Phytotherapie, Bergisch Gladbach, Deutschland; ${ }^{5}$ Deutsche Gesellschaft für Naturheilkunde, Essen, Deutschland; ${ }^{6}$ Deutsche Gesellschaft für

Rehabilitationswissenschaften, Bielefeld, Deutschland; ' Deutsche Gesellschaft für Physikalische Medizin und Rehabilitation, Dresden, Deutschland; ${ }^{8}$ Deutscher Verband der Ergotherapeuten, KarlsbadIttersbach, Deutschland; ' 9 Deutsche Gesellschaft für Orthopädische Rheumatologie, Hamburg, Deutschland; ${ }^{10}$ Physio Deutschland, Deutscher Verband für Physiotherapie (ZVK) e. V., Köln, Deutschland; ${ }^{11}$ Deutsche Gesellschaft für Psychologie, Berlin, Deutschland; ${ }^{22}$ Poliklinik, Funktionsbereich und Hiller Forschungszentrum für Rheumatologie, Universitätsklinikum Düsseldorf, Heinrich-Heine Universität Düsseldorf, Düsseldorf, Deutschland; ${ }^{13}$ Niedergelassener Allgemeinmediziner, Rheinbach, Deutschland; ${ }^{14}$ Niedergelassener Allgemeinmediziner, Weyarn, Deutschland; ${ }^{15}$ Rheumazentrum Ruhrgebiet, RuhrUniversität Bochum, Herne, Deutschland; ${ }^{16}$ Naturheilkunde und Integrative Medizin, Kliniken Essen-Mitte, Knappschafts-Krankenhaus, Essen, Deutschland; ${ }^{17}$ Rheumatologisches Praxiszentrum, München, Deutschland; ${ }^{18}$ Klinik für Integrative Medizin und Naturheilkunde, Sozialstiftung Bamberg, Klinikum am Bruderwald, Bamberg, Deutschland; ${ }^{19}$ Institut für Rehabilitationsmedizin, Martin-Luther-Universität Halle-Wittenberg, Halle, Deutschland; ${ }^{20}$ Department für Angewandte Gesundheitswissenschaften, Department of Applied Health Sciences, Hochschule für Gesundheit, University of Applied Sciences, Bochum, Deutschland; ${ }^{21}$ Institut für Allgemeinmedizin, Cochrane Metabolic and Endocrine Disorders Review Group, Universitätsklinikum Düsseldorf, Heinrich-Heine Universität Düsseldorf, Düsseldorf, Deutschland; ${ }^{22}$ Klinik für Orthopädie, Klinikum Hochsauerland, Marienhospital, Arnsberg, Deutschland; ${ }^{23}$ Psychologisches Institut, Johannes Gutenberg-Universität Mainz, Mainz, Deutschland; ${ }^{24}$ Klinik für Rheumatologie und klinische Immunologie, KEM-Kliniken Essen-Mitte, Evangelisches Krankenhaus EssenWerden, Essen, Deutschland

\title{
Management der frühen rheumatoiden Arthritis
}

\section{Interdisziplinäre Leitlinie}

\section{Zusatzmaterial online}

Die Online-Version dieses Beitrags (https:// doi.org/10.1007/s00393-020-00775-6) enthält weitere Inhalte zur Leitlinie. Beitrag und Zusatzmaterial stehen Ihnen auf www. springermedizin.de zur Verfügung. Bitte geben Sie dort den Beitragstitel in die Suche ein, das Zusatzmaterial finden Sie beim Beitrag unter „Ergänzende Inhalte“.

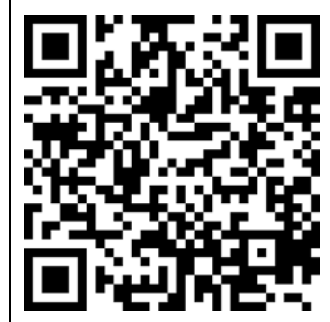

\begin{tabular}{|l}
\hline Infobox AWMF-Leitlinien \\
Register Nummer: 060/002 \\
\hline Entwicklungsstufe: S3 \\
Besonderer Hinweis: \\
Die Medizin unterliegt einem fortwährenden \\
Entwicklungsprozess, sodass alle Angaben, \\
insbesondere zu therapeutischen Verfahren, \\
immer nur dem Wissenstand zur Zeit der \\
Drucklegung der Leitlinie entsprechen \\
können. Hinsichtlich der angegebenen \\
Empfehlungen zur Therapie wurde die \\
größtmögliche Sorgfalt beachtet. Der \\
Benutzer selbst bleibt verantwortlich für \\
jede diagnostische und therapeutische \\
Applikation, Medikation und Dosierung. \\
\hline
\end{tabular}

\footnotetext{
Redaktionelle Anmerkungen

Mit dem Ziel einer besseren Lesbarkeit haben wir in der Leitlinie auf eine geschlechtsspezifische Formulierung verzichtet.

Die Autoren haben sich dafür entschieden, die begründenden Studien jeweils in den die Empfehlungen umgebenden Text einzufügen. Dieser "body of evidence" bestimmt die Empfehlung sowohl vom Inhalt als auch bezüglich der Graduierung.

$\uparrow \uparrow$ Diesen Empfehlungen liegen Studien mit großer Ergebnissicherheit zugrunde, die einen eindeutigen Nutzen gegenüber Risiko belegen.

$\uparrow$ Diesen Empfehlungen liegen Studien mit eingeschränkter Ergebnissicherheit und/ oder geringerem Nutzen gegenüber Risiko zugrunde.

$\checkmark$ Good Clinical Practice ist eine Empfehlung der Konsensusgruppe.
} 


\section{Vorwort}

Die frühzeitige Behandlung der rheumatoiden Arthritis (RA) ist von zentraler Bedeutung für den gesamten weiteren Krankheitsverlauf.

Das Ziel der Leitlinie ist, die Versorgung der Patienten mit früher RA kontinuierlich zu optimieren: in Deutschland sollen alle an einer RA Neuerkrankten innerhalb von sechs Wochen eine fachspezifische Versorgung erhalten. Wegen der sehr großen Bedeutung einer frühzeitigen Diagnose ist ein Behandlungspfad für die Erkennung der Erkrankung in diese Leitlinie integriert. Evidenz-basierte Empfehlungen für die Behandlung sind in dieser 4. überarbeiteten und erweiterten Leitlinie zusammenfassend dargestellt.

Die Leitlinie richtet sich an alle an der Versorgung der RA Beteiligten, insbesondere auch an alle primär versorgenden Ärzte, denen eine große Bedeutung und Verantwortung in der Früherkennung zukommt.

Die zugrundeliegenden Suchstrategien, Ein-Ausschluss-Kriterien und einen Studienüberblick mit Qualitätsbewertung und Evidenztabellen finden sich im Anhang.

\section{Einleitung}

\subsection{Epidemiologie}

Die Prävalenz der rheumatoiden Arthritis (RA) beträgt nach nationalen und internationalen Studien zwischen 0,3 und $1,0 \%$ - je nach Datengrundlage und Falldefinition [1, 2]. Angaben zur Inzidenz sind unsicherer, da unterschiedliche Latenzen zwischen Symptombeginn, Inanspruchnahme medizinischer Hilfe, Diagnosestellung und Therapie einer RA bestehen, und so zu unterschiedlichen Angaben über das Vorliegen einer RA führen. Allgemein wird die Inzidenz der RA in Bevölkerungsstudien mit 0,1-0,5\%o der Erwachsenen angegeben [1], nach einer systematischen Literaturrecherche aus 2010 liegt die Zahl der Neuerkrankungen in Nordamerika und Nordeuropa zwischen 20 und 50 je 100.000 Personen pro Jahr [3]. Der Häufigkeitsgipfel für Neuerkrankungen ist bei Frauen zwischen 55 und 64 Jahren, bei Männern zwischen 65 und 75, wobei Frauen etwa dreimal so häufig betroffen sind wie Männer [1,2]. Neben höherem Alter und weiblichem Geschlecht sind genetische Merkmale, Rauchen und Übergewicht mit einem erhöhten Erkrankungsrisiko für eine RA verbunden [4-6]. Es gibt Hinweise darauf, dass die Inzidenz der rheumatoiden Arthritis, welche in der zweiten Hälfte des 20. Jahrhunderts eher abgenommen hatte, in den letzten beiden Dekaden wieder leicht zugenommen hat, was zusätzlich zur demographischen Entwicklung zu einer Zunahme der Prävalenz führt $[5,7,8]$.

\subsection{Prognose}

Die der RA zugrundeliegende Gelenkentzündung führt nicht nur zu schmerzhaften und geschwollenen Gelenken und Funktionseinschränkungen, sondern unzureichend behandelt $\mathrm{zu}$ einer fortschreitenden Gelenkzerstörung. Diese Entzündung beeinflusst entscheidend die Prognose, sowohl hinsichtlich des Erhalts körperlicher Funktionen als auch hinsichtlich Komorbiditäten und Mortalität [9].

In den ersten zehn Jahren der Erkrankung erleiden etwa die Hälfte aller Patienten schwere Einschränkungen ihrer Funktionsfähigkeit [10], was durch die Anwendung veränderter Therapiekonzepte deutlich minimiert werden kann [11]. Zwar scheint der Schweregrad der Erkrankung insgesamt abgenommen zu haben [12], dennoch besteht weiter eine erhöhte Mortalität [13-15]. Auch der Verlust sozialer und finanzieller Selbständigkeit stellt für RA-Patienten ein großes Problem dar.

Eine individuelle Prognoseabschätzung ist zu Beginn der Erkrankung nur begrenzt möglich. Für eine adäquate Behandlung gilt es, insbesondere bei undifferenzierter Arthritis und früher RA selbstlimitierende von persistierenden und milde von schweren Verläufen zu unterscheiden (siehe Abschn. 2). Etwa die Hälfte der Patienten mit noch undifferenzierter Arthritis und 2/3 aller Patienten mit einer frühen RA entwickeln im Verlauf von fünf Jahren eine wesentliche Funktionseinschränkung
[16-18], die übrigen Patienten haben einen milden Verlauf[19].

Prognostisch ungünstige Faktoren für eine RA sind [9, 20-32]:

- höheres Alter bei Beginn der Erkrankung (>60 Jahre)

- weibliches Geschlecht: Frauen erleiden eine größere Beeinträchtigung der Funktionsfähigkeit und die krankheitsbedingte Mortalität ist höher

- fehlende soziale Bezugssysteme, schlechte ökonomische Bedingungen

- niedriges Bildungsniveau

- Rauchen

- positiver Rheumafaktor und/oder Antikörper gegen citrullinierte Peptide/Proteine

- bereits eingetretene knöcherne Destruktion (Erosionen, Knochenödem)

- verzögerter Therapiebeginn mit krankheitsmodifizierenden Medikamenten (DMARDs)

\subsection{Begründung der Leitlinie}

Trotz geringer Inzidenz hat die RA auf Grund der Schwere der Erkrankung und des chronischen Verlaufes eine erhebliche Bedeutung für jeden Betroffenen und die Gesellschaft. Aktuelle Untersuchungen belegen, dass eine rasche Kontrolle der Krankheitsaktivität durch den frühzeitigen Beginn einer Therapie mit krankheitsmodifizierenden Substanzen entscheidend für die weitere Prognose ist [9, 33-35].

Um dieses sogenannte, „window of opportunity“ zu nutzen, soll bei Vorliegen einer RA innerhalb von drei Monaten nach Beginn der Symptome eine krankheitsmodifizierende (DMARD) Therapie begonnen werden $[9,36,37]$. Damit dieses Ziel möglichst viele Betroffene erreichen, wird eine koordinierte interdisziplinäre Versorgung benötigt, in der möglichst frühzeitig die ersten Krankheitssignale richtig gedeutet werden, unverzüglich die Indikation für eine krankheitsmodifizierende Therapie geprüft wird und die Betroffenen zeitnah zum Rheumatologen überwiesen werden. 


\subsection{Ziel/Adressaten der Leitlinie}

Das Ziel dieser Leitlinie ist, dass in Deutschland alle von einer RA Betroffenen innerhalb von sechs Wochen eine fachspezifische Versorgung erhalten und damit eine frühe Diagnosestellung und Einleitung einer krankheitsmodifizierenden und bei Bedarf multidisziplinären Therapie.

Die Leitlinie richtet sich in erster Linie an alle primär versorgenden Ärzte und auch an alle weiteren an einer koordinierten, problemorientierten Versorgung von Rheumapatienten beteiligten Fachgruppen. Neben den Rheumatologen gehören hierzu u.a. Orthopäden, Physiotherapeuten, Ergotherapeuten, Sozialarbeiter, Pflegekräfte, Psychologen sowie Kranken- und Rentenversicherungen.

Damit diese Ziele der Leitlinie erreicht werden, sollen die Beteiligten optimale Organisationsabläufe vorhalten, z. B. für eine schnelle Übernahme von Patienten, die mit dem Verdacht auf eine RA zugewiesen werden. Darüber hinaus will die Leitlinie dazu beitragen, diejenigen Informationen, welche der Patient im Rahmen der Versorgung durch das multidisziplinäre Team erhält, zu synchronisieren.

Da im heutigen Gesundheitssystem der informierte Patient zunehmend entscheidend zum Erfolg seiner Behandlung beitragen kann, enthält auch die beigefügte Patienteninformation die in dieser Leitlinie enthaltenen Informationen und Empfehlungen.

\section{Diagnose und Prognose der frühen rheumatoiden Arthritis}

\subsection{Einleitung}

Krankheiten des Muskel- und Skelettsystems gehören zu den häufigsten und kostenträchtigsten Leiden in Deutschland und geben häufig Anlass einen Arzt aufzusuchen (Robert Koch-Institut). Muskuloskelettale Beschwerden können vielfältige, auch nicht rheumatologische Ursachen haben. Richtungsweisend für die Diagnose einer frühen rheumatoiden Arthritis (ERA, early rheumatoid arthritis) ist die Unterscheidung zwischen einer Arthritis und einer reinen Arthralgie, al- so Gelenkbeschwerden z. B. bei degenerativen Gelenkveränderungen. Wesentlich für diese Differenzierung sind eine sorgfältige Anamneseerhebung und körperliche Untersuchung. Weitere diagnostische Verfahren wie Labor und Bildgebung dienen dann zielgerichtet der Bestätigung der Diagnose, deren Ausschluss oder der Abklärung von Differenzialdiagnosen [9].

Nach Feststellung einer Arthritis ist es wichtig [9],

- die zugrundeliegende Erkrankung zu differenzieren (z. B. RA, Spondyloarthritis, Psoriasisarthritis, Kollagenosen und Vaskulitiden) und

- das Risiko für eine persistierende oder erosive Arthritis einzuschätzen,

- um darauf aufbauend eine optimale therapeutische Strategie zu entwickeln.

Während eine etablierte RA recht einfach zu diagnostizieren ist, kann sich diese Erkrankung in frühen Phasen noch diskret, atypisch oder nur vorübergehend symptomatisch zeigen [9]. Studien, welche Prädiktoren für den Übergang einer frühen, undifferenzierten Arthritis (UA, undifferentiated arthritis) in eine persistierende oder destruierende entzündliche Gelenkerkrankung untersuchten, konnten die Bedeutung anamnestischer (Dauer und Lokalisation der Beschwerden), klinischer (Befund und Verteilung von Synovitiden) und serologischer (Nachweis von Rheumafaktoren und Antikörpern gegen cyclische citrullinierte Peptide) Befunde für die Diagnose einer ERA aufzeigen $[9,38]$.

Die Klassifikationskriterien von ACR (American College for Rheumatology) und EULAR (European League Against Rheumatism) von 2010 ([39]; Anhang 9.1), basieren auf diesen Risikofaktoren. Sie erleichtern auch die frühe Diagnose einer RA [40] und damit die frühe Einleitung einer krankheitsmodifizierenden Therapie und somit die Verhinderung irreversibler Krankheitsfolgen.

\subsection{Anamnese}

Ein typischer Patient mit einer RA beschreibt folgende Symptome: Schmerz, Schwellung und Steifheit von Hand(HG), Fingergrund- (MCP), Fingermittel- (PIP) und/oder Zehengrundgelenken (MTP). Grippe-ähnliche Allgemeinsymptome treten nicht selten begleitend auf.

Bestehen die Symptome einer Arthritis (Gelenkschwellung) mindestens sechs Wochen, erhöht dies die Wahrscheinlichkeit für das Vorliegen einer frühen RA und bei einer Persistenz von mehr als drei bis sechs Monaten ist eine RA wahrscheinlich, sofern keine anderen entzündlich-rheumatischen Erkrankungen vorliegen [38]. Typisch für die etablierte RA ist das polytope (mindestens drei Gelenke) und symmetrische (beidseitige) Befallsmuster [41], das mit zunehmender Zahl befallener Gelenke wahrscheinlicher wird [39].

Die Wahrscheinlichkeit, eine RA zu entwickeln, steigt mit der Zahl der betroffenen Gelenke und deren Verteilung auf die vier Extremitäten sowie der Dauer der Morgensteifigkeit über $30 \mathrm{~min}$ [28-30], die über Tag - auch nach Ruhephasen - nicht wieder eintritt (im Gegensatz zur rezidivierenden Gelenksteife und den wiederkehrenden Anlaufschmerzen nach kurzen Ruhepausen bei der Arthrose). Eine Arthritis bereitet typischerweise auch in Ruhe Beschwerden, bei der Arthrose sind diese vorwiegend belastungs- und bewegungsabhängig.

Auch in der Frühphase der Erkrankung können mittlere und große Gelenke betroffen sein. Gelenkveränderungen der Fingerendgelenke, Daumensattelgelenke und Großzehengrundgelenke sind meist arthrotisch bedingt, weshalb diese $\mathrm{Ge}$ lenke bei der Beurteilung nach den neuen Klassifikationskriterien der RA ausdrücklich nicht berücksichtigt werden ([39]; Anhang 9.1).

\subsection{Klinischer Befund}

Die klinische Untersuchung ist die Methode der Wahl zum Nachweis einer Arthritis, obwohl bildgebende Verfahren zum Nachweis einer Synovitis sensitiver sein können [9]. Auch wenn nur ein 
einzelnes Gelenk als betroffen geschildert wird, sollte auf Pathologika anderer Gelenke oder anderer Organsysteme (z.B. der Haut) geachtet werden, weil über solche Befunde die Einordnung des Krankheitsbildes erleichtert werden kann.

\section{Good Clinical Practice $\checkmark$}

\section{Eine Gelenkschwellung unklarer Genese stellt eine Indikation zur Ganzkörperuntersuchung dar}

Die Gelenkentzündung (Arthritis) zeigt sich als Schwellung, meist begleitet von Schmerzen bei Druck bzw. Prüfung der maximalen Beweglichkeit. Prädilektionsgelenke der RA sind die Hand-, Fingergrund- und Fingermittelgelenke sowie die Zehengrundgelenke (außer MTP I, CMC I \& DIPs). Die Gelenkschwellung ist als "prallelastische“ Weichteilschwellung der Gelenkkapsel zu palpieren, die durch Erguss und/oder entzündliche Verdickung der Gelenkschleimhaut (Synovialitis) bedingt ist [9]. Auch auf weitere Entzündungszeichen wie Rötung und Überwärmung ist $\mathrm{zu}$ achten. Im Bereich der Fingergrundund Zehengrundgelenke ist oft ein sog. Querdruckschmerz (seitliches Zusammendrücken der Gelenke mittels der Untersucherhand) festzustellen.

Demgegenüber finden sich bei der Arthrose eine Deformierung und eine „knochenharte“ Auftreibung des Gelenkes (Osteophyten), die auf Druck nicht nachgibt. Im Bereich der Hände ist diese besonders leicht zu erkennen an den Fingerend- (sog. Heberden-Arthrose) oder -mittelgelenken (sog. Bouchard-Arthrose). Bei einer "aktivierten“ Arthrose entstehen durch Überbeanspruchung der Gelenke (z. B. bei Gonarthrose nach langem Gehen) auch „Reizergüsse“, die sich bei Schonung innerhalb weniger Tage wieder resorbieren. Die Ergussbildung bei der Arthritis ist hingegen weitgehend unabhängig von der Belastung.

Wenn bei einer Arthritis keine eindeutige Diagnose gestellt werden kann, sollten Risikofaktoren für eine persistierende und/oder erosive Erkrankung, einschließlich der Anzahl der geschwollenen Gelenke, Akut-Phase-Parameter,
Rheumafaktor (RF), anti-citrullinierte Peptid-Antikörper (ACPA) und bildgebende Befunde für die Entscheidung zum weiteren Vorgehen herangezogen werden (Abschn. 2.4 und 2.5; $[9,39]$ ).

\subsection{Technische Untersuchungen}

Nach den Klassifikationskriterien von 2010 [39] reicht zwar der alleinige Nachweis von RA-typischen Knochenerosionen in $\geq 3$ Gelenken für die Klassifikation als RA aus [42]. Da sich Erosionen aber noch nicht im frühen Stadium einer RA nachweisen lassen, werden für die Sicherung der klinischen Diagnose oder Verdachtsdiagnose die Ergebnisse verschiedener technischer Untersuchungen herangezogen [9].

\subsubsection{Laboruntersuchungen}

Patienten mit einer aktiven RA weisen meist unspezifische serologische Entzündungszeichen (Blutsenkungsgeschwindigkeit, BSG; C-reaktives Protein, CRP) auf, die dann auch gut die Krankheitsaktivität widerspiegeln [43]. Eine gesteigerte sog. Akut-Phase-Reaktion (meist erfasst durch ein erhöhtes CRP) korreliert dabei auch mit einem progressiv destruierenden Verlauf der Erkrankung. Ihr Rückgang unter Therapie ist ein Zeichen des guten therapeutischen Ansprechens und ein Surrogatmarker für eine Unterdrückung der destruktiven Potenz der RA. Ein Fehlen solcher unspezifischer Entzündungszeichen macht eine RA zwar unwahrscheinlich [10], schließt sie aber, insbesondere zu Beginn der Erkrankung, auch nicht aus. In einer Querschnittsuntersuchung (an 1892 RA-Patienten aus Europa und 738 aus den USA) hatten bis zu $33 \% \mathrm{zu}$ Beginn ihrer Erkrankung keine serologischen Entzündungszeichen [43]. Auf der anderen Seite muss betont werden, dass eine Erhöhung von BSG und CRP unspezifisch und somit keinesfalls beweisend für das Vorliegen einer RA sind.

Spezifische Labortests, welche die Diagnose einer RA erhärten, sind Untersuchungen auf Antikörper (Ak) gegen (cyclische) citrullinierte Peptide (CCP) und auf IgM-Rheumafaktoren (RF).
IgM-Rheumafaktoren (RF) sind in ca. $65-80 \%$ der RA-Patienten, aber auch bei anderen rheumatischen Erkrankungen und in bis zu $5 \%$ bei Gesunden zu finden. Die Spezifität von RF für eine RA liegt im ELISA (enzyme linked immunosorbent assay)-Testverfahren bei ca. $80 \%$, die Sensitivität bei ca. $70 \%$ [44].

Als Antikörper gegen citrullinierte Peptide/Proteine (ACPA) werden Antikörper gegen cyclisches Citrullin (CCP), mutiertes (MCV) und nicht mutiertes citrulliniertes (Sa) Vimentin sowie gegen citrulliniertes Fibrinogen zusammengefasst, die auch eine weitgehende Kreuzreaktivität aufweisen [45]. Über $90 \%$ der Untersuchungen zur Bedeutung der ACPA für die Diagnose und Prognose der RA basieren auf der Bestimmung von CCP-Ak (meist anti-CCP-2-Ak). Dass andere ACPA eine über die der CCP-Ak hinausgehende diagnostische oder prognostische Bedeutung haben, konnte nicht belegt werden [46-53].

CCP-Ak sind für die Diagnose der RA vergleichbar sensitiv (62-76\%) wie der RF (64-86\%), sie sind aber mit über $95 \%$ deutlich spezifischer als der (IgM-) Rheumafaktor (84-90\%) [24, 49, 54-63].

Der Nachweis von CCP-Ak kann der klinisch manifesten RA um Jahre vorausgehen $[64,65]$ und hat bei einer noch undifferenzierten Arthritis einen hohen prädiktiven Wert für die Entwicklung einer RA. Die Angaben zur Odds-Ratio (OR) für den Nachweis von CCP-Ak schwanken je nach untersuchtem Kollektiv (sehr frühe, frühe, undifferenzierte Arthritis) und der Höhe der CCPAk zwischen 64 und 8 gegenüber 29 bis 5,6 für den Rheumafaktor $[10,27,58,63$, 66]. Die positive Likelihood-Ratio für die Entwicklung einer RA lag in zwei Metaanalysen [54, 55] zwischen 21 und 13 für CCP-Ak gegenüber 5 bis 3 für den Rheumafaktor. In einer großen schwedischen epidemiologischen Untersuchung wiesen 350 von 12.590 Individuen einen positiven anti-CCP-2-Test auf. Von diesen lag bei 103 eine RA vor, wobei von den verbliebenen 247 ACPA-positiven Individuen weitere $21(8,5 \%)$ in den folgenden drei Jahren eine RA entwickelten. Der positive prädiktive Wert lag für CCP-2Ak bei $29 \%$ für eine bereits manifeste RA, der negative prädiktive Wert (kein 
Tab. 1 Anamnese und klinische Untersuchung von Patienten mit entzündlichen Gelenksymptomen

\begin{tabular}{|c|c|}
\hline Anamnese: & Körperliche Untersuchung: \\
\hline $\begin{array}{l}\text { Schmerz } \\
\text { - (Wo?, Was?, Wann? Seit } \\
\quad \text { wann?) }\end{array}$ & $\begin{array}{l}\text { Gelenkschwellung (ohne sonstige Ursache wie z. B. Trauma, Gicht) } \\
\text { - Differenzierung: Schwellung (RA verdächtig) oder knöcherne } \\
\text { Auftreibung/Deformierung? } \\
\text { - polyartikuläres, symmetrisches Verteilungsmuster in den Prädi- } \\
\text { lektionsregionen (HG, MCP, PIP, MTP) }\end{array}$ \\
\hline $\begin{array}{l}\text { Gelenksteife } \\
\text { - insbes. Morgensteife } \\
\quad \geq 60 \text { Min }\end{array}$ & Bewegungseinschränkung (nicht durch andere Ursachen bedingt) \\
\hline $\begin{array}{l}\text { Allgemeines } \\
\text { Krankheitsgefühl } \\
\text { - bis hin zu subfebrilen } \\
\text { Temperaturen }\end{array}$ & $\begin{array}{l}\text { Extraartikuläre Manifestationen } \\
\text { - z. B. Hautveränderungen (z. B. Psoriasis), Augenentzündung } \\
\text { (z. B. Skleritis, Vaskulitis, Rheumaknoten) }\end{array}$ \\
\hline
\end{tabular}

Vorliegen einer RA bei negativen CCP-2Ak) bei 99,6\%. Die entsprechenden Werte für hoch-positive CCP-2-Ak betrugen 48 und $99,5 \%$ [58].

CCP-Ak sind bei früher RA auch ein Indikator für einen schwereren, insbesondere erosiv-destruierenden Verlauf $[32,34,35,54,67]$ sowie für eine höhere serologische Entzündungsaktivität [58].

Eine Änderung des CCP-Ak-Status ist bei etablierter Erkrankung selten. Die Titerhöhe der CCP-Ak eignet sich nicht als Verlaufsparameter zur Aktivitätsbeurteilung der RA [61, 68, 69].

Die Bestimmung weiterer Auto-Ak (z.B. antinukleäre Antikörper, ANA) dient vor allem dem Nachweis oder Ausschluss anderer, klinisch manchmal ähnlich verlaufender rheumatischer Erkrankungen (z.B. Kollagenosen).

\subsubsection{Bildgebende Verfahren}

Die Röntgenuntersuchung, insbesondere die dorsovolare Aufnahme beider Hände und Füße (mit einer zweiten Ebene), ist essentieller Bestandteil der Primärdiagnostik bei RA. Das Vorliegen typischer erosiver Gelenkveränderungen an Prädilektionsgelenken (s. Erläuterung zu - Tab. 1) ist schon alleine beweisend für eine RA [39], aber kein Zeichen der frühen Phase (ERA). Auch eine aggressiv erosiv verlaufende RA führt erst nach durchschnittlich 6-24 Monate zur Ausbildung röntgenologisch fassbarer Erosionen $[69,70]$. Das Fehlen entsprechender Röntgenveränderungen schließt also das Vorliegen einer ERA keinesfalls aus. Bei einer Beschwerdedauer von im Mittel acht Wochen haben lediglich 13\% der Patienten, bei denen sich später die Diagnose RA bestätigt, röntgenologisch nachweisbare Erosionen [70].

Andere Methoden der Bildgebung wie die Gelenksonographie (einschließlich Power-Doppler (PWD)) und die Magnetresonanztomographie (MRT) erlauben eine frühere Sicherung struktureller Gelenk- und Knochenveränderungen sowie die bessere Darstellung von Knochenstoffwechselveränderungen (MRT, ggf. auch Szintigraphie) oder Gelenkergüssen (Sonographie, MRT) [71-73]. Der Nachweis einer vermehrten Vaskularisierung in der proliferierten Gelenkschleimhaut in der PWD-Sonographie und der Nachweis eines gelenknahen Knochenmarködems in der MRT gelten als früheste Zeichen noch reversibler struktureller Veränderungen der RA [74, 75].

Die MRT und die Gelenksonographie können heute die klinische Untersuchung bei der Suche nach einer Arthritis unterstützen, wobei in der MRT aufgrund ihrer hohen Sensitivität auch bei Gesunden vergleichsweise hohe Raten an Auffälligkeiten erkannt werden. Die MRT sollte deshalb von geschulten Experten bewertet werden [9]. Sowohl der klinische als auch der sonographische Nachweis einer Synovialitis korreliert bei der frühen RA mit der Entwicklung struktureller Schäden, deren Odds-Ratio (OR) für die klinische Untersuchung 2,01, für die Ultraschalluntersuchung 1,61 und für die Ultraschalluntersuchung mit Power-Doppler 1,75 beträgt [76]. Gleiches gilt für die MRT; das Ausmaß der Synovialitis und des Knochen- marködems in einem standardisierten Auswertealgorithmus (Rheumatoid Arthritis MRI Scoring System (RAMRIS), [77]) sind unabhängige Prädiktoren für radiologische Progression in konventionellen Röntgenbildern nach 24 Wochen [78]. Die Szintigraphie ist aufgrund ihrer geringen Spezifität in der Routinediagnostik nur noch in Ausnahmefällen empfohlen.

\subsection{Empfohlene Diagnostik}

\subsubsection{Anamnese und klinische Untersuchung von Patienten mit entzündlichen Gelenksymptomen (• Tab. 1).}

\section{Klinisch richtungsweisende Befunde für die Verdachtsdiagnose RA \\ - Gelenkschwellungen ohne ande- re Ursache seit mindestens sechs Wochen, \\ - polyartikuläres (symmetrisches) Verteilungsmuster und \\ - Morgensteife von mindestens $>60$ min.}

\subsubsection{Empfehlungen zur technischen Diagnostik der RA \\ (- Tab. 2, 3).}

Richtungsweisende Laborbefunde für die RA sind: Erhöhte BSG, erhöhtes CRP, Nachweis von Rheumafaktoren und/oder Nachweis von Antikörpern gegen citrullinierte Peptide (ACPA/CCP$\mathrm{AK})$.

\section{Empfehlung $\uparrow \uparrow$}

\section{Bei Verdacht auf eine rheumatoide Arthritis sollen BSG, CRP, und ACPA/ Rheumafaktor bestimmt werden}

\subsubsection{Prädiktionsmodell für eine frühe RA (• Tab. 4)}

Diese Wahrscheinlichkeiten entstammen einem Prädiktionsmodell, welches in einer spezialisierten Ambulanz für Patienten mit früher Arthritis in den Niederlanden entwickelt wurde. Eingeschlossen waren Patienten, die von den betreuenden Hausärzten auf Grund von mindestens zwei der folgenden 


\section{Tab. 2 Laboruntersuchungen}

Blutsenkung (BSG) Häufig erhöht bei (unbehandelter) RA, unspezifisch (auch bei Anämien, anderen entzündlichen Erkrankungen)

C-reaktives Protein Quantitativ genauer und schneller im Verlauf als die BSG, reflektiert besser (CRP) die sog. Akut-Phase-Reaktion (Krankheitsaktivität), genauso unspezifisch wie die BSG

Blutbild

Bei länger dauernder aktiver Erkrankung:

Entzündungsanämie (normochrom oder hypochrom, normozytär), Thrombozytose

IgM-Rheumafaktor Positiv bei 65-80\% der RA-Patienten; 55-85\% bei ERA. Spezifität ca. $80 \%$, (RF) da auch bei Kollagenosen, Virushepatitiden, Malignomen und (selten) auch bei Normalpersonen nachweisbar

Antikörper gegen citrullinierte Proteine/Peptide (ACPA)

Hochspezifisch für die RA (>95\%) und dabei genauso sensitiv (64-86\%) wie der Rheumafaktor. Kann schon vor klinischer Manifestation einer RA positiv sein und ist bei Vorliegen einer frühen Arthritis hoch-prädiktiv für einen chronischen (RA) und prädiktiv für einen erosiven Verlauf

Urinuntersuchung Ausschluss einer Hämaturie, Proteinurie als Hinweis für andere Erkrankungen (z. B. Kollagenosen)

Antinukleäre-Ak Differentialdiagnostischer Hinweis für Kollagenosen (z. B. systemischer (ANA) Lupus erythematodes, SLE), schwach positiv auch bei der RA oder Normalpersonen

Antineutrophilen- Differentialdiagnostischer Hinweis für Vaskulitiden (z. B. Granulomatose mit Cytoplasma-Ak Polyangiitis)

(ANCA)

HLA-B27

Differentialdiagnostischer Hinweis für Spondyloarthritiden

Harnsäure/

Gelenkpunktat

Abgrenzung zur polyartrikulären Gicht (selten) und infektiösen Arthritiden (meist einzelne, große Gelenke)

Tab. 3 Bildgebung

Röntgen

Bei klinischem Verdacht auf eine RA dorsovolare Aufnahmen (ggf. Schrägaufnahmen) von beiden Händen und Füßen als Ausgangsbefund für die weitere Verlaufsbeurteilung

Sonographie

Nachweis von Gelenkergüssen, synovialer Proliferation, Tenovaginitiden, Erosionen. Im Powerdoppler Nachweis einer vermehrten Vaskularisation der Synovialis.

In der Hand des erfahrenen Untersuchers vor allem aufgrund ihrer Verfügbarkeit und einfacheren Durchführbarkeit eine wichtige Ergänzung des klinischen Befundes

MRT

Hochsensitive und hochauflösende Bildgebung zu Struktur und Funktion von Knochen, Gelenken, Sehnen und Muskeln

\section{Tab. 4 Prädiktionsmodell nach Visser et al. [30]}

\begin{tabular}{|c|c|c|c|c|}
\hline \multicolumn{2}{|l|}{ Klinische Symptome } & \multicolumn{3}{|c|}{ Serologie } \\
\hline \multicolumn{2}{|c|}{$\begin{array}{l}\text { - Synovitiden in mehr als zwei Gelenkregionen } \\
\text { - Dauer }>6 \text { Wochen } \\
\text { - Morgensteife } \geq 60 \mathrm{~min}\end{array}$} & $\mathrm{RF}+$ & CCP-Ak+ & $\begin{array}{l}\text { RF und } \\
\text { CCP-Ak+ }\end{array}$ \\
\hline $\begin{array}{l}\text { Wahrscheinlichkeit } \\
\text { für persistierende Arthritis: }\end{array}$ & $46 \%$ & $71 \%$ & $80 \%$ & $92 \%$ \\
\hline Davon werden erosiv: & $52 \%$ & $78 \%$ & $86 \%$ & $95 \%$ \\
\hline
\end{tabular}

Symptome überwiesen worden waren: Gelenkschmerz, Gelenkschwellung, Bewegungseinschränkung der Gelenke. Alle Patienten wurden innerhalb von zwei Wochen nach Überweisung von einem Rheumatologen untersucht [30]. Es handelt sich also um eine Selektion

\subsubsection{Clinically Suspect Arthralgia (CSA) [79]}

Für Arthralgien ohne klinische Zeichen einer Arthritis wurden objektivierbare Kriterien entwickelt, die es Rheumatologen ermöglichen, das Kollektiv frühzeitig zu identifizieren, bei dem anhand von sieben Kriterien ein deutlich erhöhtes Risiko detektierbar ist, eine chronische Arthritis (Synovitis) bzw. eine manifeste RA mit Gelenkdestruktion zu entwickeln. Dies wird unter dem Begriff der „clinically suspect arthralgia" (CSA) subsummiert. Die CSA ist keine eigenständige Erkrankung, sondern ein Komplex aus Symptomen und Zeichen.

\section{Kriterien der CSA}

- Dauer der Symptome unter einem Jahr

- Beschwerden an den MCP-Gelenken

- Morgensteifigkeit $\geq 60$ min

- stärkste Beschwerden in den Morgenstunden

- Familienangehörige 1. Grades mit RA

- Schwierigkeiten beim Faustschluss

- positiver „Querdruckschmerz“ an MCP-Gelenken

$\mathrm{Ab}$ drei positiven Kriterien besteht ein erhöhtes Risiko für die Entwicklung einer RA. Die Sensitivität beträgt $90 \%$. Um auch eine Spezifität von $90 \% \mathrm{zu}$ erreichen, müssen mindestens vier Kriterien zutreffen. Die Anwendbarkeit dieses Scores wurde für die Ebene der Primärversorgung bisher nicht evaluiert.

\subsection{Diagnostischer Algorithmus}

(• Abb. 1).

\section{Versorgungspfad für Patienten mit früher Arthritis}

Die meisten Menschen mit neu aufgetretenen muskuloskelettalen Beschwerden kontaktieren zuerst den Hausarzt oder auch den niedergelassenen Orthopäden. Diesen Fachgruppen kommt daher auch im Management der frühen Arthritis eine entscheidende Bedeutung bei Diagnosestellung und Versorgung zu:

1. Diagnosestellung:

a) Ggf. Diagnosesicherung 


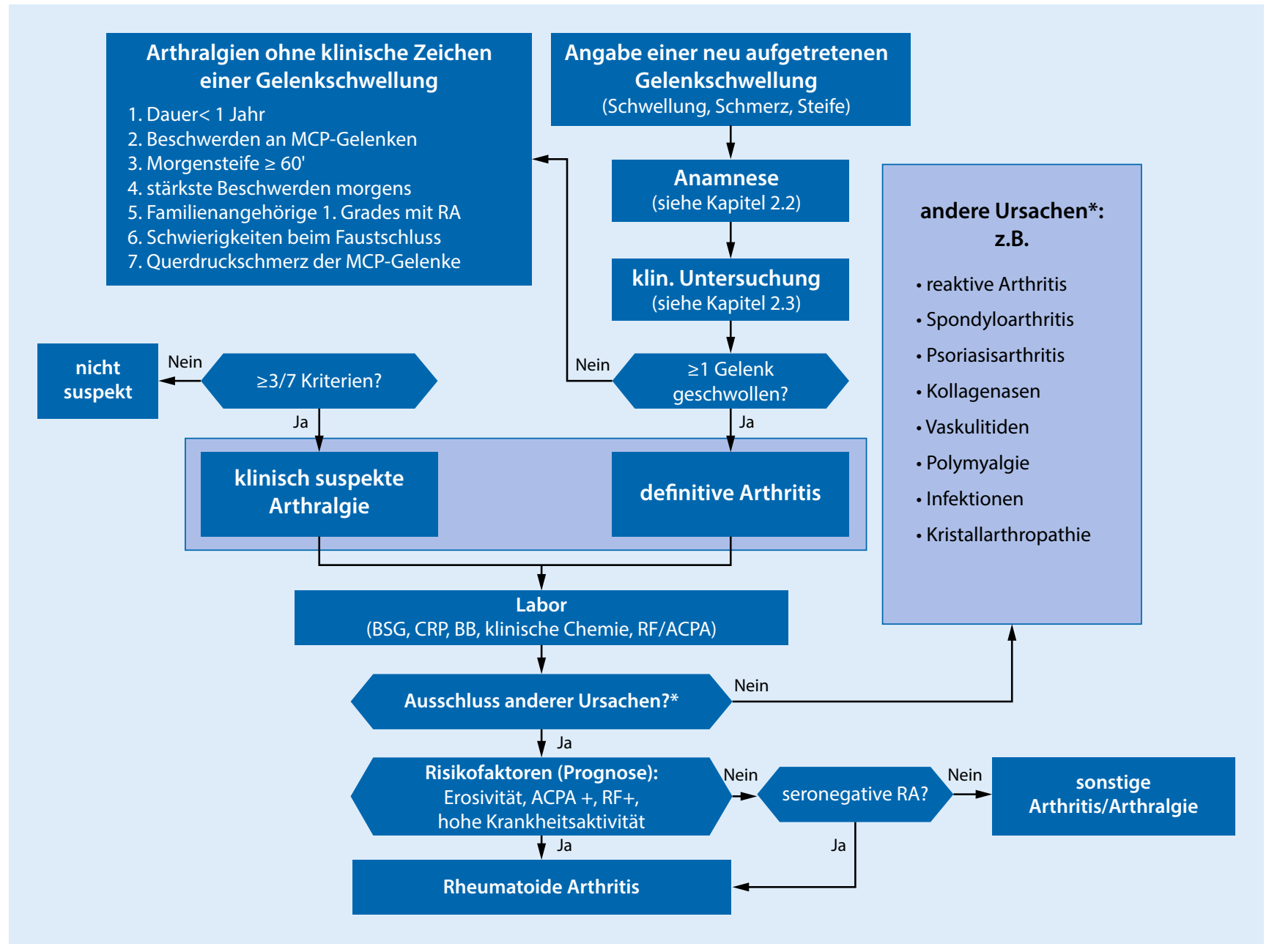

Abb. 1 A Diagnostischer Algorithmus neue "Gelenkschwellung"

b)Identifikation und Überweisung der Patienten, die einer spezialisierten Diagnostik oder Therapie bedürfen

c) Erkennung von Notfällen

2. Versorgung:

a) Bei gesicherter Diagnose ggf. Einleitung einer ersten DMARDTherapie, um das „Window of Opportunity“ zu sichern

b)Beratung von Patienten vor und während einer Therapie sowie vor und nach Konsultationen von Spezialisten, Beobachtung und Förderung der Patientencompliance (Therapieadhärenz), Behandlung von Begleit- und Folgeerkrankungen, Durchführung notwendiger Kontrollen bei einer laufenden Therapie.

c) Erkennung und Erstversorgung von Notfällen und Komplikationen

\section{Good Clinical Practice $\checkmark$}

Wurde bei neu aufgetretenen Ge-
lenkschwellungen innerhalb von
sechs Wochen keine Diagnose gesi-
chert, sollte der Patient möglichst
innerhalb von zwei Wochen einem
Rheumatologen vorgestellt werden

\subsection{Zielsetzung}

Der Versorgungspfad für die frühe Arthritis soll

1. einen Algorithmus des diagnostischen Vorgehens bei Verdacht auf eine frühe Arthritis anhand von klinischen Symptomen und (einfachen) Zusatzuntersuchungen liefern,

2. Indikatoren für die Überweisung zum Rheumatologen definieren, einschließlich Kriterien zur notfallmäßigen Vorstellung und
3. Empfehlung zu einer überbrückenden Therapie geben.

\subsection{Vorgehen bei Verdacht auf eine frühe Arthritis}

Entscheidend für die richtige Erkennung einer frühen Arthritis ist die Unterscheidung zwischen einer Arthritis und der reinen Arthralgie bei z.B. degenerativen Gelenkveränderungen (Abschn. 2.3 und 3.2.1). Typisch für eine Arthritis ist eine palpable, weiche, "elastische" Schwellung eines Gelenkes, die durch Erguss und/oder entzündliche Verdickung der Gelenkschleimhaut (Synovitis, Synovialitis) bedingt ist, begleitet von Schmerzen und Gelenksteife [9].

\subsubsection{Anamnese}

Anamnestische Differenzierungsmerkmale sind: 
- die Dauer der Gelenkschwellungen oder Gelenkschmerzen,

- der Verlauf der Beschwerden (bei RA häufig undulierend),

- die Zahl der betroffenen Gelenke (eines, wenige oder viele?),

- das Befallsmuster (bei RA häufig Fingergrundgelenke)

- ein eingeschränkter Faustschluss

- ein positives Gänslenzeichen (Querdruckschmerz der Finger- und Zehen-Grundgelenke)

- eine familiäre Disposition

- das Auftreten der Beschwerden (z. B. im Anschluss an ein Trauma, spontan oder nur nach (übermäßiger) Belastung),

- eine Morgensteifigkeit

Die Dauer der Morgensteifigkeit liegt bei nicht-entzündlichen $\mathrm{Ge}$ lenkerkrankungen in der Regel unter 30 min und bei manifester RA bei mindestens 60 min Dauer [38].

Diese Befunde sollten auch dann Anlass zu einer weiteren Abklärung sein, wenn bei Gelenkschmerzen keine typische Arthritis nachweisbar ist (siehe Abschn. 2.5.4 [79]).

\subsubsection{Ergänzende Diagnostik}

Bei jedem Verdacht auf eine entzündliche Gelenkerkrankung sollten folgende Parameter (RF, CCP-AK, BSG, CRP), Blutbild sowie Leber- und Nierenwerte bestimmt werden (ggf. sind auch CK, LDH und Harnsäure sinnvoll). Eine Gelenkschwellung mit humoralen Entzündungszeichen ist ernster zu werten und spricht eher für eine chronische Arthritis als eine ohne solche Anzeichen [9].

Bei Verdacht auf eine RA sollte die in Abschn. 2.5 dargelegte erweiterte Diagnostik erfolgen.

Eine Röntgenuntersuchung dient in der frühen Phase einer Gelenkschwellung dem Ausschluss von Frakturen oder anderen Knochenprozessen und als Grundlage für die Verlaufsbeurteilung (mittels validierter Scores, siehe Abschn. 5.2.2). Radiologisch sind Frühzeichen einer Arthritis nicht zu erkennen.

Bei Verdacht auf eine septische Arthritis (Traumata, vorherige Eingriffe, Diabetiker, immunsupprimierte Patienten, kli- nischer Befund einer hochfloriden Monarthritis, Fieber) soll unverzüglich eine diagnostische Gelenkpunktion erfolgen (ggf. hierfür Überweisung zum Orthopäden oder Rheumatologen).

\section{3 Überweisungskriterien in eine rheumatologische Mitversorgung}

Eine zeitnahe Vorstellung beim Rheumatologen ist unter folgenden Kriterien erforderlich bei:

1. Gelenkschwellung mit ungesicherter Diagnose

Dringlichkeit besteht, wenn

- mehrere Gelenke betroffen sind,

- eine Einschränkung der körperlichen Alltagsbewältigung oder Teilhabe besteht, oder

- deutliche humorale Entzündungszeichen vorliegen.

2. gesicherter Diagnose einer entzündlichen Gelenkerkrankung, wie der RA, zur Beurteilung der Krankheitsprognose und Therapieadjustierung

3. Vorliegen mehrerer Risikofaktoren und Gelenkschmerzen auch ohne Gelenkschwellung (CSA, siehe Abschn. 2.5.4)

Ein Verlust der Geh- oder Selbstversorgungsfähigkeit sowie ausgeprägte Allgemeinsymptome (Anämie, Fieber, vaskulitische Hautveränderungen) und starke Schmerzen stellen eine Indikation zur stationären Aufnahme in einer rheumatologischen Fachabteilung dar.

\section{Good Clinical Practice $\checkmark$}

Jeder Patient mit neu aufgetretener RA sollte zur Abschätzung der Langzeitprognose einem Rheumatologen zugewiesen werden

\section{4 Überbrückende Therapie}

Eine symptomatische Therapie mit oralen nicht-steroidalen Antirheumatika (NSAR) oder anderen Analgetika nach WHO-Schema kann bei entsprechenden Beschwerden, z.B. auch überbrückend und bedarfsorientiert, auch ohne endgültige Diagnosesicherung begonnen werden. Sie sollte die diagnostische Abklärung nicht verzögern.
Good Clinical Practice $\checkmark$

Von der Einleitung einer Corticosteroidtherapie ohne gesicherte Diagnose einer entzündlich-rheumatischen Erkrankung wird ausdrücklich abgeraten

Eine Corticosteroidtherapie sollte auch nicht „ex juvantibus“ erfolgen, bevor nicht eine spezielle rheumatologische Untersuchung erfolgt ist, da hierdurch die Diagnostik und Differenzialdiagnostik erschwert werden kann.

\subsection{Koordinierte Versorgung von RA-Patienten}

Auch nach Diagnosestellung und Therapieeinleitung bedürfen Patienten mit RA einer kontinuierlichen Versorgung am besten durch ein multidisziplinäres Team (Abschn. 4.3). Dieses Konzept bedarf im Sinne der Betroffenen einer individuellen Abstimmung der Aufgabenverteilung von Hausärzten und Rheumatologen. Wer bei Patienten mit RA eine Therapie mit einem DMARD (in der Regel ist dies bei Ersttherapie Methotrexat, siehe Abschn. 5.1) einleitet, sollte diese Therapie auch bzgl. des Ansprechens mittels geeigneter Scores (DAS28 (9.4.1), SDAI (9.4.2) oder CDAI (9.4.3)) und bezüglich unerwünschter Wirkungen überwachen und bei Multimorbidität auch an die Begleiterkrankungen adaptieren können.

\section{Prinzipien der Therapie}

\subsection{Partizipative Entscheidungs- findung/Patientenschulung}

Jede Entscheidung in der Versorgung von Menschen mit RA sollte auf Basis geteilter Informationen und einer gleichberechtigt aktiven Beteiligung von Patient und Arzt getroffen werden [80, 81].

Dieses Vorgehen respektiert die Autonomie des Patienten, führt zu einer höheren Patientenzufriedenheit und trägt zur Adhärenz bei [82]. Gleichzeitig erfüllt es die in den letzten Jahren im Patientenrechtegesetz (Bundesgesetzblatt Jahrgang 2013, Teil I, Nr. 9) gesundheitspolitisch geforderten Anforderungen und steigert die Qualitätssicherung. 
Um diese partizipative Entscheidungsfindung praktisch umzusetzen, soll der Patient befähigt und ermutigt werden, seine Fragen zu stellen und für sich ein Therapieziel zu benennen. Dies wiederum setzt voraus, dass der Arzt die notwendigen Informationen verständlich vermittelt (incl. Aushändigung von substanzbezogenem Informationsmaterial) und den Patienten aktiv einbezieht. Dazu sind bei den Beteiligten entsprechende Kompetenzen erforderlich.

Die Betroffenen können diese durch Patienteninformation und -schulung erwerben, die wesentlicher Bestandteile der koordinierten Versorgung von RA-Patienten sind. Die koordinierte Behandlung durch alle beteiligten Disziplinen soll gewährleisten, dass der Patient konsistente Informationen erhält. Umfassende Informationen über seine Erkrankung sowie Rat und Hilfe zur Selbsthilfe sollen den Betroffenen unterstützen, ein möglichst normales Leben $\mathrm{zu}$ führen (entsprechendes Informationsmaterial stellt z. B. die Deutsche Rheuma-Liga Bundesverband unter http://www.rheuma-liga. de zur Verfügung). Angeboten werden z.B. Selbstmanagementprogramme (Deutsche Rheuma-Liga: Herausforderung Rheuma - Nimm Dein Leben in die Hand) und Workshops zur Qualifikation von Forschungspartnern für „Partizipative Forschung“ [83].

Die Deutsche Gesellschaft für Rheumatologie (DGRh) hat darüber hinaus in Kooperation mit der Deutschen Rheuma-Liga für die RA Patientenschulungsprogramme in Form einer Patienteninformation (STRUPI) für ambulante Patienten und weitere Schulungsprogramme für den stationären und Rehabereich entwickelt.

Studien, welche verschiedene Formen von Patientenschulungen untersuchen, zeigen positive Effekte hinsichtlich funktionaler Einschränkungen, Anzahl der betroffenen Gelenke sowie der Selbstbeurteilung durch den Patienten und langfristig einen positiven Trend bezüglich des Funktionsstatus [84-94].

Ärzte finden Angebote zu Schulungen bereits in der universitären Ausbildung und in Fort- und Weiterbildung. Die Deutsche Rheuma-Liga bietet hierzu zum Beispiel das Projekt „Patient-Part- ners“"zur Fortbildung der Ärzte und Ausbildung der Studierenden an.

\section{Good Clinical Practice $\checkmark$}

Bieten Sie allen Patienten die Teilnahme an Schulungsprogrammen an und ergänzen Sie diese durch mündliche, schriftliche und webbasierte Informationen über die Erkrankung und die Behandlung

\section{Empfehlung $\uparrow$}

\section{Grundlage jeder Behandlung sollte die gemeinsame Entscheidungs- findung zwischen Arzt und Patient sein}

\subsection{Früher Therapiebeginn}

Es gibt große Evidenz dafür, dass ein möglichst frühzeitiger Einsatz von DMARDs die Prognose der RA günstig beeinflusst. Das gilt insbesondere für

- die radiologische Progression

- den Erhalt/die Wiederherstellung der Funktionalität

- das Erreichen einer (anhaltenden) Remission

- eine Reduktion der erhöhten Mortalität und

- möglicherweise sogar für die Entwicklung einer RA

Ein längerer Krankheitsverlauf vor Beginn der ersten Therapie hat zwar keinen Einfluss auf die erzielte Symptomreduktion oder auf die Akute-Phase-Antwort. Patienten mit RA entwickeln jedoch unbehandelt eine progrediente Gelenkzerstörung, die zu Funktionsverlust und Einschränkungen der Lebensqualität beiträgt. Die radiologisch fassbare Gelenkdestruktion schreitet zu Beginn der Erkrankung am stärksten fort, die Zahl der Knochenerosionen von RA-Patienten ist signifikant mit der Krankheitsdauer bis zur Ersttherapie assoziiert [95]; dies gilt auch für die sehr frühen Krankheitsphasen [96]. DMARDs können diese Krankheitsprogression und den damit einhergehenden Verlust an Funktion stoppen und die Langzeitprognose damit entscheidend verbessern $[9,19,33$, 96-100]. Dies gelingt am besten durch die frühzeitige, d.h. innerhalb von drei bis sechs Monaten nach Beschwerdebeginn eingeleitete Behandlung [101, 102]. Patienten mit einem hohen Risiko (etwa $2 / 3$ der Gesamtpopulation) profitieren von einer Therapie in den ersten sechs Monaten ganz besonders [103]. Der Langzeiteffekt der frühbegonnenen DMARDTherapie lässt sich über einen Zeitraum von fünf Jahren nachweisen.

Die Remission - dokumentiert mit definierten Instrumenten (DAS28, Boolean-Remission, ACR Remissionskriterien - siehe Anhang 9.4-9.6) - ist das Ziel dieser DMARD-Therapie [9]. Eine Remission lässt sich zu Beginn der Erkrankung häufiger erreichen als in späteren Phasen [9, 96, 98, 100, 101, 104-107]. Es gibt auch Hinweise dafür, dass bei frühem Therapiebeginn ein Teil der Patienten eine lang anhaltende Remission erreicht, die mit reduzierter Dosis und selten sogar medikamentenfrei aufrechterhalten werden kann [108, 109].

Es gibt erste Hinweise für einen positiven Effekt bei Einleitung einer DMARDTherapie bereits vor Sicherung der Diagnose einer RA. So konnte die Methotrexat-Behandlung von Patienten mit undifferenzierter Arthritis gegenüber Placebo die definitive RA-Diagnose und die radiologische Progression verzögern [110, 111]. Ein Langzeitvorteil dieses Vorgehens ist allerdings bisher noch nicht belegt.

Die Mortalität von Patienten mit RA ist signifikant erhöht [32], insbesondere bei anhaltender Krankheitsaktivität [13]. Bei einem frühen Einsatz von DMARDs findet sich jedoch keine erhöhte Mortalität der Patienten mehr [112].

Die Therapie mit konventionellen synthetischen DMARDs (csDMARDs) muss häufig (in etwa $30 \%$ ) in den ersten 24 Monaten [113]) wegen Nebenwirkungen oder Ineffektivität modifiziert werden [114], bei frühzeitigem Einsatz allerdings wegen der erhöhten Effektivität deutlich seltener [97, 99, 101]. Über einen Zeitraum von sechs Jahren bedeutet dies im Durchschnitt einen Einsatz von 3,3 csDMARDs pro Patient [115]. Die Toxizität von csDMARDs liegt insgesamt jedoch nicht über der von nur symptomatisch wirkenden NSAR [116], siehe auch Abschn. 5.1.5. 


\section{Empfehlung $\uparrow \uparrow$}

\section{Alle Patienten sollen von der Dia- gnosestellung einer rheumatoiden Arthritis an mit DMARDs behandelt werden, um eine Verzögerung der Krankheitsprogression zu erzielen und damit die Langzeitprognose zu verbessern}

\subsection{Ambulante und stationäre multidisziplinäre Behandlung und Rehabilitation}

Ein nennenswerter Teil der Patienten mit RA benötigt von Beginn an eine umfassende Behandlung, die die individuellen medizinischen, psychosozialen, arbeitsbezogenen, verhaltenstherapeutischen und ggf. krankheitsbezogenen finanziellen Probleme aufgreift. Dieser ganzheitliche Therapieansatz, der vorwiegend in Studien von Patienten mit nicht früher RA untersucht wurde, ist das Ziel einer koordinierten, problemorientierten Behandlung durch Rheumatologen, Hausärzte, Physiotherapeuten, Sporttherapeuten, Ergotherapeuten, Sozialarbeiter, Pflegekräfte, Psychologen und andere Berufsgruppen im multidisziplinären Team [117-119]. Die rheumatologisch kompetente Koordination des Teams, die den bedarfsgerechten Zugang zu den unterschiedlichen Spezialisten und Therapeuten ermöglicht, ist gegenüber den Patienten $\mathrm{zu}$ verdeutlichen. Die gemeinsame ambulante Betreuung des Patienten durch Hausund Fachärzte, evtl. unterstützt durch speziell geschulte Pflegekräfte, gewährleistet die bestmögliche Überwachung der Therapie hinsichtlich Wirksamkeit und unerwünschten Wirkungen. Gleiches gilt für das schnelle Erkennen von Komplikationen der RA oder der hierfür verabreichten Therapien.

Ausgewählte Patienten profitieren von einer intensiveren Betreuung durch ein multidisziplinäres Team im Rahmen eines akutstationären Aufenthaltes, einer Rehabilitationsklinik, einer rheumatologischen Tagesklinik oder einer ambulant von speziell geschulten Pflegekräften koordinierten Behandlung [117, 118, 120, 121]. Eine deutlichere Verbesserung von Funktion und Krankheitsaktivität wurde nach dreiwöchiger stationärer Rehabilitation gegenüber einem Hausübungsprogramm nachgewiesen [122]. Eine Metaanalyse konnte allerdings für multidisziplinäre Interventionen bei kurzen stationären Aufenthalten von weniger als 14 Tagen Dauer oder ambulanten Angeboten geringer Intensität über unterschiedliche Zeiträume von zwei Wochen bis 24 Monaten keine langfristen Effekte über zwölf Monate auf Funktionseinschränkungen, Krankheitsaktivität oder Lebensqualität sichern [123].

Die bisher nicht in Deutschland - aber in anderen Ländern - durch Pflegekräfte koordinierte multidisziplinäre Therapie ergab eine höhere Kosten-Effektivität hinsichtlich der Lebensqualität und ein günstigeres Kosten-Nutzwert-Verhältnis in der Gesamtgruppe der Patienten [124]. Allerdings zeigte die Subgruppe älterer RA-Patienten eine geringere Funktionskapazität und Zufriedenheit mit der koordinierten ambulanten Versorgung durch spezialisiertes Pflegepersonal im Vergleich $\mathrm{zu}$ traditioneller ambulanter oder stationärer Behandlung eines multidisziplinären Teams [117].

Die berufliche Orientierung während der medizinischen Rehabilitation ermöglicht die Weichenstellung für anschließende Leistungen zur Teilhabe am Arbeitsleben (berufliche Rehabilitation), die die Rückkehr ins Erwerbsleben unterstützen können [125].

Weitere Informationen $\mathrm{zu}$ den $\mathrm{Be}$ standteilen der multidisziplinären Behandlung gibt Abschn. 6.

\section{Empfehlung $\uparrow$}

\section{Alle Patienten sollten von Beginn an bedarfsgerecht in Form einer koordinierten, multidisziplinären Behandlung versorgt werden}

\subsection{Dokumentation}

Der chronische und individuell unterschiedliche Verlauf einer RA hat erhebliche Konsequenzen für die Beurteilung der Wirksamkeit einer DMARD-Therapie. Klinische harte Endpunkte wie z. B. Langzeitfunktionalität, Invalidisierungsrate oder Mortalität lassen sich kaum in einem von Studien abgedeckten Zeit- raum erfassen. Die moderne Therapiestrategie der RA [126-128] basiert auf einer regelmäßigen Erfassung und Dokumentation der Krankheitsaktivität und ihres Verlaufes in jedem Einzelfall. Diese Dokumentation ist entscheidend für die Beurteilung, den Vergleich und die Qualitätssicherung der Therapie der RA. Sie sollte zu Beginn der RA - in Abhängigkeit von der Krankheitsaktivität - alle ein bis drei Monaten erfolgen.

Als Standardinstrument hat sich in der Praxis der Disease Activity Score (DAS28, (9.4.1)) bewährt, in den verschiedene Parameter der Krankheitsaktivität eingehen. Werte $<2,6$ reflektieren eine gut kontrollierte Erkrankung (= Remission). Werte $>3,2$ bedeuten eine nicht ausreichende Kontrolle der Krankheitsaktivität, die in der Regel eine Änderung der Therapie erforderlich macht.

Neben dem DAS28 können der „simplified disease activity index“ (SDAI, 9.4.2) oder der „clinical disease activity index" (CDAI, 9.4.3) eingesetzt werden. Vergleichbar zum DAS28 fließen in den SDAI geschwollene und druckschmerzhafte Gelenke, die Einschätzung des Gesundheitszustandes durch den Patienten und den Arzt sowie das CRP (in mg/dl) ein, wobei diese Werte einfach numerisch addiert werden. Der CDAI verzichtet auf die Hinzunahme des CRP. Krankheitsremission wird im SDAI mit Werten von $<3,3$ (CDAI <2,8) definiert (moderate Krankheitsaktivität >11 (CDAI $>10)$ ); hohe Krankheitsaktivität >26 (CDAI $>22$ ). Beide Scores sind validierte Instrumente und können gleichwertig zur Kontrolle der Krankheitsaktivität eingesetzt werden [129-131].

In jüngeren Studien wird teilweise die Arbeitsfähigkeit als Therapieziel miterfasst.

\subsubsection{Beurteilung des Ansprechens auf die Therapie}

Klinische Parameter zur sind u.a.:

- subjektive Einschätzung des Patienten

- subjektive Einschätzung des Arztes

- Ausmaß der Synovitis (Anzahl geschwollener und schmerzhafter Gelenke) (ggf. ergänzend erfasst durch Arthrosonographie) 
- Dauer/Ausmaß der Gelenksteifigkeit nach Ruhe (z. B. Morgensteifigkeit)

- Gesundheits-bezogene Lebensqualität (z. B. SF-36) incl. Fatigue

- Funktionsstatus (z.B. FFbH - Funktions-Fragebogen Hannover, siehe Abschn. 9.3)

Laborparameter - radiologische Befunde - akute Phase Parameter (BSG, CRP)

- Blutbild (Besserung einer Anämie)

- radiologische Progression mittels konventioneller Röntgenbilder

\section{Empfehlung $\uparrow \uparrow$}

Die Krankheitsaktivität soll regelmäBig mittels Kompositscore (z. B. DAS28, SDAI oder CDAI) erfasst und dokumentiert werden

Neben dem klinischen Bild und serologischen Parametern gibt insbesondere der Verlauf bildmorphologisch fassbarer Veränderungen (z.B. Synovialitis, Tendovaginitis, Erosionen, Gelenkspaltverschmälerung) Auskunft über die Effektivität der Therapie und ggf. die Notwendigkeit einer Therapieänderung. Aus diesem Grund wird ergänzend zur klinischen Evaluation der zusätzliche Einsatz bildgebender Verfahren empfohlen (in der Regel Arthrosonographie und konventionelle Röntgenbilder, ggf. auch MRT) [132, 133]. Arthrosonographie und auch MRT erlauben eine ergänzende Beurteilung des Ausmaßes und der Aktivität der Synovialitis, die konventionelle radiologische Bildgebung gibt Hinweise auf den eingetretenen Schaden.

\section{Good Clinical Practice $\checkmark$}

Ergänzend können zur Beurteilung der Krankheitsaktivität bildmorphologische Verfahren (z. B. Sonographie) eingesetzt werden

Bei deutlich aktiver Erkrankung werden nach sechs und zwölf Monaten, danach jährlich, nativ-radiologische Kontrollen empfohlen [134]. Kurzfristigere Kontrollen zeigen meist keine signifikanten Änderungen und sind deshalb für die Therapieentscheidung wenig hilfreich.
Good Clinical Practice $\checkmark$

Zur Beurteilung des Langzeitoutcomes eignen sich die regelmäßige Erfassung des Funktionsstatus und die radiologische Progression

\subsection{Treat-to-Target}

In den letzten Jahren wurde für die Behandlung der RA die Effektivität der zielgerichteten Therapie (Treat-to-Target) in zahlreichen Studien belegt. Sie ist heute das Therapiekonzept der RA von der Diagnose an. Ziel der Therapie ist die Krankheitsremission gemessen mit einem validierten Instrument (siehe Abschn. 9.4-9.6).

Eine Reihe von Strategiestudien untersuchte eine auf ein Ziel (in der Regel Remission oder niedrige Krankheitsaktivität) ausgerichtete Abfolge therapeutischer Modalitäten. Es lassen sich zusammenfassend aus diesen Studien folgende Schlüsse ableiten: Erhalten RA-Patienten eine intensive Betreuung mit regelmäßiger Anpassung der Therapie gemäß dem vorgegebenen Ziel, so erreichen sie dieses Ziel (z. B. Remission) häufiger als Patienten, die eine Standardversorgung erhalten [127, 128, 135]. Zur Beurteilung des Ziels reichen aus klinischen Variablen und Laborbefunden bestehende Scores wie z.B. DAS28 aus [136], zusätzliche Ultraschalluntersuchungen zur Erfassung einer subklinischen Synovitis führen nicht $\mathrm{zu}$ einem besseren klinischen Ergebnis [136, 137].

Viele Strategie-Studien mit Vergleich von bDMARD (biologic Disease Modifying Anti-Rheumatic Drugs, sog. biologische Basistherapeutika) und csDMARD (in der Regel MTX) zeigen statistisch signifikant bessere Ergebnisse für die bDMARD-Gruppen (Beispiele: [135, 138, 139]). Dieser Vorteil ist jedoch nicht in allen ERA-RCTs zu sehen [140].

Die wichtigste Erkenntnis aus den Strategiestudien ist sicherlich, dass sich - unabhängig von den jeweils gewählten Therapiesequenzen - das Prinzip der engen Kontrolle der Krankheitsaktivität mit festem Therapieziel (z. B. DAS28-Remission) und die Therapieeskalation bei Verfehlen dieses Ziels als erfolgreich erwiesen hat. In Einklang damit zeigte eine
Studie im englischen Gesundheitssystem eine Überlegenheit in den Endpunktkategorien Klinik, Funktion und Struktur für die intensive monatliche Betreuung mit fixem Therapieablauf gegenüber der quartalsweisen Regelversorgung, ohne Mehrkosten zu erzeugen [128].

Ein optimales Zeitfenster für die Erfassung des Ansprechens bzw. des Therapieversagens lässt sich aus den Studien nicht ableiten. Die dort festgelegten Zeitintervalle zur Adaptation der Therapie schwanken zwischen zwei Wochen [139], vier Wochen $[135,138]$ und zwölf Wochen [136]. Eine Überprüfung bezüglich notwendiger Therapieanpassung spätestens alle zwölf Wochen in der Routineversorgung ist praktikabel.

\section{Empfehlung $\uparrow \uparrow$}

Wenn das Ziel der Therapie, die Remission, nach drei (spätestens sechs) Monaten nicht erreicht ist, soll die Therapie entsprechend angepasst werden

Nicht bei allen Patienten kann das Therapieziel Remission erreicht werden, die Prognose kann jedoch durch eine optimierte Therapie (Treat-to-Target) entscheidend verbessert werden. Hierzu zählen neben einem frühen Beginn eine konsequente Überprüfung des Ansprechens (siehe auch Abschn. 4.4, 9.4, 9.6.1 und 9.6.2) und ggf. Modifizierung der Therapie in Form von Eskalation (bei noch nicht optimalem Ansprechen) bzw. Deeskalation (bei erreichter Remission). Nach 3 Monaten sollte in jedem Fall ein Ansprechen (ACR oder Eular-Response; 9.6.1./2) erkennbar sein, ansonsten sollte die Therapie bereits zu diesem Zeitpunkt umgestellt werden.

Ein Teil der Patienten mit früher RA konnte nach über mindestens sechs Monate anhaltender Remission die csDMARD- und/oder bDMARD-Therapie reduzieren bzw. absetzen, wobei der Anteil an Patienten mit anhaltender Remission ohne Medikamente (sustained drug-free remission) nach bDMARD größer war als nach csDMARD [135, 140]. Zwei randomisierte placebokontrollierte Studien zeigen eine erhöhte Rezidivrate bei Beendigung der csDMARD-Therapie [141, 142]. In beiden 
Studien ist der Effekt der Immunmodulation eindeutig: Werden bei Patienten, die bereits seit fünf Jahren eine Therapie mit csDMARDs erhalten, diese abgesetzt, erleiden $38 \%$ innerhalb eines Jahres ein Rezidiv verglichen mit $22 \%$ der Patienten, bei denen die Therapie fortgeführt wird [142]. Im Durchschnitt verbleibt ein Patient ca. zehn Monate auf einer bestimmten csDMARD-Therapie, bevor diese gewechselt wird (für bDMARD liegen diesbezüglich noch keine genauen Zahlen vor). Häufige Ursachen für das Umsetzen des csDMARD sind ein Wirkverlust und/oder unerwünschte Wirkungen [143, 144]. Bezüglich der unerwünschten Wirkungen ist die dauerhafte Gabe eines DMARDs oder einer DMARD-Kombination mit einem über die Zeit nicht ansteigendem Risiko behaftet [144-146].

Eine Beendigung der Therapie aus dem Grund „Heilung“ ist selten möglich. Wenn bei eingetretener Remission ein DMARD-Reduzierungsversuch unternommen wird, ist hierunter eine engmaschige Kontrolle erforderlich.

\subsection{Komorbiditäten}

Die Prognose von Patienten mit chronisch entzündlich-rheumatischen Erkrankungen wird wesentlich durch Komorbiditäten mitbestimmt. Sie treten in Koinzidenz mit der RA auf, sind Manifestationen oder Konsequenzen der Erkrankung oder Komplikationen der Therapie. Sie haben ihrerseits Einfluss auf die gewählte Therapie.

Bereits zu Beginn der RA konnte eine Prävalenz von $32 \%$, nach 15 Jahren Krankheitsdauer eine Prävalenz von 81 \% nachgewiesen werden [147].

In der Kerndokumentation der Deutschen Kooperativen Rheumazentren von 2012 findet sich die folgende Häufigkeit bei Patienten mit etablierter RA:

Arterielle Hypertonie 36\%, degenerative Gelenkerkrankungen $23 \%$ degenerative Wirbelsäulenerkrankungen, $18 \%$, Osteoporose, $18 \%$, Schilddrüsenerkrankungen, $13 \%$ Herzerkrankungen, $12 \%$, Diabetes mellitus, $11 \%$, Fettstoffwechselstörung und Atemwegs- sowie Lungenerkrankung jeweils $10 \%$, Gastritis- oder
Ulkusanamnese 9\%, Nierenerkrankung $7 \%$, Malignome 6\%, Depressionen 6\%.

Die kardiovaskuläre Komorbidität von RA Patienten ist um das 1,5- bis 2-fache erhöht und vergleichbar dem anderer chronischer Erkrankungen, z. B. Diabetes mellitus. Das Risiko einer Herzinsuffizienz bei RA ist verdoppelt. Kardiovaskuläre Erkrankungen sind damit auch die häufigste Todesursache bei einer RA [148].

Eher durch den Krankheitsprozess selbst bedingt ist die Zunahme interstitieller Lungenerkrankungen bei RA. Sie stellen die zweithäufigste Todesursache bei Patienten mit RA dar [149].

Das Risiko für diese Folgeerkrankungen ist an die Schwere der Erkrankung und an die Kontrolle der Krankheitsaktivität gekoppelt. So sind vermeidbare schwere, kardiovaskuläre Ereignisse bei Patienten mit hochaktiver RA nahezu verdoppelt im Vergleich zur Normalbevölkerung [150]. Durch einen frühen Einsatz von DMARDs kommt es zu einer Risikoreduktion von Komorbiditäten [13].

\section{Medikamentöse Therapie}

\subsection{Antirheumatika - DMARDs}

Unter DMARDs wird eine Gruppe von Medikamenten zusammengefasst, die über symptomatische Effekte hinaus, krankheitsmodifizierende Eigenschaften besitzen. Sie sollen anders als eine symptomatische Therapie (wie z. B. mit NSAR [151]) einer Gelenkzerstörung vorbeugen, bzw. diese zumindest verzögern und somit die Funktionsfähigkeit der Gelenke erhalten. Die klinisch erkennbare Wirkungsamkeit nahezu aller zur Verfügung stehender Substanzen tritt verzögert ein, der Zeitraum bis zur vollen Wirkung beträgt abhängig von der verwendeten Substanz und dem individuellen Ansprechen 4-16 Wochen.

Zur Gruppe der DMARDs gehören:

- csDMARDs: konventionelle synthetische DMARDs,

- tsDMARDs: zielgerichtete synthetische DMARDs und

- bDMARDs: biologische DMARDs.
Bei den bDMARDs werden unterschieden:

- boDMARDs: Originalpräparate

- bsDMARDs: Biosimilars

- Tab. 5 enthält die zusammengefassten Informationen zu den zum Zeitpunkt des Erscheinens der Leitlinie in Deutschland zugelassenen und verfügbaren Substanzen.

Die häufigsten unerwünschten Wirkungen sowie die Anforderungen an die Therapieüberwachung sind in den Therapieüberwachungsempfehlungen der DGRh zusammengefasst. Zur Information der Patienten über den möglichen Nutzen, die möglichen Gefahren und die notwendigen Überwachungsmaßnahmen stehen dort auch für alle Substanzen entsprechende Patienteninformationsbögen zur Verfügung: (https://dgrh.de/ Start/Versorgung/Therapieüberwachung/ Therapieüberwachungsbögen.html).

Die Wirksamkeit von DMARDs im Vergleich zu Placebo ist in älteren Studien belegt [179-186], heute verbieten ethische Gründe eine reine PlaceboKontrollgruppe. Eine bereits 1990 veröffentliche Metaanalyse untersuchte die Wirksamkeit von sechs DMARDs anhand der Anzahl geschwollener Gelenke, der Griffstärke und der BSG; alle Substanzen waren der reinen Placebogabe überlegen [143]. Der vermehrte Gebrauch von DMARDs ist eng mit besseren Werten des „long-term disability index" korreliert [187]. Für Methotrexat und in stärkerem Ausmaß für bDMARDs gibt es Anhaltspunkte, dass die Mortalität von Patienten mit RA gesenkt wird [13, 188, 189].

Die folgenden Aussagen zu Therapien beruhen so weit wie möglich auf randomisiert kontrollierten Studien (RCTs) bei Patienten mit früher rheumatoider Arthritis (ERA).

\subsubsection{DMARD-Monotherapie}

Unter den csDMARD in der Monotherapie ist Methotrexat seitens der Wirksamkeit und Verträglichkeit zu bevorzugen [171, 172, 190-192]. Als Starttherapie führt Methotrexat in $20-30 \%$ der Fälle zu einer DAS-Remission [152, 154, 160, 174]. Bei zusätzlicher Verwendung von Corticoiden kann nach 16 Wochen 
Tab. 5 Disease Modifying Antirheumatic Drugs (DMARDs)

\begin{tabular}{|c|c|c|c|}
\hline Wirkstoff & Klasse & Präparate/Handelsnamen & Studien frühe RA (Mono/Kombi) \\
\hline Abatacept & bDMARD & Orencia (boDMARD) & Westhovens 2009 [152], Emery 2015 [153] \\
\hline Adalimumab & bDMARD & $\begin{array}{l}\text { Humira (boDMARD), } \\
\text { Amgevita (bsDMARD), } \\
\text { Hulio (bsDMARD), } \\
\text { Hyrimoz (bsDMARD) } \\
\text { Imraldi (bsDMARD) }\end{array}$ & Breedveld 2006 [154], Bejarano 2008 [155], Takeuchi 2014 [156] \\
\hline Anakinra & bDMARD & Kineret, (boDMARD) & Keine \\
\hline Certolizumab & bDMARD & Cimzia (boDMARD) & Atsumi 2016 [157], Emery 2017 [158] \\
\hline Etanercept & bDMARD & $\begin{array}{l}\text { Enbrel (boDMARD), } \\
\text { Benepali (bsDMARD), } \\
\text { Erelzi (bsDMARD) }\end{array}$ & Bathon 2000 [159], Emery 2008 [160] \\
\hline Golimumab & bDMARD & Simponi (boDMARD) & Emery 2009 [161] \\
\hline Infliximab & bDMARD & $\begin{array}{l}\text { Remicade (boDMARD), } \\
\text { Flixabi (bsDMARD), } \\
\text { Inflectra (bsDMARD), } \\
\text { Remsima (bsDMARD) }\end{array}$ & St. Clair 2004 [162] \\
\hline Rituximab & bDMARD & $\begin{array}{l}\text { Mabthera (boDMARD), } \\
\text { Rixathon (bsDMARD), } \\
\text { Truxima (bsDMARD) }\end{array}$ & Tak 2011 [163] \\
\hline Sarilumab & bDMARD & Kevzara (boDMARD) & Keine \\
\hline Tocilizumab & bDMARD & Ro-Actemra (boDMARD) & Burmester 2016 [164], Bijlsma 2016 [135] \\
\hline Azathioprin & csDMARD & $\begin{array}{l}\text { Azafalk, Azaimun, Azame- } \\
\text { dac Aza-Q, Azathioprin, } \\
\text { Colinsan, Imurek }\end{array}$ & Keine \\
\hline Cyclosporin & csDMARD & $\begin{array}{l}\text { Cicloral, Ciclosporin, Immu- } \\
\text { nosporin, Sandimmun }\end{array}$ & Hetland 2006 [165], Hetland 2008 [166] \\
\hline $\begin{array}{l}\text { Hydroxychloroquin } \\
\text { Chloroquin } \\
\text { (Antimalariamittel) }\end{array}$ & csDMARD & $\begin{array}{l}\text { Quensyl } \\
\text { Resochin, Weimerquin }\end{array}$ & $\begin{array}{l}\text { Van Jaarsveld } 2000 \text { [113], van der Heijde } 1989 \text { [167], Möttonen } 1999 \text { [168], Lande- } \\
\text { we } 1994 \text { [169] }\end{array}$ \\
\hline Leflunomid & csDMARD & Arava, Leflunomid & Keine \\
\hline Methotrexat (MTX) & CSDMARD & $\begin{array}{l}\text { Lantarel, Metex, Methotre- } \\
\text { xat, MTX }\end{array}$ & $\begin{array}{l}\text { Van der Heijde } 1989 \text { [167], Möttonen } 1999 \text { [168], Proudman } 2000 \text { [170], Bathon } \\
2000 \text { [159], Haagsma } 1997 \text { [171], Dougados } 1999 \text { [172], Boers } 1997 \text { [173], Breed- } \\
\text { veld } 2006 \text { [154], Bejarano } 2008 \text { [155], Emery } 2008 \text { [160], Westhovens } 2009 \text { [152], } \\
\text { St. Clair } 2004 \text { [162], Emery } 2009 \text { [161], Hetland } 2006 \text { [165], Van Vollenhoven } 2009 \\
\text { [174] } \\
\text { SWEFOT + diverse weitere (s. oben, fast alle mit Methotrexat [MTX] gelaufen) }\end{array}$ \\
\hline Sulfasalazin & csDMARD & $\begin{array}{l}\text { Azulfidine, Colo-Pleon, } \\
\text { Pleon, Sulfasalazin }\end{array}$ & $\begin{array}{l}\text { Van Jaarsveld } 2000 \text { [113], Möttonen } 1999 \text { [168], Proudman } 2000 \text { [170], Haagsma } \\
1997 \text { [171], Dougados } 1999 \text { [172], Boers } 1997 \text { [173], Hannonen } 1993 \text { [175] }\end{array}$ \\
\hline Baricitinib & tsDMARD & Olumiant & Fleischmann 2017 [176] \\
\hline Tofacitinib & tsDMARD & Xeljanz & Fleischmann 2016 [177], Lee 2014 [178] \\
\hline
\end{tabular}

eine Remissionsrate von $74 \%$, nach einem Jahr eine von $60,2 \%$ erreicht werden [193].

Das in Deutschland am zweithäufigsten verwendete csDMARD Leflunomid wurde bei Patienten mit ERA nicht gezielt untersucht, zum Wirksamkeitsnachweis bei RA in späteren Stadien liegen vier vergleichende randomisierte kontrollierte Studien vor [194-197].

Danach folgen als csDMARD Sulfasalazin und Cyclosporin A. Schlechter wirksam sind Antilmalariamittel, wobei hier differenzierte Aussagen aufgrund des Alters der Studien und damit der Endpunktauswahl und Qualität unsicherer werden.

Die früher verwendeten Goldpräparate Natriumaurothiomalat und Auranofin waren zwar wirksam und sind in Deutschland noch zugelassen, werden aber nicht mehr vertrieben (deshalb nicht aufgelistet).

Ein kontrollierter Vergleich von $\mathrm{Me}$ thotrexat mit den anderen csDMARDs in der Erstlinientherapie fehlt. Im Vergleich der Monotherapie mit Methotrexat und den bDMARDs Etanercept oder Adali- mumab zeigen sich Remissionsraten in ähnlicher Höhe, bei vergleichbarer Verträglichkeit verhindert Methotrexat die radiologische Progression jedoch weniger [154, 159, 198, 199]. Hingegen zeigt sich das auf Interleukin-6-Blockade beruhende bDMARD Tocilizumab in Monotherapie im Vergleich zu Methotrexat auch klinisch überlegen [135, 164], ebenso die tsDMARDs Baricitinib und Tofacitinib [176, 177].

Im Gegensatz zu den oben dargestellten Daten bei ERA zeigte sich in einer großen systematischen Übersichtsarbeit, 
die nicht auf ERA beschränkt war [200], kein csDMARD oder bDMARD in der Monotherapie im Vergleich zu den anderen eindeutig überlegen in Bezug auf die klinische Wirksamkeit. In dieser Arbeit waren bDMARD gegenüber csDMARD in Bezug auf den radiologischen Outcome vorteilhaft, außerdem war die Kombination bDMARD + Methotrexat dercsDMARD-Monotherapie überlegen.

\section{Empfehlung $\uparrow \uparrow$}

\section{Methotrexat soll als erstes csDMARD in} der Monotherapie eingesetzt werden

\subsubsection{DMARD-Kombinations- therapie}

Unter Kombinationstherapie wird der gleichzeitige Einsatz von zwei oder mehreren csDMARD (meist noch ergänzt um ein Corticoid) oder auch der verknüpfte Einsatz eines bDMARD oder tsDMARD mit einem oder mehreren csDMARD verstanden.

In klinischen Studien wurden fast ausnahmslos Kombinationen mit Methotrexat untersucht. Kombinationen von Methotrexat mit Sulfasalazin oder Cyclosporin A sind in Einzelstudien der Monotherapie mit Methotrexat allenfalls geringgradig klinisch und radiologisch überlegen ohne eindeutige Hinweise auf schlechtere Verträglichkeit [165, 170-172, 201-203]. In einer prospektiven randomisierten Studie mit offenem Design zeigten die Kombinationen Methotrexat \& Sulfasalazin und Methotrexat \& Leflunomid im Vergleich zu Methotrexat mono (in allen drei Gruppen in Kombination mit Prednisolon) keine Vorteile [193].

bDMARDs wurden in klinischen Studien meist in Kombination mit Methotrexat gegen eine Monotherapie mit Methotrexat verglichen. Hiervon sind Studien bei Methotrexat-Versagern abzugrenzen; diese entsprechen eher Placebo-Studien.

Die Kombination Adalimumab \& Methotrexat ist gegenüber Monotherapien mit Adalimumab oder Methotrexat klinisch und radiologisch besser wirksam und besser verträglich [154, 155, 199]. Abatacept \& Methotrexat und Infliximab \& Methotrexat sind gegenüber Methotre- xat klinisch und radiologisch besser wirksam und ähnlich verträglich [152, 162 , 204, 205]. Die Kombination Infliximab \& Methotrexat ist gegenüber der Kombination Sulfasalazin \& Hydroxychloroquin \& Methotrexat klinisch besser wirksam und besser verträglich [174]. Die Kombination Etanercept \& Methotrexat ist gegenüber Methotrexat klinisch und radiologisch besser wirksam und besser verträglich $[160,206]$. Ebenso haben sich die Kombinationen Certolizumab \& Methotrexat [158] und Tocilizumab \& Methotrexat $[135,164]$ klinisch, funktionell und radiologisch gegenüber Methotrexat als überlegen erwiesen.

Auch die beiden tsDMARDs Baricitinib [176] und Tofacitinib [177] zeigten sich in Kombination mit Methotrexat gegenüber Methotrexat-Monotherapie klinisch, funktionell und radiologisch überlegen.

In einer systematischen Übersichtsarbeit bei Patienten mit ERA zeigte sich der Vorteil einer Kombinationsbehandlung gegenüber Methotrexat-Monotherapie als statistisch signifikant in Bezug auf die Remissionsrate [207]. Dabei wurden Studien mit unterschiedlichen Behandlungsregimen in unterschiedlichen Therapiesituationen (darunter auch Strategievergleiche, s. unten) gepoolt.

Umfassendere und dem teils widersprechende Daten liegen für RAPatienten jeglicher Krankheitsdauer vor: Eine systematische Übersichtsarbeit [208] sieht die initiale MethotrexatMonotherapie gegenüber csDMARDKombinationen insgesamt als überlegen an, jedoch bei Monotherapieversagern eine nicht eindeutige Datenlage. In einer großen systematischen Übersichtsarbeit [200] konnte bei Therapieversagen der Monotherapie eine generelle Überlegenheit der Kombinationsbehandlung gesehen werden, ohne dass eine spezifische Kombination als überlegen identifiziert werden konnte. In einem Cochrane-Review [209] zeigten alle Biologika außer Anakinra vergleichbar gute Wirksamkeit und Adalimumab, Rituximab sowie Etanercept eine bessere Verträglichkeit als andere Biologika.

\section{Empfehlung/Statement $\uparrow \uparrow$}

In der Kombination von DMARDs soll Methotrexat enthalten sein

\subsubsection{DMARD-Therapiestrategien}

Die wichtigste Erkenntnis aus den Strategiestudien ist sicherlich, dass sich unabhängig von den jeweils gewählten Therapie-Sequenzen - das Prinzip der engen Kontrolle der Krankheitsaktivität mit festem Therapieziel (z. B. DAS28-Remission) und die Therapieeskalation bei Verfehlen dieses Ziels als erfolgreich erwiesen hat (siehe Abschn. 4.5). Dies ist für einen Verlauf von bis zu zehn Jahren gezeigt [108]. Eine frühe Kombinationsbehandlung im Rahmen eines komplexen Therapiekonzeptes verhindertgegenüber der Monotherapie bzw. Sequenztherapie weitgehend die radiologische Progression [101, 127, 140, 168, 173]. Es gibt auch Hinweise auf klinische Überlegenheit [210,211], allerdings ohne optimierten Einsatz von Glucocorticoiden. Methotrexat ist unter den csDMARDs für den Therapiebeginn als Kombinationspartner oder Monotherapeutikum zu bevorzugen, da seine Wirkung schnell einsetzt [168, 173, 190]. Dieser Effekt wird durch eine Step-down-Behandlung mit Corticosteroiden verstärkt [101, 127, 173, 212].

In Einklang damit zeigte eine Studie im englischen Gesundheitssystem eine Überlegenheit in den Endpunktkategorien Klinik, Funktion und Struktur für die intensive monatliche Betreuung mit fixem Therapieschema gegenüber der quartalsweisen Regelversorgung ohne Mehrkosten [128]. Bei inkompletter Response auf csDMARD zeigte eine nachfolgende bDMARD- oder tsDMARDTherapie in einem systematischen Review eine klinisch relevante Besserung in Bezug auf ACR 50-Response (9.7.1), Funktionsstatus und Remissionsrate [209]. 
Tab. 6 Checkliste vor Einleitung einer immunsuppressiven Therapie

Abschätzung des individuellen vorbestehenden Infektionsrisikos (wichtigste Risikofaktoren Alter, Krankheitsaktivität, Glucocorticoid-Therapie, Ko-/Multimorbidität, frühere schwere Infektionen)

Aktualisierung des Impfstatus gemäß STIKO-Empfehlungen (obligatorisch Influenza, Pneumokokken, Tetanus - einmalig in Kombi mit Diphtherie/Pertussis). Auf ausreichenden Impfschutz ist auch während der Therapie zu achten (z. B. jährliche Influenza-Impfung)

Screening auf latente Tuberkulose und Hepatitis B (bei tsDMARD und bDMARD)

Zusätzliches Screening je nach individueller Anamnese (z. B. HIV)

Einleitung einer Schutztherapie bei positivem Ausfall dieses Screenings (Tuberkulostatika bzw. antivirale Therapie)

Aufklärung des Patienten bezüglich des erhöhten Infektionsrisikos und ggf. nötiger Therapiepausen

Aushändigung von substanzbezogenem Informationsmaterial (siehe Abschn. 4.1)

\section{Empfehlung $\uparrow \uparrow$}

Bei Patienten, die nicht ausreichend auf eine csDMARD-Therapie ansprechen, soll ein bDMARD oder tsDMARD als Kombinationspartner eingesetzt werden

\subsubsection{Wahl des ersten DMARD}

Eine geprüfte Differentialindikation der verschiedenen csDMARDs für die ERA liegt nicht vor. Die allgemeinen Daten zur Therapie mit csDMARDs belegen die Vorteile einer Methotrexattherapie aufgrund des relativ schnellen Ansprechens und der längerfristigen Kontrolle der Erkrankung [171, 172, 190-192, 213-215]. Kann Methotrexat nicht verwendet werden (z. B. bei Unverträglichkeit oder Kontraindikationen), ist ein guter Therapieerfolg auch mit anderen csDMARD erreichbar (siehe S2e Leitlinie DGRh, Fiehn 2018 [216]).

\subsubsection{Therapiesicherheit}

\section{Toxizität Zur Toxizität von csDMARDs} liegen zwei Metaanalysen von Felson vor, welche 79 Studien mit insgesamt $149 \mathrm{Be}$ handlungsgruppen umfassen [143, 217]. Danach bricht im Verlauf eines Jahres nahezu ein Drittel der Patienten (30,3\%) die Therapie mit csDMARD ab. Bei der Hälfte ist Toxizität die Ursache. In der kombinierten Nutzen-Risiko Analyse geht Hydroxychloroquin mit der geringsten Toxizität einher bei allerdings nur moderater Wirksamkeit. Für Methotrexat ist das Nutzen-Risiko-Verhältnis am besten. Sulphasalazin reicht vom Nutzen nahe an
Methotrexat heran, geht aber mit einer geringfügig höheren Toxizität einher.

Folsäure ( $1 \mathrm{mg} / \mathrm{Tag})$ und Folinsäure (2,5 mg/Woche) verringern die Häufigkeit von Leberwerterhöhungen unter Methotrexat und senken damit die Rate an Therapieabbrüchen [218]. Dies wird durch eine Metaanalyse bestätigt, in der bei einer Folsäure-Dosis von $\leq 7 \mathrm{mg}$ / Woche zusätzlich auch eine signifikante Reduzierung von Übelkeit und gastrointestinalen Nebenwirkungen ermittelt wurde [219].

Für Leflunomid liegen deutlich weniger Daten bezüglich möglicher Störeffekte vor, insbesondere bezüglich der Langzeitanwendung. Ein nicht auf die ERA fokussierter systematischer Review mit Vergleich der Sicherheit bei Leflunomid und Methotrexat zeigt mehr Leberwertanstiege unter Leflunomid, mehr gastrointestinale Nebenwirkungen unter Methotrexat bei sonst vergleichbarer Sicherheit [220].

Bei einer Therapie mit bDMARD und tsDMARD ist mit einem leicht erhöhten Infektionsrisiko zu rechnen. Schwere Infektionen treten etwa in $1 \%$ auf [209], können im Einzelfall aber ein lebensbedrohliches Ausmaß erreichen [13, 221]. In einer weiteren Metaanalyse wurde für die gesamte Gruppe der bDMARDS ein etwas höheres Risiko für schwere Infektionen im Vergleich zu csDMARDs bestätigt, zwischen den einzelnen Substanzen zeigten sich keine relevanten Unterschiede [222]. Ein erhöhtes Risiko für Reaktivierung von Tuberkulose wurde in dieser Metaanalyse für die TNF-Inhibitoren bestätigt. Ein erhöhtes Risiko für Perforationen im unteren Gastroin- testinaltrakt unter Tocilizumab im Vergleich zu csDMARD und anderen bDMARDs mit einer Inzidenzrate von 2,7 vs. $0,2-0,6 / 1000$ Patientenjahre wurde in einer Kohortenstudie gezeigt [223].

Es ist besonders $\mathrm{zu}$ beachten, dass bei operativen Eingriffen wegen eines möglicherweise erhöhten Infektionsrisikos und Wundheilungsstörungen Therapiepausen mit substanzbezogen unterschiedlicher Dauer nötig sein können. Bezüglich näherer Einzelheiten wird auf die Empfehlungen der DGRh verwiesen ([224]; - Tab. 6).

\section{Empfehlung $\uparrow \uparrow$}

\section{Unter immunsuppressiver Therapie soll das erhöhte Infektionsrisiko der Patienten beachtet werden}

Spätschäden Bei der Auswahl der geeigneten Substanz aus der Gruppe der DMARDs muss das Risiko einer unkontrollierten Krankheitsaktivität, welche zu weiteren Schäden führen kann, gegenüber dem Risiko kumulativer oder später Toxizität der Arzneimittel abgewogen werden.

Das Risiko der Entwicklung von Malignomen unter Therapie mit Immunsuppressiva ist Gegenstand von Beobachtungsstudien, die Ergebnisse sind unter Berücksichtigung verschiedener Einflussgrößen zu interpretieren: Patienten mit RA erhalten im Verlaufe ihrer Erkrankung unterschiedlichste DMARDs und NSAR und das Risiko bestimmter Malignome scheint bereits durch die Erkrankung als solche erhöht [225-227] und ist darüber hinaus mit dem Schweregrad der RA korreliert [228].

In einer Meta-Analyse von RCTs mit TNF-Inhibitoren wurde eine dosisabhängig erhöhte Rate an Malignomen gesehen [221]. Andere Metaanalysen [209, 222, 229] und Daten aus großen europäischen Registern [230, 231] haben eine Malignom-Häufung unter bDMARDs nicht bestätigt. Sicherheitsbedenken sind heute kein Grund mehr, bDMARDs erst nach csDMARDs einzusetzen, da letztere nicht risikoärmer einzuschätzen sind. 


\section{Good Clinical Practice $\checkmark$}

Informieren Sie Ihre Patienten über unerwünschte Wirkungen der medizinischen Therapie und händigen Sie Informationsmaterial aus Überwachen Sie die Therapie ihrer Patienten im Hinblick auf mögliche unerwünschte Wirkungen (s. Therapieüberwachungsbögen)

Zur Behandlung eines Patienten mit früher rheumatoider Arthritis gehört ein ausreichender Impfschutz gemäß den STIKO-Empfehlungen

\subsection{Glucocorticoide (GC)}

Die GC-Therapie hat sich aufGrund ihrer symptomlindernden und entzündungshemmenden Wirkung in der Behandlung der ERA bewährt [232]. Der Effekt setzt in der Regel rasch ein. Daher ist die überbrückende Gabe von GC eine Möglichkeit, eine symptomatische Besserung zu erzielen, bis der Effekt der csDMARDs einsetzt. Der symptomatische Effekt von GC ist dem von NSAR überlegen [233, 234]. Als optimale GC-Startdosis haben sich in mehreren Studien täglich $30 \mathrm{mg}$ Prednisolon erwiesen [193, 235]; bisher ist aber nicht systematisch untersucht, ob bei niedrigerer Krankheitsaktivität ein ausreichender Effekt nicht auch mit 10 oder $20 \mathrm{mg}$ erreicht werden kann. Die Startdosis kann daher individuell in einem Bereich von 10 und 30 mg Prednisolon pro Tag gewählt werden. Innerhalb von acht Wochen sollte in den Low-DoseBereich ( $\leq 7,5 \mathrm{mg}$ Prednisolon/d) reduziert werden [193].

Für Patienten mit ERA ohne vorherige Therapie mit csDMARDs ist beschrieben, dass der symptomlindernde Effekt von GC im Laufe der Zeit nachlässt, so dass nach einem Jahr gegenüber den $\mathrm{Pa}$ tienten, die keine GC erhalten haben, kein Unterschied hinsichtlich der Gesamtfunktionalität feststellbar ist.

Ein Modified-Release-Prednison mit abendlicher Einnahme und nächtlicher Wirkstofffreisetzung führt im Vergleich zur Standard-Prednisolon-Gabe bei gleicher Dosierung zu einer signifikanten Verringerung der Morgensteifigkeit und kann deshalb bei Patienten, bei denen dieser Befund im Vordergrund steht, eine sinnvolle Alternative darstellen [236].

Nach zu schnellem Absetzen von GC besteht die Gefahr eines Rebound-Effektes [237].

\section{Empfehlung $\uparrow \uparrow$}

Bis zum Erreichen der Wirkung einer csDMARD-Therapie soll die Krankheitsaktivität mit einer Glukokortikoid-Therapie unterdrückt werden

\section{Good Clinical Practice $\checkmark$}

Überschreiten Sie eine Startdosis von $30 \mathrm{mg}$ Prednisolon-Äquivalent nur in Ausnahmefällen

\subsubsection{Beeinflussung der Funktion}

Auch wenn ein gewisser Nutzen der GCTherapie hinsichtlich der Funktionalität berichtet wird [238], konnte bisher kein objektivierbarer Langzeiteffekt nachgewiesen werden. Studien, welche den HAQ (Health Assessment Questionnaire, siehe Abschn. 9.2) [239] zur Beurteilung der Funktionalität verwenden, zeigen einen frühen Vorteil einer initial hohen „step-down“-GC-Gabe [173]. Die Verbesserung der HAQ-Werte, die durch die zusätzliche Gabe von GC erreicht wird, ist nach einem Jahr nicht mehr signifikant; nach 15 Monaten lässt sich kein Unterschied mehr nachweisen [240]. Bisher ist keine kontrollierte Studie publiziert, die belegt, welche Auswirkungen eine GC-Therapie auf die Funktionalität im Langzeitverlauf tatsächlich hat. Die aktuellen EULAR Empfehlungen raten unter Berücksichtigung der unerwünschten Langzeitwirkungen (s. Abschn. 5.2.3), die begleitende GC-Therapie nach drei bzw. spätestens sechs Monaten zu beenden [241].

\section{Good Clinical Practice $\checkmark$}

Reduzieren Sie die Glukokortikoiddosis innerhalb von acht Wochen in den LowDose-Bereich ( $\leq 7,5 \mathrm{mg} / \mathrm{d}$ Prednisolon) und beenden Sie diese Therapie nach drei bis sechs Monaten

\subsubsection{Radiologische Progression}

Oral verabreichte GC verzögern relevant die radiologisch nachweisbare Gelenkzerstörung. Nach Absetzen der GC schreitet die Progression der Gelenkzerstörung nach den Ergebnissen früherer, noch ohne bDMARD, tsDMARD und moderne Therapiestrategien durchgeführter Studien fort [238, 240, 242-244]. Neuere Studien zeigen, dass sich der GC-Effekt vor allem im ersten Halbjahr manifestiert [245]. Ein Zusatznutzen der GC ab dem zweiten Behandlungsjahr bei optimierter DMARD-Therapie konnte bisher in keiner Studie gezeigt werden.

\subsubsection{Unerwünschte Wirkungen}

Systematische Übersichtsarbeiten von RCTs mit RA-Patienten jeder Erkrankungsdauer belegen, dass unter GCTherapie das Risiko für Frakturen, Infektionen und Herz-Kreislauf-Erkrankungen steigt [234, 243].

Aus Beobachtungsstudien ist bekannt, dass die GC-Therapie der RA weitere unerwünschte Wirkungen auslöst; hierzu gehören u.a. Katarakte und avaskuläre Nekrosen [246-248].

Es liegen ebenfalls Berichte über eine erhöhte Mortalitätsrate vor [13, 249]. Dabei muss man allerdings berücksichtigen, dass Patienten, die Glucocorticoide erhielten, möglicherweise schwerer krank waren.

Sowohl die kumulative als auch die durchschnittliche GC-Dosis sind unabhängige, starke Prädiktoren der unerwünschten Effekte [248]. Als bedenklich gilt ein Tagesdosisbereich über $5 \mathrm{mg}$ [250]. Studien mit längerer Beobachtungsdauer wären erforderlich, um den kumulativen Effekt einer niedrig dosierten GC-Gabe und der intermittierenden Gabe beurteilen zu können.

Bei Beginn einer GC-Therapie mit $\geq 7,5 \mathrm{mg}$ Prednisolonäquivalent und einem voraussichtlichen Therapiezeitraum von mindestens drei Monaten sollte initial eine Knochendichtemessung erfolgen und eine Osteoporoseprophylaxe eingeleitet werden. Als Grundtherapie wird neben Maßnahmen zur Verminderung der Risikofaktoren eine Vitamin-D-Gabe empfohlen sowie eine ausreichende $\mathrm{Zu}$ fuhr von Kalzium (s. Leitlinie des Dachverbandes der deutschsprachigen os- 
teologischen Fachgesellschaften: DVOLeitlinie [http://www.dv-osteologie. org/uploads/Leitlinie\%202017/Finale \%20Version\%20Leitlinie\%20Osteoporose \%202017_end.pdf]).

\section{Good Clinical Practice $\checkmark$}

Leiten Sie bei Beginn einer Glukokortikoidtherapie Maßnahmen zur Osteoporoseprophylaxe entsprechend der aktuellen DVO-Leitlinie ein

\subsubsection{Intraartikuläre Therapie}

Die intraartikuläre GC-Gabe ist eine häufig angewandte Maßnahme, um eine schnelle, manchmal auch anhaltende Linderung von Beschwerden und Reduktion der Schwellungen einzelner Gelenke (target-joints) zu erzielen.

Intraartikuläre GC-Injektionen

- ermöglichen die lokale Therapie einzelner entzündeter Gelenke, bei minimalen unerwünschten systemischen Effekten

- können eine symptomatische Besserung während der Latenzzeit von DMARDs bewirken

- eignen sich zur Therapie besonders befallener einzelner Gelenke, wenn die Krankheitsaktivität insgesamt gut unter Kontrolle ist

- können zur Therapie von Mon-/ Oligoarthritiden herangezogen werden, wenn eine Therapie mit DMARDs nicht angemessen erscheint

Es liegen jedoch nur wenige kontrollierte Studien zur intraartikulären Therapie vor. Langzeiteffekte bezüglich der Funktion oder der radiologischen Progression solcherart behandelter Gelenke sind nicht untersucht.

Die Verabreichung einer intraartikulären Injektion hat unter sterilen Kautelen zu erfolgen. Nach den Ergebnissen einer großen retrospektiven Untersuchung in Frankreich ist die Infektion als Komplikation der intraartikulären GC-Injektion sehr selten (1:77.000) [251]. Abpunktieren der Gelenkflüssigkeit vor GC-Injektion führt zu einer Halbierung des Risikos des Auftretens eines Rückfalls [252]. Die körperliche Schonung nach Injektion in das Kniegelenk verbessert den symptomatischen Effekt der Behandlung [253]. Nach Injektion in das Handgelenk ist $\mathrm{Ru}$ higstellung jedoch ungünstig [254].

Differenzialdiagnostisch ist bei Entzündung einzelner Gelenke immer auch ein Empyem in Betracht zu ziehen.

Die Patienten sind über Maßnahmen zu informieren, die sie ergreifen sollen, wenn das Gelenk nicht zur Ruhe kommt.

\section{Good Clinical Practice $\checkmark$}

Erwägen Sie für eine schnelle, manchmal auch anhaltende Besserung der Symptome in "Zielgelenken" die intraartikuläre GC-Injektion

\subsection{Symptomatische analgetische Therapie}

\subsubsection{Nichtsteroidale Antirheuma- tika (NSAR)}

NSAR werden begleitend symptomatisch aufgrund ihrer schmerzlindernden Wirkung eingesetzt. Die am häufigsten eingesetzten nicht-selektiven NSAR sind Diclofenac, Ibuprofen und Naproxen. Von den selektiven COX-2 (Cyclooxygenase2)-Hemmern (Coxiben) sind gegenwärtig Celecoxib und Etoricoxib in Deutschland zugelassen. Das ebenfalls zugelassene Parecoxib spielt aufgrund der intravenösen Applikation keine Rolle in der Therapie der RA.

Es gibt Belege für eine gute Wirksamkeit der NSAR auf die Gelenkschmerzen der RA. Sie verringern die Gelenksteife und verbessern die Mobilität, ohne jedoch das Krankheitsgeschehen anhaltend und langfristig zu beeinflussen $[255,256]$. Sie können ergänzend überbrückend bis zum Wirkungseintritt der DMARD-Therapie eingesetzt werden. Dabei ist die Wirksamkeit der selektiven COX-2-Hemmer mit der nichtselektiver NSAR vergleichbar.

Die unerwünschten Wirkungen können ein wesentlicher limitierender Faktor einer Therapie mit nicht-selektiven NSAR oder selektiven COX-2-Hemmern sein. Die unerwünschten Arzneimittelreaktionen sind bestimmt durch die Dosis, die Halbwertszeit der einzelnen Substanzen, die Therapiedauer und durch bestimmte Risikofaktoren seitens der Pati- enten [257]. Hiervon abhängig sollte die Wahl des NSAR ggf. in Kombination mit einem Protonenpumpeninhibitor getroffen werden [257-259].

\subsubsection{Nicht-Opioide}

Auch Nicht-Opioidanalgetika können zur symptomatischen Therapie bei der frühen rheumatoiden Arthritis eingesetzt werden. Es gibt Hinweise dafür, dass Paracetamol effektiv die Schmerzen bei Patienten mit RA lindern kann, jedoch in seiner Wirksamkeit den NSAR unterlegen ist (die durchgeführten Studien sind zum überwiegenden Teil alt und von mangelhafter methodischer Qualität [260-264]). Somit beschränkt sich der Einsatz von Paracetamol auf Ausnahmefälle, z. B. bei bestehenden Kontraindikationen gegen NSAR.

\subsubsection{Opioidanalgetika}

Die Anwendung von Opioidanalgetika zur symptomatischen Therapie von Patienten mit RA sollte die Ausnahme darstellen, insbesondere bei Patienten mit ERA. Die Indikation sollte erst nach Ausschöpfung aller bisher genannten symptomatischen Therapieoptionen gestellt werden; eine Kombination mit einem NSAR oder Nicht-Opioidanalgetika kann kurzzeitig (bis zu sechs Wochen) eingesetzt werden $[265,266]$.

In Ausnahmefällen und bei bestehenden Kontraindikationen gegen NSAR kann ihre Gabe auch bei Patienten mit ERA gerechtfertigt sein. Die Auswahl der einzelnen Substanzen sollte sich am Stufenschema der Weltgesundheitsorganisation (WHO) orientieren. Nur starke Opioide übertreffen andere Arzneien hinsichtlich der Schmerzreduktion, resultieren aber in schlechterer Funktionstüchtigkeit [267].

\section{Good Clinical Practice $\checkmark$}

Reduzieren Sie bei gutem Ansprechen auf die DMARD-Therapie die nicht-selektiven NSAR bzw. die selektiven COX2-Hemmer soweit wie möglich 


\section{Nicht-medikamentöse Interventionen in der multidisziplinären Behandlung}

\subsection{Physiotherapie}

Die Physiotherapie ist ein wesentlicher Bestandteil der Behandlung von Patienten mit RA, auch mit ERA. Zentrale Elemente der Physiotherapie sind Sportbzw. Bewegungsprogramme und physikalische Therapie, bei denen die Behandlung individuell auf die jeweilige Situation des Patienten angepasst wird. Für die Therapiesteuerung sind die Krankheitsaktivität, das Krankheitsstadium des Patienten, das Ausmaß der körperlichen Einschränkungen und die Prognose maßgeblich.

Im Speziellen wird angestrebt, Schmerzen und Schwellungen zu lindern und Gelenkmobilität, Kraft und Ausdauer zu steigern, um die Lebensqualität der Patienten zu verbessern [268].

Die im Folgenden dargestellte Evidenz bezieht sich ausschließlich auf RA, da keine explizite Evidenz für die physiotherapeutische Behandlung der ERA zur Verfügung steht. Die bestehende Evidenz lässt sich aber nach Einschätzung der Kommission sehr gut auf die frühe RA übertragen.

\subsubsection{Bewegungstherapie und Sporttherapie}

Schonung und Ruhe haben mehr negative als positive Folgen für die meisten Patienten mit RA [269] und können zu zunehmender Schwäche und funktioneller Beeinträchtigung führen; dem wirkt die Bewegungstherapie entgegen [270-272].

Bewegungs- bzw. Sporttherapie ist die planmäßige, gezielte Anwendung von $\mathrm{Be}$ wegungsübungen mit dem Ziel, Schäden an den Bewegungsorganen zu begegnen und funktionelle Defizite auszugleichen. Übungen im warmen Bewegungsbad werden gegenüber Trockenübungen von den Patienten subjektiv besser eingeschätzt mit entsprechend höherer Compliance. Allerdings verbesserten o. g. funkionelle Defizite sich bei beiden Verfahren ähnlich [273]. Zum Erhalt der Gelenkfunktion, der Muskelkraft und der Beweglichkeit ist eine regelmäßige Physiotherapie über die Erstverordnung hi- naus sinnvoll, sodass fortlaufende Behandlungen einen nachhaltigen Behandlungserfolg ermöglichen können.

Im Rahmen der Sporttherapie werden dynamische Trainingsprogramme mit dem Ziel durchgeführt, die negativen Effekte der RA mit muskulärer Kraft, Ausdauer und aerober Kapazität (Belastbarkeit) des Patienten auszugleichen. Spezielle regelmäßige Kraft und/ oder Ausdauertrainingsprogramme können die Muskelkraft und den Grad der funktionellen und psychischen Beeinträchtigung verringern ohne negative Effekte auf Schmerz, Krankheitsaktivität oder strukturelle Gelenkveränderungen zu haben. Krafttraining ist im Vergleich $\mathrm{zu}$ Ausdauertraining in Bezug auf Lebensqualität und Funktion effektiver [274-280]. Dabei sollte das Training individuell auf die Fähigkeiten und Bedürfnisse der Patienten zugeschnitten [281] und vor allem supervidiert und regelmäßig durchgeführt werden [282, 283].

Darüber hinaus können personalisierte Physiotherapie (Einzelbehandlung mit Anleitung zum Selbstmanagement mit dem Fokus auf Bewegungsinterventionen) bzw. Bewegungsinterventionen wie Stretching, Kraft- und/oder Ausdauertraining, Training im Wasser oder Tai Chi zur Linderung von Fatigue beitragen [284-287].

Die langfristige Compliance für regelmäßige Bewegungsübungen und körperliche Aktivität wird durch persönlichen Kontakt zu Therapeuten und zur Gruppe gestärkt [288, 289].

\section{Empfehlung $\uparrow$}

Ihre Patienten sollten regelmäßig dynamische Bewegungsübungen und individuell abgestimmtes Kraft- und Ausdauertraining durchführen

\section{Good Clinical Practice $\checkmark$}

Verordnen Sie allen Patienten mit Funktionseinschränkungen Physiotherapie

\subsubsection{Physikalische Therapie}

Obwohl die Balneotherapie zu den ältesten Therapieformen der RA gehört, ist die Evidenz zur Effektivität spärlich. Die Autoren von zwei systematischen Übersichtsarbeiten $\mathrm{zu}$ Balneotherapie konnten nur geringe Effekte für eine Wirksamkeit im Vergleich zu keiner Intervention nachweisen und auch keine spezielle Anwendung favorisieren [290, 291].

Geringe Evidenz (nur ein RCT) gibt es für die Effektivität von Massagetherapie im Arm- bzw. Schulterbereich. In der einzig eingeschlossenen Studie von Field et al. [292] konnten signifikante Verbesserungen in Bezug auf Schmerz, Griffkraft und der Range of Motion (ROM) durch Massagen mit mittlerem Druck nachgewiesen werden.

Trotz empirisch guter lokaler symptomatischer Wirkung der Kälteapplikation für akut entzündete Gelenke wird in einer systematischen Übersichtsarbeit die Datenlage für die Beurteilung der Kältetherapie als unzureichend eingeschätzt [293]. Eine Überlegenheit der Ganzkörper-Kältetherapiegegenüber lokalen Kälteanwendungen konnte in einer einfach verblindeten kontrollierten Studie nicht gesichert werden [294].

Auch für Wärmeapplikation sowie zur Elektro- oder Laser-Therapie werden die Daten in Übersichtsarbeiten als unzureichend oder widersprüchlich eingeschätzt [293, 295-297]; begrenzte Hinweise existieren lediglich für den symptomatischen Effekt von Wachsanwendungen, transkutaner elektrischer Nervenstimulation (TENS) und Ultraschalltherapie [298]. Es liegt ein Cochrane Review vor [295], der konventionelle TENS (C-TENS) und Akupunktur-like TENS (AL-TENS) miteinander und zu Placebo vergleicht. Es zeigt sich, dass AL-TENS gegenüber Placebo eine signifikante Verbesserung des Ruheschmerzes, nicht aber des GreifSchmerzes erreichte. C-TENS hingegen führte im Vergleich zu Placebo nicht zu einer Schmerzreduktion, aber zu einer größeren Zufriedenheit auf Seiten der Patienten. Die Studien sind sehr klein und methodisch von mittlerer Qualität.

\subsection{Sport und körperliche Aktivität}

Die positiven Effekte von Sport und Training sind neben dem Erhalt von Gelenkführung und Beweglichkeit in einer ausreichend kräftigen Muskulatur sowie der 
Wirkung auf den Gesamtorganismus zu sehen. Bei Empfehlungen zum Sport bzw. Training ist die individuelle Belastbarkeit auf jeden Fall zu berücksichtigen. Im akuten Schub sollten die Patienten ihre bisherige Sportart bzw. Bewegungsangebote schmerzadaptiert weiterführen. Regelmäßige Bewegungsangebote wie Kraftund/oder Ausdauerprogramme, z.B. in Fitness-Studios oder Kurse in öffentlichen Bewegungsbädern, können zudem Schmerzen lindern und die Funktion verbessern [299].

Eine gute Möglichkeit, die körperliche Aktivität von Arthritis-Patienten zu erhöhen, kann Yoga sein. Hier gibt es gute Evidenz für positive Effekte in Bezug auf Lebensqualität sowie physische und psychische Aspekte [300-302].

Für Tai Chi dagegen ist die Evidenz inkonsistent. Es liegen zwei systematische Übersichtsarbeiten mit RCTs zu Tai Chi bei RA ohne Differenzierung nach Erkrankungsdauer vor [303, 304]. In einem Review wird eine Verbesserung der Beweglichkeit gesehen [303].

\section{Good Clinical Practice $\checkmark$}

Fördern Sie die Motivation Ihrer Patienten zu sportlicher Aktivität und Bewegung. Einschränkungen in Bezug auf bestimmte Sportarten sind nicht erforderlich

\subsection{Ergotherapie}

Ergotherapie ist eine wichtige Säule in der Versorgung von Patienten mit einer ERA. In der Therapie werden individuell bedeutsame Alltagshandlungen geübt und ggf. Kompensationsstrategien erlernt, damit der Klient diese (wieder) bestmöglich ausführen kann; Hilfsmittel werden angepasst, der sichere Umgang mit ihnen trainiert und Adaptionen der persönlichen Umwelt (häuslich, ggf. beruflich) vorgenommen. Individuelle Beratung und Schulung (Arbeitsplatzberatung, Gelenkschulung) gehören bei drohender Einschränkung der Handfunktion, der Alltagsaktivitäten und/ oder der beruflichen Tätigkeit zu einer klientenzentrierten, alltags- und betätigungsorientierten Ergotherapie. Ziel ist, Menschen mit früher RA dabei zu un- terstützen, ihre Handlungsfähigkeit im Alltag, ihre gesellschaftliche sowie berufliche Teilhabe und ihre Lebensqualität zu erhalten oder zu verbessern.

Nach den Ergebnissen einer systematischen Übersichtsarbeit liegt jedoch begrenzte Evidenz für den Nutzen einer umfassenden Ergotherapie bei Patienten mit RA vor, definiert als eine Verbesserung des Funktionsstatus [305, 306]. Bei Analyse der Einzelmaßnahmen lässt sich allein für die Anleitung zum gelenkschonenden Verhalten ein Effekt belegen; auch hier ist verbesserte Funktionalität das Resultat. Lamb et al. [307] zeigen in einer jüngeren randomisiert kontrollierten Studie auf, dass individuelle Übungsprogramme für die oberen Extremitäten die Handfunktionen positiv beeinflussen. $\mathrm{Zu}$ ähnlichen Ergebnissen kommen Cima et al. [308], die eine verbesserte Funktionalität und eine größere Handkraft durch Übungsprogramme nachweisen. Dogu et al. [309] belegen, dass isometrische und isotonische Übungsprogramme nicht nur die Handkraft und -funktion verbessern, sondern auch die Krankheitsaktivität sowie Schmerzen vermindern. Der Nutzen von Gelenkschienen wird unterschiedlich beurteilt und ist nicht durch Studien hoher Qualität belegt [310]. Es existieren Hinweise für einen begrenzten Effekt hinsichtlich der Schmerzreduktion. Orthesen sind individuell anzufertigen und nach Gebrauchskontrolle anzupassen.

In Bezug auf ergotherapeutische Interventionen am Arbeitsplatz weisen Baldwin et al. [311] in einer über zwei Jahre angelegten randomisiert kontrollierten Studie verminderte krankheitsbedingte Einschränkungen am Arbeitsplatz sowie eine Verbesserung der körperlichen Funktionsfähigkeit und Verminderung von Schmerzen nach. Diese Ergebnisse werden durch Macedo et al. [312] untermauert, deren Studienergebnisse nahelegen, dass arbeitsplatzbezogene Interventionen zum Erhalt der Erwerbstätigkeit beitragen und Arbeitsunfähigkeit verringern.

\section{Empfehlung $\uparrow$}

Alle Patienten mit Einschränkung der Handfunktion, der Alltagsaktivitäten und/oder der beruflichen Tätigkeit sollten Ergotherapie erhalten

\subsection{Orthopädische Schuhversor- gung}

Neben der Beachtung von gutem Schuhwerk, welches ausreichend Komfort, Mobilität und Stabilität bietet, ist bei anhaltenden Fußbeschwerden unter geringer Krankheitsaktivität nach den Hilfsmittelrichtlinien die Verordnung von individuell angefertigten orthopädischen Schuheinlagen bzw. Schuhen durch fachkundige Verordner sinnvoll. Hierdurch können die Schmerzen und die Druckbelastung auf den Vorfuß reduziert werden [313-317]. Eine eindeutige Verbesserung auf die Funktion des Fußes (Gangart und -geschwindigkeit) konnte nicht nachgewiesen werden $[315,318]$. Weiterhin ist nicht geklärt, inwieweit typische, im Verlauf neu auftretende bzw. die Progredienz bereits bestehender Fehlstellungen des Rück- oder Vorfußes protrahiert werden können.

\section{Good Clinical Practice $\checkmark$}

Stellen Sie Ihre Patienten mit Fußbeschwerden trotz ansonsten ausreichender Therapie einem Spezialisten für fachgerechte Schuhversorgung vor Bei Fußbeschwerden kann die adäquate Einlagen- bzw. Schuhversorgung zu einer Schmerzlinderung führen

\subsection{Psychologische Interventionen}

Psychologische Interventionen sollen vor allem durch eine günstige Beeinflussung von psychischer Stabilität, körperlicher Aktivität, aktivem Coping-Stil und Stress die Verminderung von Schmerz, Behinderung und Krankheitsaktivität unterstützen. Wesentliche Formen im Rahmen von Selbsthilfeangeboten sowie Psychotherapie sind multimodale kognitiv-behaviorale Interventionen, Entspannungstechniken sowie Schmerz-, Krankheits- und Stressbewältigungsprogramme außerhalb und innerhalb der 
Patientenschulung (s. Abschn. 4.1). Psychologische Interventionen haben ihre Effektivität in zahlreichen Studien (RCTs und Meta-Analysen) nachgewiesen u.a. bzgl. Coping, Selbstwirksamkeit, körperliche Aktivität, Schmerz, Behinderung im Alltag und reduzierter Krankheitskosten [319-329].

\section{Empfehlung $\uparrow$}

Patienten sollten zur Senkung des Schmerzerlebens, zur Steigerung des Aktivitätsniveaus und zur Förderung der Krankheitsbewältigung psychotherapeutische Interventionen (insbesondere aus dem Bereich der kognitiven Verhaltenstherapie) erhalten

\section{Komplementäre Verfahren bei Rheumatoider Arthritis}

\subsection{Akupunktur, traditionelle chinesische und indische Medizin, Phytotherapie, Homöopathie, Diäten, Mind-Body-Medizin}

Es liegen zwei ältere systematische Übersichtsarbeiten mit RCTs zur Anwendung der Akupunktur bei RA (ohne Differenzierung nach Erkrankungsdauer) vor [330, 331]. Beide zeigten bei heterogener Studienlage keinen signifikanten Effekt bezüglich klinischer Endpunkte (meist Schmerzscores) gegenüber Placebo oder anderen Interventionen.

Zur Effektivität von TCM (traditionelle chinesische Medizin)-Kräutertherapien bei RA gibt es keine systematischen Übersichtsarbeiten. Kontrollierte Studien zu verschiedenen Rezepturen von nachvollziehbarer, höherer Qualität liegen aktuell weder aus dem Gebiet des Ayurveda noch der TCM vor. Eine systematische Übersichtsarbeit zur ayurvedischen Behandlung bei RA sieht keine ausreichende Evidenz für einen Nutzenbeleg [332].

Zur Anwendung von Phytotherapeutika bei RA liegen zwei ausführliche systematische Übersichtsarbeiten vor $[333,334]$. Da für die meisten pflanzlichen Arzneien/Wirkstoffe entweder nur einzelne oder zwei Studien vorlagen, wurde die Evidenzlage als kritisch bewertet. Auch die Studienqualität und/oder die Probandenzahl waren meist nicht ausreichend. Die Analysen ergaben jedoch eine mögliche Evidenz (moderate Qualität) für Gamma-Linolensäure-haltige Öle (Nachtkerzenöl, Johannisbeer-, Borretsch-Samenöl) zur Symptomlinderung. Unerwünschte Nebenwirkungen bei Einnahme solcher Öle waren im Vergleich zu Placebo nicht signifikant.

Einen Spezialfall stellt die Dreiflügelfrucht (Tripterygium Wilfordii HOOK.F. (TwHF)) dar, die in China sehr verbreitet zur Behandlung der RA eingesetzt wird. Sie wird in Deutschland als Nahrungsergänzungsmittel angeboten und zunehmend auch zur Behandlung der RA eingenommen. In Deutschland ist die Dreiflügelfrucht nicht als Arznei zugelassen. Die Studienlage ist unzureichend und beschränkt sich fast ausschließlich auf China mit schlechter zugrunde liegender Studienqualität. Zurzeit liegen zwei Metaanalysen vor [335, 336]. TwHF wurde einerseits ergänzend zu Methotrexat verabreicht und soll zusätzlich Symptomlinderung bewirkt haben, nur eine der Studien war von guter Qualität. Andere Studien verglichen TwHF mit konventioneller Medikation: im direkten Vergleich war TwHF Sulfasalazin und Plazebo überlegen, im indirekten Vergleich noch anderen Entzündungshemmern oder Immunmodulatoren. Die Dreiflügelfrucht ist eine Giftpflanze, also nicht frei von unerwünschten Wirkungen, diese bleiben jedoch im Allgemeinen hinter denen der synthetischen DMARDs zurück [337].

$\mathrm{Zu}$ einer homöopathischen Behandlungsoption bei RA liegt ein fünfarmiges, doppelblindes RCT von hoher Qualität vor [338]. Ergebnis der Studie war, dass einzig die homöopathische Konsultation einen nicht unerheblichen statistisch relevanten positiven Einfluss auf die RA (DAS28, Schwellung, Schmerz, Stimmung) aufweisen konnte.

Eine Aussage über die Wirksamkeit spezieller Diäten bei RA ist wegen fehlender valider Evidenz nicht möglich. Ein Cochrane-Review liegt vor, die aufgenommenen Studien sind heterogen und z. T. schlecht berichtet [339].

Verfahren der Mind-Body-Medizin sind für die Behandlung der RA wenig beforscht. Eine Übersichtsarbeit [334] fand zwei RCTs zu Meditation und progressiver Muskelentspannung. Es zeigten sich keine überzeugenden Ergebnisse, aber auch keine Nebenwirkungen.

\section{Good Clinical Practice $\checkmark$}

Für eine Anwendung spezieller komplementärer Verfahren (Akupunktur, traditionelle chinesische und indische Medizin, Diäten, Phytotherapie, Homöopathie, Mind-Body-Medizin) kann aufgrund mangelnder Evidenz keine Empfehlung ausgesprochen werden

\subsection{Nahrungsergänzungen}

Jiang et al. 2016 beschreiben in ihrer systematischen Übersichtsarbeit 18 RCTs zum Einfluss von Fischöl, i.e. marinen n-3 mehrfach ungesättigten Fettsäuren ( $n$-3 PUFA) auf die Eikosanoid-Konzentration, davon fünf RCTs bei RA. Die Sub-Gruppenanalyse der RA-Studien ergab eine signifikante Reduktion von Leukotrien B4 (LTB4) unter Supplementierung [340]. 2012 hatten Miles et al. 23 RCTs zu marinen mehrfach ungesättigten Fettsäuren bei RA untersucht. Die Heterogenität (Dauer, Dosierung, Ölsorte etc.) der Studien ließ keine Metaanalyse zu, die Studienqualität (Jadad Score) war gut bis mittelgradig. Festgestellt wurde eine moderate Evidenz bei Verbesserung von Schmerz, Morgensteifigkeit, Gelenkschwellung und Krankheitsaktivität [341].

Es liegen zudem neuere einzelne RCTs zu marinen Ölen vor, die obige Ergebnisse bestätigen (z. B. Olendzki [342]). Bei dem RCT von Proudman et al. 2015 konnte gezeigt werden, dass die zusätzliche Einnahme von $10 \mathrm{~mL} / \mathrm{d}$ Fischöl (hohe Dosierung vs Minimaldosierung, doppelblind) ein Ansprechen (Remission, Response etc.) einer Triple-DMARD-Basistherapie bei neu aufgetretener RA signifikant verbessern konnte [343, 344].

\section{Good Clinical Practice $\checkmark$}

Omega-3-Fettsäuren können Symptome der RA lindern 


\section{Patientenleitlinie}

Die Leitlinie „Management der frühen rheumatoiden Arthritis"hat dasZiel, dass in Deutschland alle an einer RA Neuerkrankten innerhalb von sechs Wochen eine fachspezifische Versorgung erhalten. Über eine frühzeitige angemessene Versorgung können eine bessere Prognose und Lebensqualität der Betroffenen erreicht werden. Wichtig sind dabei ein rechtzeitiges Erkennen und Deuten von Krankheitszeichen und der frühzeitige Beginn einer spezifischen Therapie.

Begründung der Patientenversion der Leitlinie: Die vorliegende Patienteninformation dient dazu, Sie, die Patienten, verständlich über das Krankheitsbild, die diagnostischen Maßnahmen und die Therapiemöglichkeiten $\mathrm{zu}$ informieren. Mit diesen Informationen soll Ihnen die Möglichkeit gegeben werden, gemeinsam mit Ihrem Arzt aktiv an Ihrer Behandlung teilzuhaben. Die Patienteninformation basiert auf den Empfehlungen der Medizinischen Leitlinie „Management der frühen rheumatoiden Arthritis", die von einer Expertengruppe verschiedener Fachrichtungen und Patientenvertretern systematisch entwickelt und wissenschaftlich begründet wurde.

Die wesentlichen Informationen dieser Leitlinie für Patienten ergeben sich aus der Beantwortung folgender vier Fragen: „Was bedeutet die Erkrankung für mich?", "Was verbirgt sich hinter einer Rheumatiden Arthritis?", „Was kann mein Arzt für mich tun?" „Was kann ich selber tun?".

\subsection{Was bedeutet die Erkrankung für mich?}

Bei Ihnen wurde die Diagnose Rheumatoide Arthritis (RA) gestellt. Wie sich diese Krankheit bei Ihnen auswirkt, wissen Sie selbst am besten. Typische Beschwerden sind eine Morgensteifigkeit meist der Fingergelenke mit Bewegungseinschränkungen und Kraftlosigkeit der Hände. Die Gelenke schmerzen infolge der Entzündung. Alltagstätigkeiten, die Ihnen bisher leicht gefallen sind, können nun auf einmal schwer fallen, wenn nicht sogar unmöglich werden. Im Laufe der Zeit können weitere Gelenke betroffen sein. Manchmal steht auch ein allgemei- nes Krankheitsgefühl im Vordergrund. All das kann Ihre Lebensqualität mehr oder weniger einschränken. Die Krankheit kann bei jedem Einzelnen sehr unterschiedlich verlaufen.

Die Leittlinie klärt die Ärzte über diese Frühsymptome auf, die genutzt werden um die Diagnose der Erkrankung zu sichern.

\subsection{Was verbirgt sich hinter einer RA?}

Das Krankheitsgeschehen und die Abläufe im Körper sind nicht einfach zu verstehen. Wir möchten Sie ermuntern, mehr darüber zu verstehen und zu wissen, weil Sie dann besser nachvollziehen können, wieso der Arzt Medikamente oder weiterführende Therapien, wie zum Beispiel Physiotherapie, Ergotherapie und andere, verordnet.

Bei einer RA handelt es sich

a) um eine systemische, d.h. den ganzen Körper betreffende, Entzündung.

b) Die Krankheit zeigt sich vor allem an den Gelenken.

c) Es handelt sich um eine chronische Erkrankung, d.h. lang andauernde Erkrankung, für die wir bisher keine Heilung kennen.

d) Der Begriff „Rheumatoide Arthritis" bedeutet "Gelenkentzündung, die zum rheumatischen Formenkreis gehört". Eine frühere Bezeichnung lautete "chronische Polyarthritis“ (poly= viele, Arthritis $=$ Gelenkentzündung).

e) Die Erkrankung verläuft bei vielen Patienten schubweise, d.h. es kann entzündungsfreie Intervalle geben.

f) Es handelt sich um die häufigste chronisch entzündliche Erkrankung der Gelenke.

g) Frühe RA bedeutet, dass häufig noch keine bleibenden Gelenkschäden aufgetreten sind.

\subsubsection{Das Gelenk}

Ein Gelenk ist die Verbindung zweier Knochen. Es besteht zumeist aus einem Gelenkkopf und einer Gelenkpfanne, die zueinander passen und gegeneinander beweglich sind. Mit den Gelenken sind die Bewegungen unseres Körpers überhaupt erst möglich. Die Gelenkflächen sind mit Knorpel überzogen, welcher als Gleitfläche und Stoßdämpfer zwischen den Knochen wirkt. Eine Gelenkkapsel umgibt das Gelenk. Die innere Schicht der Gelenkkapsel ist mit der Gelenkinnenhaut (Synovialis) überzogen, die die Synovialflüssigkeit herstellt, um das Gelenk „zu schmieren“.

\subsubsection{Auslöser der RA}

Die Ursache der RA ist bis heute nicht vollständig geklärt und Gegenstand intensiver Forschung. Eine große Bedeutung hat im Krankheitsprozess unser Immunsystem, welches uns vor Mikroorganismen (Bakterien, Viren, Pilze etc.), Fremd- und Schadstoffen von außen, aber auch vor Fremd- und Schadstoffen aus dem eigenen Körper stammend (entartete Zellen, innere Keime), schützt. Die „Waffe“ unseres Immunsystems, um gefährliche Eindringlinge unschädlich zu machen, ist die Entzündung. In der Regel bemerken wir nichts von der Arbeit unseres Immunsystems, was ein Zeichen eines gut funktionierenden Immunsystems ist.

Bekannt ist, dass im Immunsystem, wenn auch sehr selten, Erkennungsfehler passieren können. Wenn unser Immunsystem nicht mehr zwischen „eigen" und „fremd“ unterscheidet, dann bekämpft es mit der Waffe der Entzündung körpereigene Strukturen. Dies nennt man Autoimmunität. Im Falle der RA zeigt sich diese Autoimmunität an der Gelenkinnenhaut. Hier kommt es zu einer chronischen Entzündung.

\subsubsection{Folgen einer unbehandelten RA}

Bleibt eine RA unbehandelt, dann kann die chronische Entzündung der Gelenkinnenhaut auf die umliegenden Strukturen wie Knorpel, Knochen und Weichteilgewebe übergreifen und diese zerstören. Knorpel und Knochen werden angegriffen, was Gelenkbewegungen sehr erschwert bis unmöglich macht. Die Folgen können Fehlstellungen der Gelenke und Verformungen sein. Die Gelenke verlieren unbehandelt im Verlaufe weniger Jahre ihre Funktion, was zu starken Beeinträchtigungen im Alltag führen kann. 


\subsubsection{Ziel der Therapie}

Das Ziel der Therapie heißt „Remission". Remission bedeutet, dass die Entzündung kontrolliert ist und es damit nicht zu weiteren Gelenkzerstörungen kommt. Dies bedeutet, dass die Krankheit unter Kontrolle ist und ruht. Dieses Therapieziel ist heute für viele Betroffene erreichbar.

\subsubsection{So früh wie möglich zum Rheumatologen}

Wird die Krankheit in den ersten sechs Monaten der Krankheitszeichen (Symptome) wie Gelenkschmerzen und vor allem Gelenkschwellungen sicher diagnostiziert und eine Basistherapie begonnen, besteht die beste Aussicht auf eine sog. Remission. In diesem Zeitraum sind die Gelenke durch die Entzündung noch nicht unwiderruflich angegriffen. Spätfolgen der rheumatoiden Arthritis zerstörte Gelenke mit Funktionsverlust können in diesem Zeitfenster am ehesten verhindert werden. Aber auch wenn die Erkrankung erst später diagnostiziert wird, ist eine sog. Basistherapie (siehe unten) dringend empfohlen.

\subsubsection{Vorhersage des Krankheits- verlaufs (Prognose)}

Die Ausprägungen der RA zu Beginn und im Krankheitsverlauf sind individuell sehr unterschiedlich. Gerade am Anfang der Erkrankung ist der Verlauf für den einzelnen Patienten nur begrenzt vorhersagbar. Die Entzündung, das Vorliegen verschiedener Laborparameter (siehe Abschn. 8.3.2) sowie die Dauer bis zur Einleitung einer Basistherapie spielen hierbei eine entscheidende Rolle.

\subsection{Was kann mein Arzt für mich tun?}

Eine eindeutige Diagnose ist die wichtigste Voraussetzung für die Therapie. Die folgenden Untersuchungen dienen neben der Anamnese dazu:

\subsubsection{Körperliche Untersuchung durch den Rheumatologen}

Der Arzt untersucht Sie körperlich und tastet dabei die Gelenke ab und unterscheidet eine entzündliche Schwellung von z. B. einer knöchernen Auftreibung, wie sie häufig bei der Arthrose (degenerative Gelenkveränderung ohne primäre Entzündung) vorkommt. Das sichtbare Verteilungsmuster der Entzündung in den betroffenen Gelenken (vor allem Fingerknöchel und Fingermittelgelenke) gibt weitere Hinweise auf eine RA. Die Krankheitsgeschichte Ihrer Familie (Familienanamnese) kann ebenso Aufschluss geben, denn es kommt nicht selten vor, dass ein Verwandter ebenfalls eine entzündlich-rheumatische Erkrankung hat oder hatte.

\subsubsection{Labor}

Blutsenkungsgeschwindigkeit (BSG oder BKS) Die BSG ist eine Untersuchung unseres Blutes, die durch einen erhöhten Wert relativ einfach einen entzündlichen Prozess in unserem Körper aufzeigen kann. Allerdings ist sie dabei nicht charakteristisch für eine bestimmte Form einer Entzündung. Im Gegenteil, sie kann auch bei vielen anderen Erkrankungen erhöht sein, ohne dass sich eine Ursache dafür findet. Auf der anderen Seite schließt eine normale BSG einen entzündlichen Vorgang im Körper nicht aus.

C-reaktives Protein (CRP) Der CRP Wert ist ebenfalls ein Hinweis auf eine Entzündung. Dieser Wert ist z. B. auch bei Infektionen erhöht. Das CRP deutet etwas sicherer und schneller als die BSG auf eine Entzündung hin.

Rheumafaktor (RF) Der RF ist ein Autoantikörper gegen bestimmte körpereigene Eiweiße und ist bei vielen Patienten mit RA im Blut nachweisbar. Allerdings haben auch etwa 1/3 der Patienten mit RA keinen RF. Ebenso gibt es Menschen, bei denen ein RF nachgewiesen wird, die aber keine RA haben. Mit der Bestimmung des RF kann man die Diagnose RA wahrscheinlicher machen, aber weder beweisen noch ausschließen.

Antikörper gegen citrullinierte Peptide/Proteine (ACPA) Hierzu zählen die sogenannten CCP-Antikörper, mutierte MCV-Antikörper, nicht mutierte MCVAntikörper und Antikörper gegen citrulliniertes Fibrinogen. Am häufigsten werden in der Praxis CCP-Antikörper bestimmt. Er richtet sich gegen bestimmte körpereigene Strukturen (körpereigene Proteine). Sind die CCP-Antikörper erhöht, ist dies ein wichtiger Hinweis auf das Vorliegen einer frühen RA und ein Hinweis auf den möglichen Krankheitsverlauf sowie das Risiko für eine Gelenkzerstörung.

\subsubsection{Bildgebung}

Röntgen Bereits zu Beginn der RA werden die Hände und Füße mittels Röntgenaufnahmen untersucht, um den Ausgangszustand der Gelenke abzubilden. Im weiteren Verlauf der Erkrankung werden diese Untersuchungen in bestimmten Situationen wiederholt, um den Erfolg der Therapie zu überprüfen und die Prognose besser beurteilen zu können. Röntgenaufnahmen können allerdings nur einen bereits eingetretenen Gelenkschaden abbilden, den man heute vollständig verhindern will und zumeist auch kann. Für die kurzzeitige Verlaufskontrolle werden heute häufiger andere bildgebende Verfahren eingesetzt (z.B. Sonographie, siehe unten), da diese die Entzündungsreaktion deutlich sensitiver erfassen können.

Sonographie Die Sonographie benutzt Ultraschallwellen, die sich im Gewebe ausbreiten und dort von den verschiedenen Gewebearten unterschiedlich reflektiert werden. Die Ultraschalluntersuchung der Gelenkelässt den Rheumatologen Entzündungen der Gelenke (Arthritis) oder Sehnenscheiden (Tendovaginitis) schneller und genauer erkennen als mittels Röntgenuntersuchung. Sie dient heute häufig auch zur Therapiekontrolle, da sie sehr sensitiv entzündliche Veränderungen der Gelenke erfassen kann. Die Sonographie wird heute von vielen Rheumatologen sehr regelhaft eingesetzt und unterstützt dabei anstehende Therapieentscheidungen.

Magnetresonanztomographie (MRT, Kernspintomographie) Eine MRT ist ein Schnittbildverfahren, das mittels eines Magnetfeldes, also ohne Röntgenstrahlen, die verschiedenen Gewebearten mit und ohne Kontrastmittel sehr klar darstellen kann. Weichteilschwellungen und frühe Knochenveränderungen kön- 
nen im Gegensatz zum konventionellen Röntgen gut erkannt werden und können somit ebenfalls Hinweise auf eine frühe RA liefern. Allerdings können auch einige Gesunde typische Veränderungen zeigen. Die MRT wird heute noch nicht flächendeckend eingesetzt.

Skelettszintigraphie Die Szintigraphie ist ein bildgebendes Verfahren unter Verwendung von radioaktiven Substanzen, die sich innerhalb einer kurzen Zeitspanne (Halbwertszeit) wieder im Körper abbauen und ausgeschieden werden. Dem Patienten wird ein radioaktives Arzneimittel (Tracer) intravenös gespritzt, um anschließend die Verteilung und Anreicherung des Tracers im Gewebe und im Knochen darzustellen. Die Szintigraphie spielt heute für die frühe Diagnose der RA keine wichtige Rolle, da sie sehr frühe Veränderungen häufig nicht gut erkennen und nicht immer zwischen einer entzündlichen und degenerativen Gelenkerkrankung unterscheiden kann.

\subsection{Prinzipien der Therapie}

Wie in Abschn. 8.2.4 und 8.2.5 beschrieben, ist das Ziel der Therapie die Remission. Um dieses Ziel zu erreichen, ist in erster Linie der frühzeitige Beginn einer medikamentösen Therapie sehr wichtig. Darüber hinaus sind aber auch nicht-medikamentöse Therapien wie zum Beispiel Physiotherapie, Ergotherapie und Sport, aber auch psychologische Unterstützung und Patientenschulungen wichtige Bausteine in der gesamten Therapie.

\subsubsection{Medikamentöse Therapie}

Basistherapie Bei der Basistherapie kommen langfristig wirkende Antirheumatika zum Einsatz. Das heißt, die Wirkung dieser Medikamente tritt erst nach einigen Wochen bis Monaten ein. Sie werden mit „DMARD“ abgekürzt. DMARD steht hierbei für „diseasemodifying-anti-rheumatic drug“, krankheitsmodifizierende Medikamente. Sie haben häufig keine direkte Wirkung auf die Symptome einer RA. Sie verändern den Verlauf der Erkrankung, indem sie an den Entzündungsprozessen im Immunsystem ansetzen, den Entzündungsprozess verlangsamen und im besten
Fall zum Stillstand bringen, worauf in der Folge die Symptome zurückgehen. Je früher Sie ein Basistherapeutikum erhalten, umso besser kann es wirken. Bei den DMARDs werden csDMARDs, bDMARDs und tsDMARDs unterschieden.

a) csDMARDs sind sogenannte konventionelle synthetische (steht in diesem Zusammenhang für künstlich hergestellt) DMARDs (auch klassische DMARDs genannt). $\mathrm{Zu}$ ihnen zählen Methotrexat (MTX), Leflunomid, Sulfasalazin, Chloroquin, Hydroxychloroquin Ciclosporin und Azathioprin,

MTX stellt das Mittel der ersten Wahl dar. Es greift in den FolsäureStoffwechsel ein und sorgt darüber dafür, dass es das gegen sich selbst arbeitende Immunsystem in seiner Fähigkeit dämpft.

b) bDMARDs sind sogenannte biologische (steht in diesem Zusammenhang für biotechnologisch hergestellt) DMARDs wie Abatacept, Adalimumab, Anakinra, Certolizumab, Etanercept, Golimumab, Infliximab, Tocilizumab, Sarilumab, Rituximab. Sie richten sich gegen bestimmte Botenstoffe der Entzündung im Körper (z.B.: Tumornekrosefaktor alpha, Interleukin-1 und -6) und unterdrücken so die Entzündungsreaktion.

c) tsDMARDs sind sogenannte zielgerichtete synthetische DMARDs wie Baricitinib oder Tofaticinib. Sie heißen auch Januskinase-Inhibitoren und richten sich zielgenau gegen die Produktion der entzündlichen Botenstoffe in den Zellen selbst.

Glukokortikoide („Cortison“) Glukokortikoide gehören zu den Hormonen, die in der Nebennierenrinde des Menschen gebildet werden. Cortisol ist eines davon. Es wird vorwiegend in den frühen Morgenstunden produziert und ist für den menschlichen Stoffwechsel lebensnotwendig. Als Medikament „Cortison“ wirkt es rasch entzündungshemmend und unterdrückt Reaktionen des Immunsystems. Es gibt viele Menschen, die Cortison ablehnend gegenüberstehen. Jedoch ist es einer der besten entzün- dungshemmenden Wirkstoffe, die zur Behandlung zur Verfügung stehen.

Cortisontabletten werden meist in den frühen Morgenstunden eingenommen, um die körpereigene Hormonproduktion möglichst wenig zu beeinträchtigen. Da die Wirkung der Basistherapeutika (s. oben) gelegentlich erst mehrere Wochen oder Monate nach der ersten Gabe eintreten kann, ist zu Beginn der Erkrankung der Einsatz von Cortison häufig sinnvoll, um die Entzündung in den Gelenken bereits früh $\mathrm{zu}$ hemmen. Cortison lindert rasch die Symptome. Wenn das Basistherapeutikum wirkt, sollte die Cortisongabe in Absprache mit dem Arzt langsam reduziert und ganz ausgeschlichen werden.

Cortison kann auch direkt in ein stark betroffenes Gelenk gespritzt werden, um dort eine schnelle Linderung der Beschwerden zu erzielen.

Cortison sollte nicht als Dauertherapie dienen und zeitnah (max. 3-6 Monate) nach Beginn der Therapie wieder beendet werden. Bei dauerhaft hohem Cortisonbedarf sollte eine Umstellung oder Anpassung der Basistherapie diskutiert werden.

Schmerzmittel Schmerzmittel sind insbesondere in akuten Schüben unter Umständen unumgänglich und zudem sinnvoll, da sie zum Teil auch entzündungshemmend wirken. Sie lassen sich grob in nicht-steroidale Antirheumatika (NSAR), Nichtopioide und in Opioide unterteilen.

NSAR $=$ Nicht-steroidale $\quad(=$ ohne Cortison) Antirheumatika wirken entzündungshemmend und schmerzstillend. Sie haben keinen Einfluss auf den Verlauf der Entzündung, sondern wirken rein symptomatisch. Dennoch gibt es Belege, dass durch ihren Einsatz die Gelenksteifigkeit ab- und die Beweglichkeit zunehmen.

Unter dem Einsatz von NSAR kann es zu unerwünschten Wirkungen besonders an Magen-Darm, Nieren und Herz kommen. Daher ist es wichtig, bei dem Einsatz dieser Medikamente ihre Vorerkrankungen und andere Medikamente zu berücksichtigen. Es ist sinnvoll bei der RA eine möglichst niedrige und noch wirksame Dosis der NSAR einzunehmen. Zu den 
NSAR gehören z. B. Diclofenac, Ibuprofen, Naproxen und Indometacin. Wenn Ihre DMARD Behandlung gut anspricht - und Sie dann keine Schmerzen oder Morgensteifigkeit mehr haben -, können Sie die NSAR auch vollständig absetzen.

$\mathrm{Zu}$ den Nichtopioiden zählt zum Beispiel Paracetamol. Es ist in der Wirksamkeit bei der RA den NSAR unterlegen, kommt jedoch dann zum Einsatz, wenn NSAR nicht vertragen werden oder Kontraindikationen gegen NSAR bestehen. Auch hier liegt eine rein symptomatische Wirkung vor.

Opioide sind ebenfalls rein symptomatisch wirksam. Sie sollten erst zum Einsatz kommen, wenn alle anderen Schmerzmittel ohne Erfolg eingesetzt oder nicht vertragen wurden. Die Auswahl der einzelnen Substanzen aus der Gruppe der Opioide sollte sich am Stufenschema der Weltgesundheitsorganisation (WHO) orientieren. Opioide spielen heute durch die zahlreichen und guten DMARD Therapien eine immer kleinere Rolle und werden nur noch in Ausnahmefällen eingesetzt.

Hinweis zum Einsatz der DMARD Therapien, ihrer Überwachung und $\mathrm{zu}$ unerwünschten Wirkungen finden Sie auf den Therapie-Überwachungsbögen der einzelnen Medikamente im Internet: https://dgrh.de/Start/Versorgung/ Therapieüberwachung/Therapieüberwa chungsbögen.html.

\subsubsection{Die Wahl des passenden Medikaments}

$\mathrm{Zu}$ Beginn einer RA weiß man als Patient und als Arzt oft nicht, wie der Verlaufüber die Jahre sein wird. Unabhängig davon ist eine frühe Behandlung mittels DMARD besonders wirksam. Man sollte sich also möglichst früh zu dieser entscheiden und nicht erst nach ein oder zwei Jahren, nachdem man seinen bisherigen Verlauf erlebt hat.

Die Wahl des für sie passenden Medikaments hängt dann von zahlreichen Faktoren ab: Ihrer individuellen Prognose, der vorliegenden Krankheitsaktivität, möglichen anderen Vorerkrankungen (z. B. von Infektionserkrankungen wie Tuberkulose), bekannten und unerwünschten Reaktionen ihrerseits auf bestimmte Medikamentengruppen (z. B. in
Form von Allergien) und ganz persönlichen Faktoren ihres Lebens (z. B. bestehender Kinderwunsch oder konkrete Familienplanung).

Sollte eine Anpassung der ersten Therapie von Nöten sein, werden DMARDs zumeist kombiniert, da sie sich in ihrer Wirksamkeit gegenseitig verstärken. Das erhöht die Wahrscheinlichkeit für das Erzielen einer Remission. Ganz konkret bedeutet dies, dass beim Einsatz eines tsDMARDs oder eines bDMARDs in der Regel mit einem csDMARDs (zumeist Methotrexat) kombiniert werden sollte.

Die systemische medikamentöse Therapie kann durch gezielte lokale Behandlung einzelner Gelenke erweitert werden.

\subsubsection{Nicht-Medikamentöse Therapie} Multidisziplinäre Behandlung und Rehabilitation Wichtig ist für die $\mathrm{Be}$ handlung der RA, dass möglichst alle Fachrichtungen, die für die Versorgung der Betroffenen hilfreich sein können, zusammen ihren Beitrag leisten. Diese multidisziplinäre Versorgung ist sowohl in der ambulanten als auch stationären Behandlung und Rehabilitation bedeutsam. Hieran beteiligt sind internistisch und orthopädisch tätige Rheumatologen, Hausärzte, Physiotherapeuten, Sporttherapeuten, Ergotherapeuten, Sozialarbeiter, Pflegekräfte, und Psychologen. Ziel ist es, die individuellen medizinischen, psychosozialen, arbeitsbezogenen, verhaltenstherapeutischen und ggf. krankheitsbezogenen finanziellen Probleme als Team aufzugreifen. Eine medizinische Rehabilitation ermöglicht die Weichenstellung für anschließende Leistungen zur Teilhabe am Arbeitsleben (berufliche Rehabilitation), die die Rückkehr ins Erwerbsleben nach einer möglicherweise längeren Krankheitsphase mit Arbeitsunfähigkeit unterstützen können.

Physiotherapie: Schmerzende und geschwollene Gelenke ruhig zu halten und damit zu schonen, führt eher zu negativen Folgen wie zunehmender Schwäche und funktionellen Einschränkungen durch Versteifung der Gelenke. Hier setzt die Bewegungstherapie an, die sowohl im Trockenen als auch im warmen Wasser durchgeführt werden kann. Gezielte
Bewegungsübungen sollen funktionelle Schäden und Beeinträchtigungen ausgleichen, dynamische Übungen und Ausdauertrainingsprogramme stärken Ihre Muskeln, Ihre Ausdauer sowie Ihre Belastbarkeit. Die Übungen sollen keine negativen Auswirkungen auf Schmerz, Krankheitsaktivität oder Gelenkveränderungen haben.

Sport: Bei früher RA und fehlender funktioneller Einschränkung können prinzipiell alle Sportarten durchgeführt werden. Letztlich ist Sport sicher und gefährdet ihre Gelenke nicht. Im Gegenteil vermehren sich zunehmend die Hinweise, dass sportliche Aktivität die Erkrankung positiv beeinflusst und unterstützt. Sport sollte Spaß machen.

Balneotherapie: Die Balneotherapie gehört zu den ältesten Therapieformen der RA. In der wissenschaftlichen Literatur gibt es allerdings nur wenig Hinweise für eine Wirksamkeit. Spezielle Anwendungen können nicht empfohlen werden, auch wenn es im Einzelfall sicher positive Effekte gibt.

Thermotherapie: Erfahrungsgemäß nützt die lokale Kälteanwendung zur Linderung der Beschwerden bei einer akuten Entzündung in einzelnen Gelenken. Eine Überlegenheit der GanzkörperKältetherapie (sog. Kältekammern) gegenüber lokalen Kälteanwendungen ist nicht gesichert.

Ergotherapie: Die Ergotherapie erhält die Beweglichkeit der Gelenke und die Muskelkraft der Hände. Sie lernen und üben, Ihre Gelenke im häuslichen, aber auch beruflichen Alltag schonend einzusetzen. Sie bekommen eine Vorstellung von Hilfsmitteln, die Ihnen Alltagsaktivitäten erleichtern, und Schmerzen vermindern können, wie z.B. Öffner für Flaschen, Marmeladengläser, Stiftverdickungen und Griffe für Kämme, Zahnbürsten und Messer sowie Scheren mit automatischem Öffnungsmechanismus.

Orthopädische Schuhversorgung: Bei einer RA können nach Bedarf Einlagen, orthopädische Schuhzurichtungen (z.B. Abrollhilfen für den Mittelfuß, den Fußballen und die Zehen) sowie in Einzelfällen auch orthopädische Schuhe verordnet und vom Orthopädie-Schuhmacher angefertigt werden. 
Psychologische Unterstützung Psychologische Unterstützung kann der Verminderung von Schmerz, Stress, Behinderung im Alltag und Krankheitsaktivität dienen und die Selbstwirksamkeit erhöhen. Wesentliche Formen sind Entspannungstechniken sowie Schmerz-, Krankheits- und Stressbewältigungsprogramme außerhalb und innerhalb der Patientenschulung sowie Psychotherapie.

Ergänzende Verfahren Ergänzende (sog. alternative) Verfahren werden zusätzlich zur notwendigen medikamentösen Behandlung bei RA eingesetzt. Ihre Wirkung ist wissenschaftlich nicht bewiesen. Es ist dringend davon abzuraten, ausschließlich ergänzende Verfahren bei RA anzuwenden, da diese die von der RA verursachten Gelenkschäden nicht aufhalten.

Das gilt für alle ergänzende Verfahren wie Akupunktur (chinesische Heilkunst), Ayurveda (indische Heilkunst), Diät, Homöopathie, Phytotherapie (Heilpflanzen), Radon-Therapie (schwach radioaktives Edelgas), TaiChi (chinesische Bewegungstherapie), TENS (Transkutane elektrische Nervenstimulation = Elektrotherapie), Nahrungser gänzungen. Sprechen Sie in jedem Fall ergänzende Therapien mit Ihrem Rheumatologen ab.

\section{Patienteninformation/Patientenschu-} lung/Partizipative Entscheidungsfindung: Was kann ich selber tun? Informieren Sie sich über Ihre Erkrankung und machen Sie sich über seriöse Quellen schlau (s. Abschn. Weitere Unterstützung und Informationen). Patientenschulungen helfen Ihnen dabei, geben Ihnen die nötigen Informationen über Ihre Erkrankung und tragen zudem zur Schmerz-, Krankheits- und Stressbewältigung bei. Diese Schulungen sind ein wesentlicher Bestandteil Ihrer multidisziplinären Versorgung und wurden von der Deutschen Gesellschaft für Rheumatologie in Zusammenarbeit mit der Deutschen Rheuma-Liga entwickelt.

Sie sind in Ihrem Behandlungsprozess ein gleichberechtigter Partner Ihres Arztes (das sog. Prinzip der Partizipativen Entscheidungsfindung). Je besser Sie über Ihre Erkrankung und die
Zusammenhänge zwischen Symptomen, Verlauf und Behandlungsmöglichkeiten aber auch -notwendigkeiten informiert sind, umso besser können sie aktiv und gleichberechtigt mit ihrem Arzt über die Behandlung entscheiden.

Um die vielfältigen seelischen und körperlichen Begleiterscheinungen einer RA besser zu bewältigen, kann es Sie in Ihrer Krankheitsbewältigung unterstützen, sich einer Selbsthilfegruppe anzuschließen oder sich von erfahrenen anderen Betroffenen Rat zu holen. Hierbei hilft die Deutsche Rheuma-Liga. Dies kann dazu beitragen, negative seelische Folgen der Erkrankung zu vermindern. Ein neues Selbstbewusstsein im Umgang mit Ihrer Erkrankung trägt zum Erhalt Ihres seelischen Wohlbefindens und der Freude am Leben bei.

Umfassende Informationen und Hilfe zur Selbsthilfe erhalten Sie z. B. über die Deutsche Rheuma-Liga (www.rheumaliga.de).

\section{Weitere Unterstützung und Informatio- nen}

- www.dgrh.de

- www.rheuma-wegweiser.de

- www.rheuma-liga.de

- www.rheumanet.org

- www.patienten-information.de/

- www.gesundheitsinformation.de/

\subsection{Dokumentation der Krankheitsaktivität}

Von Beginn der Erkrankung an sollte möglichst alle drei Monate Ihre Krankheitsaktivität und der Verlauf Ihrer Erkrankung dokumentiert werden. Hier$\mathrm{zu}$ werden verschiedene Scoringsysteme (z. B. Disease Activity Score von $28 \mathrm{Ge}$ lenken (DAS28), Clinical Disease Activity Index (CDAI) oder Simplified Disease Activity Index (SDAI)) eingesetzt. Diese Werte, die sich aus der Zahl der schmerzhaften und geschwollenen Gelenke, Ihrem Befinden und ggf. durch Entzündungswerte errechnen lassen, dienen dazu, Ihr Ansprechen auf die Therapie zu beurteilen. So wird auch eine Remission festgestellt.

\subsection{Rheumatologischer Akutfall}

Haben Sie starke Beschwerden, geschwollene Gelenke und einen hohen Leidensdruck? Es handelt sich nicht um einen Notfall im klassischen Sinne, der lebensbedrohlich ist, zögern Sie jedoch nicht, Ihren Rheumatologen aufzusuchen, er wird die Medikation an die Krankheitsaktivität anpassen. Auch Fieber kann vor allem unter einer Cortison Therapie und unter DMARD Behandlung ein Warnsignal sein.

\subsection{Anregungen für Ihren Besuch beim Rheumatologen}

\section{Vor dem Termin}

- Vergegenwärtigen Sie sich genau Ihre Beschwerden und nehmen Sie alle medizinischen Unterlagen mit.

- Es kann hilfreich sein, den Arztbesuch schriftlich vorzubereiten.

- Schreiben Sie sich Fragen auf und ordnen Sie sie nach Ihrer persönlichen Wichtigkeit.

Während des Termins Lassen Sie sich Ihre Diagnose, die anstehenden Untersuchungen und die Therapie erklären und fragen Sie nach, wenn Sie etwas nicht verstanden haben. Es gibt keine dummen Fragen!

Die folgenden Fragen können für Sie wichtig sein:

- Welches Ergebnis ist durch die Behandlung zu erwarten?

- Welche Nebenwirkungen und Komplikationen können auftreten?

- Wie lange wird die Behandlung voraussichtlich dauern?

- Darf ich während der Behandlung meinen normalen Lebensgewohnheiten nachgehen?

- Vertragen sich die Medikamente mit meinen bereits einzunehmenden Medikamenten?

Sie entscheiden gemeinsam mit dem Arzt über die notwendige Therapie. Falls Sie unsicher sind, fragen Sie nach oder nehmen Sie sich ein paar Tage Bedenkzeit. Manchmalkann auch eine Zweitmeinung weiterhelfen. 


\section{Leitlinien}

Tab. 7 ACR/EULAR Klassifikationskriterien für die rheumatoide Arthritis von 2010

\begin{tabular}{|c|c|c|c|c|}
\hline Geschwollen/schmerzhaft & Serologie & Akute Phase Parameter & Symptomdauer & Punkte \\
\hline$\square \leq 1$ (mittel)großes Gelenk & $\square$ RF \& ACPA negativ & $\square$ CRP \& BSG normal & $\square<6$ Wochen & 0 \\
\hline$\square$ 2-10 (mittel)große Gelenke & - & $\square$ CRP o. BSG erhöht & $\square \geq 6$ Wochen & 1 \\
\hline$\square$ 1-3 kleine Gelenke & $\square$ RF oder ACPA niedrig positiv & - & - & 2 \\
\hline$\square$ 4-10 kleine Gelenke & $\square$ RF oder ACPA hoch positiv & - & - & 3 \\
\hline$\square>10$ Gelenke; $\geq 1$ kleines & - & - & - & 5 \\
\hline
\end{tabular}

\section{Ergänzende Erläuterungen:}

Definition kleine Gelenke: Fingergrund- (MCP) und Fingermittelgelenke (PIP) 1-5; Zehengrundgelenke (MTP) 2-5, Großzehenmittelgelenke (IP 1) und Handgelenke. Ausgeschlossen von der Bewertung sind: Daumensattelgelenke (CMC 1), Großzehengrundgelenke (MTP 1), Finger- und Zehenendgelenke (DIP).

Definition mittlerer und großer Gelenke: Schulter-, Ellenbogen-, Hüft-, Knie-, Sprunggelenke

Für die Bewertung eines Gelenkes als betroffenes Gelenk, muss nicht die Eingangsdefinition einer definitiven Synovitis erfüllt sein. Es wird jedes geschwollene oder druckschmerzhafte Gelenk der obigen Liste gewertet.

Serologie: Rheumafaktor oder ACPA werden als hoch-positiv gewertet, wenn deren Wert über dem 3-fachen des oberen Normwertes liegt. Das Kriterium einer akut-Phase-Reaktion ist erfüllt, wenn CRP oder BSG erhöht sind. Bei der BSG sind physiologisch erhöhte Werte (Alter, Geschlecht, Schwangerschaft) zu berücksichtigen und im Zweifelsfalle nicht zu werten.

Definition Symptomdauer: Bezieht sich auf das Gelenk, welches zum Zeitpunkt der Untersuchung nach Angabe des Patienten am längsten betroffen ist.

Tab. 8 Health Assessment Questionnaire (HAQ): Fragebogen zum Gesundheitszustand

\begin{tabular}{|c|c|c|c|c|c|}
\hline & $\begin{array}{l}\text { Ohne jede } \\
\text { Schwierigkeit } \\
\text { (O Punkte) }\end{array}$ & $\begin{array}{l}\text { Mit einigen } \\
\text { Schwierigkeiten } \\
\text { (1 Punkt) }\end{array}$ & $\begin{array}{l}\text { Mit großen } \\
\text { Schwierigkeiten } \\
\text { (2 Punkte) }\end{array}$ & $\begin{array}{l}\text { Nicht dazu in der } \\
\text { Lage } \\
\text { (3 Punkte) }\end{array}$ & $\begin{array}{l}\text { Summe } \\
\text { (Pkte.) }\end{array}$ \\
\hline \multicolumn{6}{|l|}{ 1. Ankleiden und Körperpflege } \\
\hline $\begin{array}{l}\text { Können Sie sich ankleiden, inkl. Binden von } \\
\text { Schnürsenkeln und Schließen von Knöpfen? }\end{array}$ & $\square$ & $\square$ & $\square$ & $\square$ & - \\
\hline Können Sie Sich die Haare waschen? & $\square$ & $\square$ & $\square$ & $\square$ & - \\
\hline \multicolumn{6}{|l|}{ 2. Aufstehen } \\
\hline $\begin{array}{l}\text { Können Sie von einem Stuhl ohne Armlehnen } \\
\text { aufstehen? }\end{array}$ & $\square$ & $\square$ & $\square$ & $\square$ & - \\
\hline $\begin{array}{l}\text { Können Sie sich ins Bett legen und wieder } \\
\text { aufstehen? }\end{array}$ & $\square$ & $\square$ & $\square$ & $\square$ & - \\
\hline \multicolumn{6}{|l|}{ 3. Essen und Trinken } \\
\hline Können Sie Fleisch schneiden? & $\square$ & $\square$ & $\square$ & $\square$ & - \\
\hline $\begin{array}{l}\text { Können Sie eine volle Tasse oder ein volles Glas } \\
\text { zum Mund führen? }\end{array}$ & $\square$ & $\square$ & $\square$ & $\square$ & - \\
\hline $\begin{array}{l}\text { Können Sie einen neuen Milchkarton (Tetra- } \\
\text { Pak) öffnen? }\end{array}$ & $\square$ & $\square$ & $\square$ & $\square$ & - \\
\hline \multicolumn{6}{|l|}{ 4. Gehen } \\
\hline $\begin{array}{l}\text { Können Sie im Freien auf ebenem Gelände } \\
\text { gehen? }\end{array}$ & $\square$ & $\square$ & $\square$ & $\square$ & - \\
\hline Können Sie fünf Treppenstufen hochgehen? & $\square$ & $\square$ & $\square$ & $\square$ & - \\
\hline \multicolumn{6}{|l|}{-} \\
\hline \multicolumn{6}{|c|}{ Bitte kreuzen Sie alle Hilfsmittel an, die Sie gewöhnlich für die oben genannten Tätigkeiten benutzt haben: } \\
\hline \multicolumn{3}{|c|}{$\square$ Hilfsmittel zum Anziehen (Knopfhaken, Reißverschlusshilfe, verlängerter Schuhlöffel) } & \multicolumn{3}{|l|}{$\square$ Gehwagen } \\
\hline \multicolumn{3}{|l|}{$\square$ Spezialstuhl oder erhöhter Stuhl } & \multicolumn{3}{|l|}{$\square$ Krücken } \\
\hline \multicolumn{3}{|l|}{$\square$ Besondere Hilfsmittel beim Essen und Trinken } & \multicolumn{3}{|l|}{$\square$ Rollstuhl } \\
\hline \multicolumn{3}{|l|}{$\square$ Stock } & \multicolumn{3}{|l|}{$\square$ Andere } \\
\hline \multicolumn{6}{|c|}{ Bitte kreuzen Sie alle Tätigkeiten an, bei denen Sie für gewöhnlich Hilfe einer anderen Person benötigen. } \\
\hline$\square$ Anziehen und Körperpflege & $\square$ Aufstehen & & $\square$ Essen & $\square$ Gehen & \\
\hline
\end{tabular}




\begin{tabular}{|c|c|c|c|c|}
\hline $\begin{array}{l}\text { Ohne jede } \\
\text { Schwierigkeit } \\
\text { (O Punkte) }\end{array}$ & $\begin{array}{l}\text { Mit einigen } \\
\text { Schwierigkeiten } \\
\text { (1 Punkt) }\end{array}$ & $\begin{array}{l}\text { Mit großen } \\
\text { Schwierigkeiten } \\
\text { (2 Punkte) }\end{array}$ & $\begin{array}{l}\text { Nicht dazu in der } \\
\text { Lage } \\
\text { (3 Punkte) }\end{array}$ & $\begin{array}{l}\text { Summe } \\
\text { (Pkte.) }\end{array}$ \\
\hline
\end{tabular}

\section{Hygiene}

Können Sie sich ganz waschen und abtrocknen?

Können Sie in der Badewanne baden?

Können Sie sich auf die Toilette setzen und wieder aufstehen?

\section{Erreichen von Gegenständen}

Können Sie einen ca. 2 kg schweren Gegenstand ( $z$. B. eine große Tüte Zucker) von einer Stelle über Kopfhöhe herunterheben?

Können Sie sich bücken, um ein Kleidungsstück vom Fußboden aufzuheben?

7. Greifen und Öffnen

Können Sie Autotüren öffnen?

Können Sie Konservengläser öffnen, die schon einmal offen waren?

Können Sie Wasserhähne auf- und zudrehen?

\section{Andere Tätigkeiten}

Können Besorgungen machen und einkaufen?

Können Sie in ein Auto ein- und aussteigen?

Können Sie Haus- oder Gartenarbeiten verrichten (z. B. Staubsaugen, Unkraut jäten)?

$-$

Bitte kreuzen Sie alle Hilfsmittel an, die Sie gewöhnlich für die oben genannten Tätigkeiten benutzt haben:

$\square$ Erhöhter Toilettensitz

$\square$ Badewannensitz $\square$ Badewannenhandgriff

$\square$ Greifhilfen mit langem Handgriff

Bitte kreuzen Sie alle Tätigkeiten an, bei denen Sie für gewöhnlich Hilfe einer anderen Person benötigen.

\begin{tabular}{l|ll|l}
$\square$ Hygiene & $\square$ Erreichen von Gegenständen & $\square$ Greifen und & $\square$ Besorgungen und Hausarbei- \\
Öffnen & ten
\end{tabular}

Scoring: Addition der Werte aller 8 Bereiche und anschließende Division durch 8 ergibt einen Wert zwischen 0 und 3. Keine Beeinträchtigung $=0$, stärkste Beeinträchtigung $=3$.

\section{Nach dem Termin}

- Machen Sie sich nach Ihrem Arztbesuch Gedanken, was Sie an Informationen bekommen haben und ob Sie das alles gut verstanden haben. Wenn nicht, dann fragen Sie beim nächsten Arztbesuch unbedingt nach.

- Geben Sie dem Arzt auch eine Rückmeldung, wenn bei Ihnen die verordnete Therapie nicht anschlägt oder es zu Nebenwirkungen kommt. Äußern Sie auch mögliche Bedenken. Nur so kann Ihr Arzt die Therapie verändern und noch individueller anpassen.

- Seien Sie gegenüber Ihrem Arzt ehrlich. Sprechen Sie mit Ihrem Arzt darüber, wenn Sie eine alternative Heilmethode ausprobieren möchten.

\section{Anhang}

\subsection{ACR/EULAR Klassifikations- kriterien für die rheumatoide Arthritis von 2010}

Die Kriterien wurden entwickelt, um Patienten möglichst verlässlich in einem früheren Stadium der Arthritis als rheumatoide Arthritis klassifizieren zu können, um so eine frühe Therapie zu ermöglichen. Diese Klassifikationskriterien werden ausdrücklich auch zur Diagnosestellung einer (frühen) RA empfohlen [39].

Voraussetzung für die Anwendung der nachfolgend tabellarisch gelisteten Kriterien ist das Vorliegen mindestens einer sicheren Synovitis in mindestens einem
Prädilektions-Gelenk bei fehlenden Hinweisen für eine andere Ursache (Trauma, andere entzündliche oder degenerative Gelenkaffektion).

Wenn nach den Items in 0 Tab. 7 mindestens 6 Punkte (letzte Spalte) erfüllt sind, kann die Erkrankung als RA klassifiziert werden. In den Spalten gilt jeweils nur der höchste Punktwert (z. B. ergeben 4 kleine (3 Pkt.) und 2 mittlere Gelenke (1 Pkt.) 3 Punkte).

\subsection{Health Assessment Questionnaire (HAQ): Fragebogen zum Gesundheitszustand}

- Tab. 8 


\section{Tab. 9 Funktionsfragebogen Hannover (FFBH)}

\begin{tabular}{|c|c|c|c|c|}
\hline & & Ja & $\begin{array}{l}\text { Mit } \\
\text { Mühe }\end{array}$ & Nein \\
\hline 1 & Können Sie ein Brot streichen? & 1 & 2 & 3 \\
\hline 2 & Können Sie aus einem normal hohen Bett aufstehen? & 1 & 2 & 3 \\
\hline 3 & $\begin{array}{l}\text { Können Sie mit der Hand schreiben (mindestens eine Post- } \\
\text { karte)? }\end{array}$ & 1 & 2 & 3 \\
\hline 4 & Können Sie Wasserhähne auf- und zudrehen? & 1 & 2 & 3 \\
\hline 5 & $\begin{array}{l}\text { Können Sie sich strecken, um z. B. ein Buch von einem hohen } \\
\text { Regal oder Schrank zu holen? }\end{array}$ & 1 & 2 & 3 \\
\hline 6 & $\begin{array}{l}\text { Können Sie einen mindestens } 10 \mathrm{~kg} \text { schweren Gegenstand } \\
\text { (z. B. einen vollen Wassereimer oder Koffer) hochheben und } \\
10 \mathrm{~m} \text { weit tragen? }\end{array}$ & 1 & 2 & 3 \\
\hline 7 & Können Sie sich von Kopf bis Fuß waschen und abtrocknen? & 1 & 2 & 3 \\
\hline 8 & $\begin{array}{l}\text { Können Sie sich bücken und einen leichten Gegenstand } \\
\text { (z. B. ein Geldstück oder zerknülltes Papier) vom Fußboden } \\
\text { aufheben? }\end{array}$ & 1 & 2 & 3 \\
\hline 9 & $\begin{array}{l}\text { Können Sie sich über einem Waschbecken die Haare wa- } \\
\text { schen? }\end{array}$ & 1 & 2 & 3 \\
\hline 10 & Können Sie 1 Stunde auf einem ungepolsterten Stuhl sitzen? & 1 & 2 & 3 \\
\hline 11 & $\begin{array}{l}\text { Können Sie } 30 \text { Minuten ohne Unterbrechung stehen (z. B. in } \\
\text { einer Warteschlange)? }\end{array}$ & 1 & 2 & 3 \\
\hline 12 & Können Sie sich im Bett aus der Rückenlage aufsetzen? & 1 & 2 & 3 \\
\hline 13 & Können Sie Strümpfe an- und ausziehen? & 1 & 2 & 3 \\
\hline 14 & $\begin{array}{l}\text { Können Sie im Sitzen einen kleinen heruntergefallenen } \\
\text { Gegenstand (z. B. eine Münze) neben Ihrem Stuhl aufheben? }\end{array}$ & 1 & 2 & 3 \\
\hline 15 & $\begin{array}{l}\text { Können Sie einen schweren Gegenstand (z. B. einen gefüll- } \\
\text { ten Kasten Mineralwasser) vom Boden auf den Tisch stellen? }\end{array}$ & 1 & 2 & 3 \\
\hline 16 & Können Sie sich einen Wintermantel an- und ausziehen? & 1 & 2 & 3 \\
\hline 17 & $\begin{array}{l}\text { Können Sie ca. } 100 \text { Meter schnell laufen (nicht gehen), etwa } \\
\text { um einen Bus zu erreichen? }\end{array}$ & 1 & 2 & 3 \\
\hline \multirow[t]{2}{*}{18} & $\begin{array}{l}\text { Können Sie öffentliche Verkehrsmittel (Bus, Bahn usw.) be- } \\
\text { nutzen? }\end{array}$ & 1 & 2 & 3 \\
\hline & $\Sigma$ & & & \\
\hline
\end{tabular}

\subsection{Funktions-Fragebogen Hannover - FFBH}

In den folgenden Fragen (• Tab. 9) geht es um Tätigkeiten aus dem täglichen Leben. Bitte beantworten Sie jede Frage so, wie es für Sie im Moment (in Bezug auf die letzten 7 Tage) zutrifft und kreuzen Sie die entsprechende Zahl an. Sie haben drei Antwortmöglichkeiten:

1. Ja: Sie können die Tätigkeit ohne Schwierigkeiten ausführen;

2. Ja, aber mit Mühe: Sie haben dabei Schwierigkeiten, z. B. Schmerzen, es dauert länger als früher oder Sie müssen sich dabei abstützen;

3. Nein, oder nur mit fremder Hilfe: Sie können es gar nicht oder nur, wenn eine andere Person Ihnen dabei hilft.
DAS28: $>5,1$ : hohe Krankheitsaktivität, $<3,2$ : niedrige Krankheitsaktivität, $<2,6$ : Remission

\subsubsection{Simple Disease Activity Index (SDAI) [346]}

Summen Score aus druckschmerzhaften (TJC) und geschwollenen (SJC) Gelenken von 28 beurteilten (28-JC, siehe - Abb. 2), Einschätzung der Krankheitsaktivität durch den Arzt (VASarzt) und durch den Patienten selbst (VASpat) auf einer visuellen Analaogskala (VAS, $0-10 \mathrm{~cm}$ ) und des CRP in $\mathrm{mg} / \mathrm{dl}$ gemäß folgender Formel:

$$
\begin{aligned}
& \text { SDAI = TJC28 + SJC28 + VASpat }+ \\
& \text { VASarzt + CRP }[\mathrm{mg} / \mathrm{dl}]
\end{aligned}
$$

SDAI: >26: hohe Krankheitsaktivität, $>11 \leq 26$ : mittlere Krankheitsaktivität, 3,4-11,0: niedrige Krankheitsaktivität, $<3,3$ : Remission

\subsubsection{Clinical Disease Activity Index (CDAI) [347]}

Summen Score aus druckschmerzhaften (TJC) und geschwollenen (SJC) Gelenken von 28 beurteilten (28-JC, siehe - Abb. 2), Einschätzung der Krankheitsaktivität durch den Arzt (VASarzt) und durch den Patienten selbst (VASpat) auf einer visuellen Analaogskala (VAS, $0-10 \mathrm{~cm})$ gemäß folgender Formel:

\section{$\mathrm{CDAI}=\mathrm{TJC} 28+\mathrm{SJC} 28+$ VASpat +}

VASarzt

CDAI: >22: hohe Krankheitsaktivität, >10-22: mittlere Krankheitsaktivität, 2,9-10,0: niedrige Krankheitsaktivität, <2,8: Remission

Zur klinischen Aktivitätseinschätzung erfolgt bei der RA die Beurteilung folgender 28 Gelenke (28-JC, siehe - Abb. 2) hinsichtlich Schwellung und Druckschmerzhaftigkeit:

Schultern (2), Ellenbogen (2), Handgelenke (2), Fingergrundgelenke (MCP) (10), Fingermittelgelenke (PIP) (10), Kniegelenke (2). 


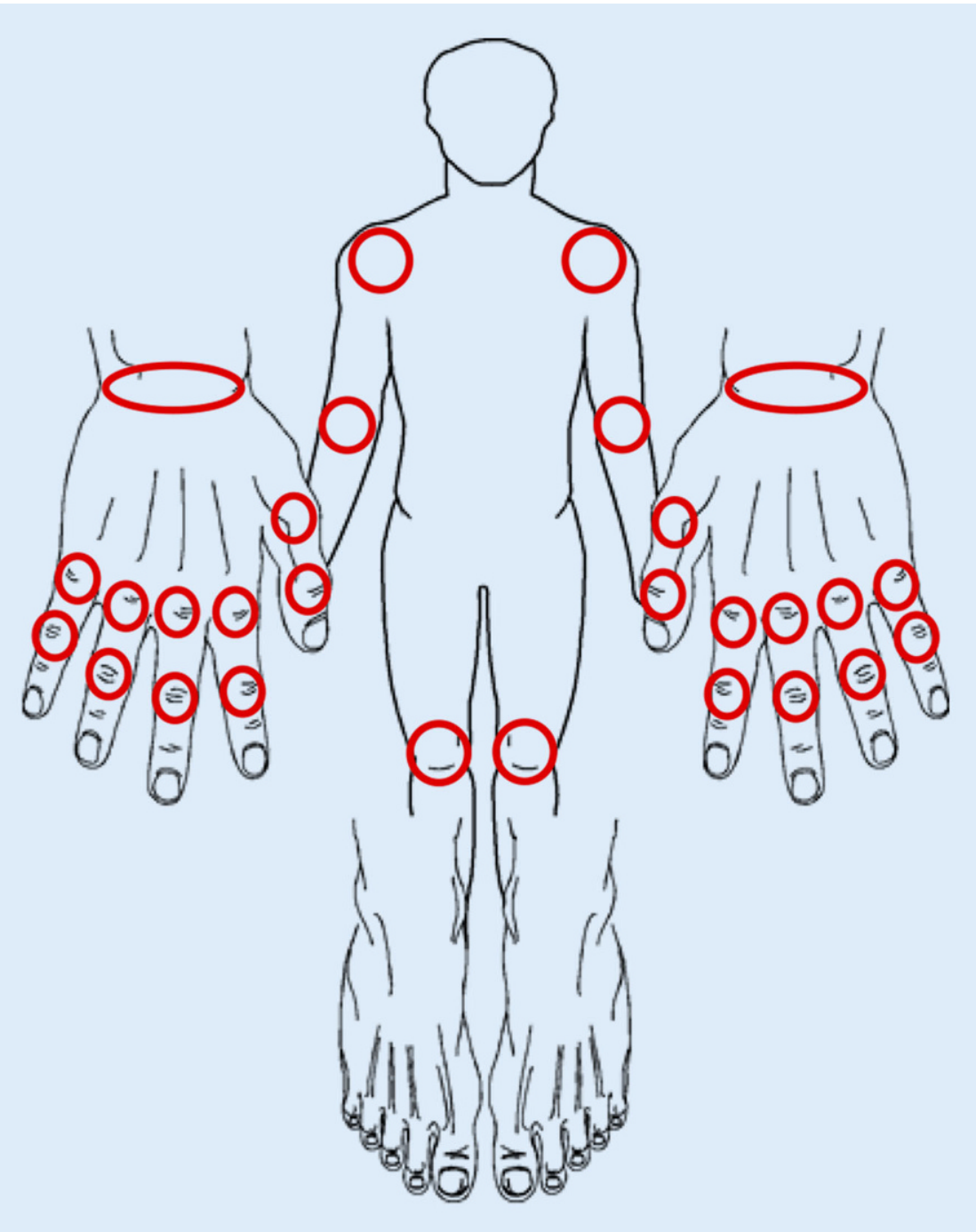

Abb. 2 \ Gelenke des 28-Joint-Counts (28-JC)

\subsection{ACR/EULAR Definitionen einer \\ Remission der rheumatoiden \\ Arthritis in klinischen Studien [126]}

\subsubsection{Boolesche Definition}

$\mathrm{Zu}$ jedem Zeitpunkt muss der Patient alle folgenden Punkte erfüllen:

- Anzahl der druckschmerzhaften

Gelenke $\leq 1 \dagger$

- Anzahl der geschwollenen $\leq 1 \dagger$

- C-reaktives Protein $\leq 1 \mathrm{mg} / \mathrm{dl}$

- Patientenselbsteinschätzung der

Krankheitsaktivität $\leq 1$ (auf einer

Skala von $0-10) \ddagger$

\subsubsection{Indexbasierte Definition}

Der Patient muss zu jedem Zeitpunkt einen Simplified Disease Activity Index Score (SDAI) von $\leq 3,3$ haben. $\$$

- $\dagger$ Bei druckschmerzhaften und geschwollenen Gelenken kann die Verwendung eines 28-Joint Count (s. Abb. 2) andere aktiv beteiligte Gelenke, insbesondere an Füßen und Sprunggelenken, übersehen, so dass es besser ist, Füße und Knöchel bei der Beurteilung der Remission mit einzubeziehen.

- $\ddagger$ Für die Beurteilung der Remission empfehlen wir folgende Darstellung und Wortlaut für das „Global assessment“: Eine horizontale $10 \mathrm{~cm}$ lange visuelle Analog- oder LikertSkala mit dem besten Urteill und niedrigsten Wert auf der linken Seite und dem schlechtesten Urteil und höchsten Wert auf der rechten Seite. Wortlaut der Frage „Patient global assessment“: „In Anbetracht all der Aspekte, wie sich Ihre Arthritis auf Sie auswirkt: wie fühlt sich Ihre Arthritis heute an?" (Skala sehr gut bis sehr schlecht). Für die Gesamtbeurteilung durch den behandelnden Arzt/Assistenten: „Wie beurteilen Sie die aktuelle Krankheitsaktivität des Patienten?" (Skala nicht aktiv bis sehr aktiv).

- $\$$ siehe Abschn. 9.4.2

\subsection{Instrumente zur Evaluation der antirheumatischen Basistherapie}

\subsubsection{ACR-Response-Kriterien}

- Anzahl der empfindlichen/ schmerzhaften Gelenke

- Anzahl der geschwollenen Gelenke

Bei mindestens 3 der folgenden 5 Parameter muss es zu einer Besserung im Vergleich zum Ausgangswert gekommen sein:

- Gesamtbeurteilung der Krankheitsaktivität durch den Arzt (physician's global assessment)

- Gesamtbeurteilung der Krankheitsaktivität durch den Patienten (patient's global assessment)

- Patientenbeurteilung des Schmerzes (visuelle Analogskala)

- Funktionsbehinderungsindex (Health Assessment Questionnaire HAQ)

- akute Phase Parameter (CRP/BSG)

ACR 20, ACR 50, ACR 70 entsprechen jeweils einer $20 \%$-, $50 \%$ - oder $70 \%$-Besserung der oben genannten Kriterien.

\subsubsection{EULAR-Response-Kriterien}

Den EULAR-Kriterien liegt die Interpretation der Veränderungen der Werte des DAS28 (Disease Activity Score) zu Grunde, der Folgendes beinhaltet:

- Anzahl schmerzhafter Gelenke

- Anzahl geschwollener Gelenke

- BSG

- Gesamtbeurteilung der Krankheitsaktivität durch den Patienten 
Tab. 10 Interpretation der Veränderung der DAS28-Werte

\begin{tabular}{l|l|l|l}
$\begin{array}{l}\text { DAS28 Verbesserung } \rightarrow \\
\text { Aktueller DAS28 }\end{array}$ & $>\mathbf{1 , 2}$ & $\mathbf{0 , 6}$ and $\leq \mathbf{1 , 2}$ & $\mathbf{5 0 , 6}$ \\
\hline$\leq 3,2$ & Good response & Moderate response & No response \\
\hline$>3,2$ and $\leq 5,1$ & Moderate response & Moderate response & No response \\
$>5,1$ & Moderate response & No response & No response
\end{tabular}

DAS28-Werte $>2,8$ reflektieren üblicherweise eine Krankheitsaktivität, welche die Aufnahme in klinische Studien zur Beurteilung der Wirksamkeit der Basistherapeutika zulässt.

Interpretation der Veränderung der DAS28-Werte (• Tab. 10).

\subsubsection{Radiologische Progression}

Zwei Score Systeme werden im Wesentlichen verwendet: Sharp Method und Larsen Methode [134].

\subsection{Therapieüberwachungsbögen Arzt und Patient (Links)}

https://www.dgrh.de/Start/Versorgung/ Therapieüberwachung/Therapie überwachungsbögen.html

\section{Korrespondenzadresse}

\section{Prof. Dr. M. Schneider}

Poliklinik, Funktionsbereich und Hiller Forschungszentrum für Rheumatologie, Universitätsklinikum Düsseldorf, HeinrichHeine Universität Düsseldorf Moorenstr. 5, 40225 Düsseldorf, Deutschland info@dgrh.de schneiderm@med.uni-duesseldorf.de

\section{Einhaltung ethischer Richtlinien}

Interessenkonflikt. Angaben zum Interessenkonflikt aller Leitlinienautoren finden Sie als ausführliche tabellarische Darstellung „Darlegung potenzieller Interessenkonflikte" im Zusatzmaterial online.

Für diesen Beitrag wurden von den Autoren keine Studien an Menschen oder Tieren durchgeführt. Für die aufgeführten Studien gelten die jeweils dort angegebenen ethischen Richtlinien.

\section{Literatur}

1. Zink A, Albrecht K (2016) Wie häufig sind muskuloskeletale Erkrankungen in Deutschland? ZRheumatol 75:346-353

2. Hense $S$, Luque Ramos A, Callhoff J, Albrecht $K$ Zink A, Hoffmann F (2016) Prävalenz der rheu- matoiden arthritis in deutschland auf basis von Kassendaten.ZRheumatol 75:819-827

3. Carmona L, Cross M, Williams B, Lassere M, March L (2010) Rheumatoid arthritis. Baillieres Best Pract Res Clin Rheumatol 24:733-745

4. Chang K, Yang SM, Kim SH, Han KH, Park SJ, Shin JI (2014) Smoking and rheumatoid arthritis. IJMS 15:22279-22295

5. Crowson CS, Matteson EL, Davis JM, Gabriel SE (2013) Contribution of obesity to the rise in incidence of rheumatoid arthritis. Arthritis Care Res 65:71-77

6. Hedström AK, Stawiarz L, Klareskog L, Alfredsson L (2018) Smoking and susceptibility to rheumatoid arthritis in a swedish population-based case-control study. Eur JEpidemiol 33:415-423

7. Myasoedova E, Crowson CS, Kremers HM, Therneau TM, Gabriel SE (2010) Is the incidence of rheumatoid arthritis rising?: Results from olmsted county, minnesota, 1955-2007. Arthritis Rheum 62:1576-1582

8. Pedersen JK, Svendsen AJ, Hørslev-Petersen K (2007) Incidence of rheumatoid arthritis in the southern part of denmark from 1995 to 2001. TORJ 1:18-23

9. Combe B, Landewe R, Daien $\mathrm{Cl}$, Hua C, Aletaha D, Álvaro-Gracia JM et al (2017) 2016 update of the early arthritis. Ann Rheum Dis 76:948-959

10. Young A, Dixey J, Cox N, Davies P, Devlin J, Emery P et al (2000) How does functional disability in early rheumatoid arthritis ( $r a$ ) affect patients and their lives? Results of 5 years of follow-up in 732 patients from the early ra study (eras). Rheumatology 39:603-611

11. Verstappen SM (2013) Outcomes of early rheumatoid arthritis - the who icf framework. Baillieres Best Pract Res Clin Rheumatol 27:555-570

12. Nikiphorou E, Norton S, Carpenter L, Dixey J, Walsh AD, Kiely P et al (2017) Secular changes in clinical features at presentation of rheumatoid arthritis: Increase in comorbidity but improved inflammatory states. Arthritis Care Res 69:21-27

13. Listing J, Kekow J, Manger B, Burmester G-R, Pattloch D, Zink A et al (2015) Mortality in rheumatoid arthritis: theimpact of disease activity, treatment with glucocorticoids, tnfa inhibitors and rituximab. Ann Rheum Dis 74:415-421

14. Meune C, Touzé E, Trinquart L, Allanore Y (2009) Trends in cardiovascular mortality in patients with rheumatoid arthritis over 50 years: a systematic review and meta-analysis of cohort studies. Rheumatology 48:1309-1313

15. Radovits BJ, Fransen J, AI Shamma S, Eijsbouts AM, van Riel PL, Laan RF (2010) Excess mortality emerges after 10 years in an inception cohort of early rheumatoid arthritis. Arthritis Care Res 62:362-370

16. Lindqvist $E$, Saxne T, Geborek P, Eberhardt K (2002) Ten year outcome in a cohort of patients with early rheumatoid arthritis: health status, disease process, and damage. Ann Rheum Dis 61:1055-1059 eular recommendations for the management of
17. van Zeben $D$, Hazes JM, Zwinderman $A H$ Vandenbroucke JP, Breedveld FC (1994) The severity of rheumatoid arthritis: a 6-year followup study of younger women with symptoms of recent onset. JRheumatol 21:1620-1625

18. Wiles NJ, Lunt M, Barrett EM, Bukhari M, Silman AJ, Symmons DP et al (2001) Reduced disability at five years with early treatment of inflammatory polyarthritis: Results from a large observational cohort, using propensity models to adjust for disease severity. Arthritis Rheum 44:1033-1042

19. Bukhari Ma S, Wiles NJ, Lunt M, Harrison BJ, Scott DGI, Symmons DPM et al (2003) Influence of disease-modifying therapy on radiographic outcome in inflammatory polyarthritis at five years: results from a large observational inception study. Arthritis Rheum 48:46-53

20. Boire $G$, Cossette $P$, de Brum-Fernandes $A J$, Liang P, Niyonsenga T, Zhou ZJ et al (2005) Anti-sa antibodies and antibodies against cyclic citrullinated peptide are not equivalent as predictors of severe outcomes in patients with recent-onset polyarthritis. Arthritis Res Ther 7:R592-R603

21. Gorman JD (2006) Smoking and rheumatoid arthritis: another reason to just say no. Arthritis Rheum 54:10-13

22. Nielen MMJ, van der Horst $A R$, van Schaardenburg D, van der Horst-Bruinsma IE, van de Stadt RJ, Aarden L et al (2005) Antibodies to citrullinated human fibrinogen (acf) have diagnostic and prognostic value in early arthritis. Ann Rheum Dis 64:1199-1204

23. Nyhäll-Wåhlin BM, Jacobsson LTH, Petersson IF, Turesson C, group Bs (2006) Smoking is a strong risk factor for rheumatoid nodules in early rheumatoid arthritis. Ann Rheum Dis 65:601-606

24. Nell VPK, Machold KP, Stamm TA, Eberl G, Heinzl H, Uffmann M et al (2005) Autoantibody profiling as early diagnostic and prognostic tool for rheumatoid arthritis. Ann Rheum Dis 64:1731-1736

25. Schellekens GA, Visser $H$, de Jong $B A$, van den Hoogen FH, Hazes JM, Breedveld FC et al (2000) The diagnostic properties of rheumatoid arthritis antibodies recognizing a cyclic citrullinated peptide. Arthritis Rheum 43:155-163

26. Scott IC, Tan R, Stahl D, Steer S, Lewis CM, Cope AP (2013) The protective effect of alcohol on developing rheumatoid arthritis: A systematic review and meta-analysis. Rheumatology 52:856-867

27. Symmons DPM (2002) Epidemiology of rheumatoid arthritis: determinants of onset, persistence and outcome. Best Pract Res Clin Rheumatol 16:707-722

28. van der Helm-van Mil AHM, le Cessie S, van Dongen $\mathrm{H}$, Breedveld FC, Toes REM, Huizinga TWJ (2007) A prediction rule for disease outcome in patients with recent-onset undifferentiated arthritis: how to guide individual treatment decisions. Arthritis Rheum 56:433-440

29. van der Helm-van Mil AHM, Detert J, le Cessie $S$, Filer A, Bastian H, Burmester GR et al (2008) Validation of a prediction rule for disease outcome in patients with recent-onset undifferentiated arthritis: moving toward individualized treatment decision-making. Arthritis Rheum 58:2241-2247

30. VisserH, le CessieS, VosK, BreedveldFC, Hazes JMW (2002) How to diagnose rheumatoid arthritis early: a prediction model for persistent (erosive) arthritis. Arthritis Rheum 46:357-365

31. Vittecoq $O$, Incaurgarat $B$, Jouen-Beades $F$, Legoedec J, Letourneur O, Rolland D et al (2004) Autoantibodies recognizing citrullinated 
rat filaggrin in an elisa using citrullinated and noncitrullinated recombinant proteins as antigens are highly diagnostic for rheumatoid arthritis. Clin Exp Immunol 135:173-180

32. WolfeF, ZwillichSH(1998)Thelong-term outcomes of rheumatoid arthritis: a 23-year prospective, longitudinal study of total joint replacement and its predictors in 1,600 patients with rheumatoid arthritis. Arthritis Rheum 41:1072-1082

33. van Nies JA, Tsonaka R, Gaujoux-Viala C, Fautrel B, van der Helm-van Mil AH (2015) Evaluating relationships between symptom duration and persistence of rheumatoid arthritis: Does a window of opportunity exist? Results on the leiden early arthritis clinic and espoir cohorts. Ann Rheum Dis 74:806-812

34. Emery P (1995) Therapeutic approaches for early rheumatoid arthritis. How early? How aggressive? Br JRheumatol 34(Suppl 2):87-90

35. Machold KP, Eberl G, Leeb BF, Nell V, Windisch B, Smolen JS (1998) Early arthritis therapy: rationale and current approach.JRheumatolSuppl53:13-19

36. Boers M (2003) Understanding the window of opportunity concept in early rheumatoid arthritis. Arthritis Rheum 48:1771-1774

37. O'Dell JR (2002) Treating rheumatoid arthritis early: a window of opportunity? Arthritis Rheum 46:283-285

38. Emery P, Breedveld FC, Dougados M, Kalden JR, Schiff MH, Smolen JS (2002) Early referral recommendationfornewlydiagnosed rheumatoid arthritis: evidence based development of a clinical guide. Ann Rheum Dis 61:290-297

39. Aletaha D, Neogi T, Silman AJ, Funovits J, Felson DT, Bingham CO 3rd et al (2010) 2010 rheumatoid arthritis classification criteria: An American College of Rheumatology/European League Against Rheumatism collaborative initiative. Ann Rheum Dis 69:1580-1588

40. Radner H, Neogi T, Smolen JS, Aletaha D (2014) Performance of the $2010 \mathrm{acr} / \mathrm{eular}$ classification criteria for rheumatoid arthritis: a systematic literature review. Ann Rheum Dis 73:114-123

41. Bukhari M, Lunt M, Harrison BJ, Scott DGl, Symmons DPM, Silman AJ (2002) Erosions in inflammatory polyarthritis are symmetrical regardless of rheumatoid factor status: Results from a primary care-based inception cohort of patients. Rheumatology 41:246-252

42. Knevel R, Lukas C, van der Heijde D, Rincheval N, Combe B, van der Helm-van Mil AH (2013) Defining erosive disease typical of $r a$ in the light of the acr/eular 2010 criteria for rheumatoid arthritis; results of the data driven phase. Ann Rheum Dis 72:590-595

43. Sokka T, Pincus T (2009) Erythrocyte sedimentation rate, c-reactive protein, or rheumatoid factor are normal at presentation in $35 \%-45 \%$ of patients with rheumatoid arthritis seen between 1980 and 2004: Analyses from finland and the united states. JRheumatol 36:1387-1390

44. Saraux A, Berthelot JM, Chalès $G$, Le Henaff $C$, Mary JY, Thorel JB et al (2002) Value of laboratory tests in early prediction of rheumatoid arthritis. Arthritis Rheum 47:155-165

45. Ioan-Facsinay $A$, el-Bannoudi $H$, Scherer $H U$, van der Woude D, Ménard HA, Lora M et al (2011) Anti-cyclic citrullinated peptide antibodies are a collection of anti-citrullinated protein antibodies and contain overlapping and non-overlapping reactivities. Ann Rheum Dis 70:188-193

46. Bang H, Egerer K, Gauliard A, Lüthke K, Rudolph PE, Fredenhagen $G$ et al (2007) Mutation and citrullination modifies vimentin to a novel autoantigen for rheumatoid arthritis. Arthritis Rheum 56:2503-2511

47. Damjanovska L, Thabet MM, Levarth EW, StoekenRijsbergen G, van der Voort El, Toes RE et al (2010) Diagnostic value of anti-mcv antibodies in differentiating early inflammatory arthritis. Ann Rheum Dis 69:730-732

48. Innala L, Kokkonen H, Eriksson C, Jidell E, Berglin E, Dahlqvst SR (2008) Antibodies against mutated citrullinated vimentin are a better predictor of disease activity at 24 months in early rheumatoid arthritis than antibodies against cyclic citrullinated peptides. JRheumatol 35:1002-1008

49. Lee YH, Bae SC, Song GG (2015) Diagnostic accuracy of anti-mcv and anti-ccp antibodies in rheumatoid arthritis: a meta-analysis.ZRheumatol 74:911-918

50. Luime JJ, Colin EM, Hazes JMW, Lubberts E (2010) Does anti-mutated citrullinated vimentin have additional value as a serological marker in the diagnosticand prognosticinvestigation of patients with rheumatoid arthritis? A systematic review. Ann Rheum Dis 69:337-344

51. Mathsson L, Mullazehi M, Wick MC, Sjöberg O, van Vollenhoven $R$, Klareskog $L$ et al (2008) Antibodies against citrullinated vimentin in rheumatoid arthritis: Higher sensitivity and extended prognostic value concerning future radiographic progression as compared with antibodies against cyclic citrullinated peptides. Arthritis Rheum 58:36-45

52. Syversen SW, Goll GL, van der Heijde D, Landewé $R$ Lie BA, Odegård $S$ et al (2010) Prediction of radiographic progression in rheumatoid arthritis and the role of antibodies against mutated citrullinated vimentin: Results from a 10-year prospective study. Ann Rheum Dis 69:345-351

53. van der Linden MPM, van der Woude D, loanFacsinay A, Levarht EWN, Stoeken-Rijsbergen G, Huizinga TWJ et al (2009) Value of anti-modified citrullinated vimentin and third-generation anticyclic citrullinated peptide compared with secondgeneration anti-cyclic citrullinated peptide and rheumatoid factor in predicting disease outcome in undifferentiated arthritis and rheumatoid arthritis. Arthritis Rheum 60:2232-2241

54. Nishimura K, Sugiyama D, Kogata Y, Tsuji G, Nakazawa T, Kawano S et al (2007) Meta-analysis: diagnostic accuracy of anti-cyclic citrullinated peptide antibody and rheumatoid factor for rheumatoid arthritis. Ann Intern Med 146:797-808

55. Whiting PF, Smidt N, Sterne JAC, Harbord R, Burton A, Burke M et al (2010) Systematic review: accuracy of anti-citrullinated peptide antibodies for diagnosing rheumatoid arthritis. Ann Intern Med 152:456-464; W155-66

56. Bas S, Perneger TV, Seitz M, Tiercy JM, RouxLombard P, Guerne PA (2002) Diagnostic tests for rheumatoid arthritis: comparison of anticyclic citrullinated peptide antibodies, antikeratin antibodies and igm rheumatoid factors. Rheumatology 41:809-814

57. Berglin E, Johansson T, Sundin U, Jidell E, Wadell G, Hallmans $G$ et al (2006) Radiological outcome in rheumatoid arthritis is predicted by presence of antibodies against cyclic citrullinated peptide before and at disease onset, and by iga-rfat disease onset. Ann Rheum Dis 65:453-458

58. Hensvold AH, FrisellT, Magnusson PKE, HolmdahIR, Askling J, Catrina Al (2017) How well do acpa discriminate and predict ra in the general population: a study based on 12590 populationrepresentative swedish twins. Ann Rheum Dis 76:119-125
59. Kastbom A, Forslind K, Ernestam S, Geborek P, Karlsson JA, Petersson IF et al (2016) Changes in the anticitrullinated peptide antibody response in relation to therapeutic outcome in early rheumatoid arthritis: results from the swefot trial. Ann Rheum Dis 75(2):356 (http://onlinelibrary. wiley.com/o/cochrane/clcentral/articles/369/CN01164369/frame.html)

60. Lindqvist E, Eberhardt K, Bendtzen K, Heinegård D, Saxne T (2005) Prognostic laboratory markers of joint damage in rheumatoid arthritis. Ann Rheum Dis 64:196-201

61. Rönnelid J, Wick MC, Lampa J, Lindblad S, Nordmark B, Klareskog L et al (2005) Longitudinal analysis of citrullinated protein/peptide antibodies (anti-cp) during 5 year follow up in early rheumatoid arthritis: Anti-cp status predicts worse disease activity and greater radiological progression. Ann Rheum Dis 64:1744-1749

62. van Boekel MAM, Vossenaar ER, van den Hoogen FHJ, van Venrooij WJ (2002) Autoantibody systems in rheumatoid arthritis: Specificity, sensitivity and diagnostic value. Arthritis Res 4:87-93

63. van Gaalen $F A$, Linn-Rasker SP, van Venrooij WJ, de Jong BA, Breedveld FC, Verweij $\mathrm{CL}$ et al (2004) Autoantibodies to cyclic citrullinated peptides predict progression to rheumatoid arthritis in patients with undifferentiated arthritis: A prospective cohort study. Arthritis Rheum 50:709-715

64. Nielen MMJ, van Schaardenburg D, Reesink HW, van de Stadt RJ, van der Horst-Bruinsma $I E$, de Koning MHMT et al (2004) Specific autoantibodies precede the symptoms of rheumatoid arthritis: A study of serial measurements in blood donors. Arthritis Rheum 50:380-386

65. Rantapää-Dahlqvist S, de Jong BAW, Berglin E, Hallmans G, Wadell G, Stenlund H et al (2003) Antibodies against cyclic citrullinated peptide and iga rheumatoid factor predict the development of rheumatoid arthritis. Arthritis Rheum 48:2741-2749

66. Mjaavatten MD, Uhlig T, Haugen AJ, Nygaard $\mathrm{H}_{4}$ Sidenvall G, Helgetveit $\mathrm{K}$ et al (2009) Positive anti-citrullinated protein antibody status and small joint arthritis are consistent predictors of chronic disease in patients with very early arthritis: Results from the nor-veac cohort. Arthritis Res Ther 11:R146

67. Syversen SW, Gaarder PI, Goll GL, Ødegård S, Haavardsholm EA, Mowinckel P et al (2008) High anti-cyclic citrullinated peptide levels and an algorithm of four variables predict radiographic progression in patients with rheumatoid arthritis: Results from a 10-year longitudinal study. Ann Rheum Dis 67:212-217

68. Kastbom A, Strandberg G, Lindroos A, Skogh T (2004) Anti-ccp antibody test predicts the disease course during 3 years in early rheumatoid arthritis (the swedish tira project). Ann Rheum Dis 63:1085-1089

69. Sanmartí R, Gómez-Centeno A, Ercilla G, Larrosa M, Viñas O, Vazquez I et al (2007) Prognostic factors of radiographic progression in early rheumatoid arthritis: A two year prospective study after a structured therapeutic strategy using dmards and very low doses of glucocorticoids. Clin Rheumatol 26:1111-1118

70. Machold KP, Stamm TA, Eberl GJM, Nell VKP, Dunky A, Uffmann M et al (2002) Very recent onset arthritis-clinical, laboratory, and radiological findings during the first year of disease. JRheumatol 29:2278-2287 
71. Hetland $\mathrm{ML}$, Ejbjerg $B$, Horslev-Petersen $\mathrm{K}$ Jacobsen S, Vestergaard A, Jurik AG et al (2009) Mri bone oedema is the strongest predictor of subsequent radiographic progression in early rheumatoid arthritis. Results from a 2-year randomised controlled trial (cimestra). Ann Rheum Dis 68:384-390

72. Joshua F, Lassere M, Bruyn GA, Szkudlarek M, Naredo E, Schmidt WA et al (2007) Summary findings of a systematic review of the ultrasound assessment of synovitis. JRheumatol 34:839-847

73. Østergaard M, Pedersen SJ, Døhn UM (2008) Imaging in rheumatoid arthritis-status and recent advances for magnetic resonance imaging ultrasonography, computed tomography and conventional radiography. Best Pract Res Clin Rheumatol 22:1019-1044

74. Joshua F, Edmonds J, Lassere M (2006) Power doppler ultrasound in musculoskeletal disease: a systematic review. Semin Arthritis Rheum 36:99-108

75. Strunk J, Backhaus M, Schmidt W, Kellner H (2010) Color doppler sonography for investigation of peripheral joints and ligaments. Z Rheumatol 69:164-170

76. Dougados M, Devauchelle-Pensec V, Ferlet JF, Jousse-Joulin S, D'Agostino MA, Backhaus M et al (2013) The ability of synovitis to predict structural damage in rheumatoid arthritis: a comparative study between clinical examination and ultrasound. Ann Rheum Dis 72(5):665 (http:// onlinelibrary.wiley.com/o/cochrane/clcentral/ articles/980/CN-00916980/frame.html.)

77. Østergaard M, Peterfy C, Conaghan P, McQueen F, Bird P, Ejbjerg B et al (2003) Omeract rheumatoid arthritis magnetic resonance imaging studies. Core set of mri acquisitions, joint pathology definitions, and the omeract ra-mriscoring system JRheumatol 30:1385-1386

78. Baker JF, Ostergaard M, Emery P, Hsia EC, Lu J, Baker DG et al (2014) Early mri measures independently predict 1-year and 2-year radiographic progression in rheumatoid arthritis: Secondary analysis from a large clinical trial. Ann Rheum Dis 73(11):1968 (http://onlinelibrary.wiley.com/ o/cochrane/clcentral/articles/269/CN-01122269/ frame.html)

79. van Steenbergen HW, Aletaha D, Beaart-van de Voorde LJJ, Brouwer E, Codreanu C, Combe B et al (2017) Eular definition of arthralgia suspicious for progression to rheumatoid arthritis. Ann Rheum Dis 76:491-496

80. Härter M (2004) Shared decision making — from the point of view of patients, physicians and health politics is set in place. Z Arztl Fortbild Qualitatssich 98:89-92

81. Bieber C, Gschwendtner K, Müller N, Eich W (2016) Partizipative entscheidungsfindung (pef)_patient und arzt als team. Psychother Psychosom Med Psychol 66:195-207

82. Loh A, Simon D, Kriston L, Härter M (2007) Patientenbeteiligung bei medizinischen entscheidungen. Dtsch Arztebl Int 104:1483

83. Wiek DBP, Clausen J (2016) Patientenbeteiligung an forschungsprojekten: Die forschungspartner der deutschen rheuma-liga.ZRheumatol 75:236

84. Allam A, Kostova Z, Nakamoto K, Schulz PJ (2015) The effect of social support features and gamification on a web-based intervention for rheumatoid arthritis patients: Randomized controlled trial. J Med Internet Res 17(1):e14 (http://onlinelibrary. wiley.com/o/cochrane/clcentral/articles/185/CN01111185/frame.html.)
85. Cheung PP, Lahiri M, Teng GG, Lim AY, Lau TC, Lateef A et al (2015) A randomized controlled trial for improving patient self-assessment of synovitis in rheumatoid arthritis with education by ultrasonography: the raeus study. Rheumatology 54(7):1161 (http://onlinelibrary.wiley.com/o/ cochrane/clcentral/articles/087/CN-01086087/ frame.html)

86. Fraenkel L, Matzko CK, Webb DE, Oppermann B, Charpentier P, Peters E et al (2015) Use of decision support for improved knowledge, values clarification, and informed choice in patients with rheumatoid arthritis. Arthritis Care Res 67(11):1496 (http://onlinelibrary.wiley.com/o/ cochrane/clcentral/articles/736/CN-01105736/ frame.html.)

87. Gronning K, Skomsvoll JF, Rannestad T, Steinsbekk A (2012) The effect of an educational programme consisting of group and individual arthritis education for patients with polyarthritis-a randomised controlled trial. Patient Educ Couns 88:113-120

88. Homer D, Nightingale P, Jobanputra P (2009) Providing patients with information about diseasemodifying anti-rheumatic drugs: Individually or in groups? A pilot randomized controlled trial comparing adherence and satisfaction. Musculoskeletal Care 7(2):78 (http://onlinelibrary. wiley.com/o/cochrane/clcentral/articles/343/CN 00719343/frame.html)

89. John H, Hale ED, Treharne GJ, Kitas GD, Carroll D (2013) A randomized controlled trial of a cognitive behavioural patient education intervention vs a traditional information leaflet to address the cardiovascular aspects of rheumatoid disease. Rheumatology 52(1):81-90. https://doi.org/10. 1093/rheumatology/kes237 (http://onlinelibrary. wiley.com/o/cochrane/clcentral/articles/527/CN 00863527/frame.html.)

90. Lovisi Neto BE, Jennings F, Barros Ohashi $C$ Silva PG, Natour J (2009) Evaluation of the efficacy of an educational program for rheumatoid arthritis patients. Clin Exp Rheumatol 27(1):28-34 (from: http://onlinelibrary.wiley.com/o/cochrane/ clcentral/articles/210/CN-00705210/frame.html)

91. Manning VL, Hurley MV, Scott DL, Coker B, Choy E, Bearne LM (2014) Education, selfmanagement, and upper extremity exercise training in people with rheumatoid arthritis: A randomized controlled trial. Arthritis Care Res (Hoboken) 66(2):217-227. (http://onlinelibrary. wiley.com/o/cochrane/clcentral/articles/532/CN00978532/frame.html)

92. Ndosi M, Johnson D, Young T, Hardware B, Hill J, Hale C et al (2016) Effects of needs-based patien education on self-efficacy and health outcomes in people with rheumatoid arthritis: a multicentre, single blind, randomised controlled trial. Ann Rheum Dis 75(6):1126-1132. (http://onlinelibrary. wiley.com/o/cochrane/clcentral/articles/404/CN01158404/frame.html)

93. Niedermann K, Buchi S, Ciurea A, Kubli R, SteurerStey C, Villiger PM et al (2012) Six and 12 months effects of individual joint protection education in people with rheumatoid arthritis: a randomized controlled trial. Scand J Occup Ther 19:360-369

94. Pot-Vaucel M, Aubert MP, Guillot P, Glemarec J, Berthelot JM, Le Goff B et al (2016) Randomised study versus control group of customised therapeutic education for patients in follow-up for rheumatoid arthritis. Joint Bone Spine 83:199-206

95. Jansen $L M$, van der Horst-Bruinsma IE, van Schaardenburg D, Bezemer PD, Dijkmans BA (2001) Predictors of radiographic joint damage in patients with early rheumatoid arthritis. Ann Rheum Dis 60:924-927

96. BoselloS, Fedele AL, Peluso G, Gremese E, Tolusso B, Ferraccioli $G$ (2011) Very early rheumatoid arthritis is the major predictor of major outcomes: clinical acr remission and radiographic non-progression. Ann Rheum Dis 70:1292-1295

97. Egsmose C, Lund B, Borg G, Pettersson H, Berg E, Brodin U et al (1995) Patients with rheumatoid arthritis benefit from early 2nd line therapy: 5 year followup of a prospective double blind placebo controlled study. J Rheumatol 22:2208-2213

98. Gremese E, Salaffi F, Bosello SL, Ciapetti A, BobbioPallavicini F, Caporali R et al (2013) Very early rheumatoid arthritis as a predictor of remission: $A$ multicentre real life prospective study. Ann Rheum Dis 72:858-862

99. Tsakonas E, Fitzgerald AA, Fitzcharles MA, Cividino A, Thorne JC, M'Seffar A et al (2000) Consequences of delayed therapy with secondline agents in rheumatoid arthritis: A 3 year followup on the hydroxychloroquine in early rheumatoid arthritis (hera) study. J Rheumatol 27:623-629

100. Hua C, Daien Cl, Combe B, Landewe R (2017) Diagnosis, prognosis and classification of early arthritis: results of a systematic review informing the 2016 update of the eular recommendations for the management of early arthritis. RMD Open 3:e406

101. van der Kooij SM, de Vries-Bouwstra JK, GoekoopRuiterman YPM, Ewals JAPM, Han KH, Hazes JMW et al (2008) Patient-reported outcomes in a randomized trial comparing four different treatment strategies in recent-onset rheumatoid arthritis. Arthritis Care Res 61:4-12

102. Wiles NJ, Dunn G, BarrettEM, Harrison BJ, Silman AJ, Symmons DP (2000) One year followup variables predict disability 5 years after presentation with inflammatory polyarthritis with greater accuracy than at baseline. J Rheumatol 27:2360-2366

103. Lard LR, Boers M, Verhoeven A, Vos K, Visser $H_{\text {, }}$ Hazes JMW et al (2002) Early and aggressive treatment of rheumatoid arthritis patients affects the association of hla class ii antigens with progression of joint damage. Arthritis Rheum 46:899-905

104. Lukas C, Combe B, Ravaud P, Sibilia J, Landew R, van der Heijde D (2011) Favorable effect of very early disease-modifying antirheumatic drug treatment on radiographic progression in early inflammatory arthritis: data from the etude et suivi des polyarthrites indifferenciees recentes (study and followup of early undifferentiated polyarthritis). Arthritis Rheum 63:1804-1811

105. Möttönen T, Hannonen P, Korpela M, Nissilä M, Kautiainen $\mathrm{H}$, Ilonen J et al (2002) Delay to institution of therapy and induction of remission using single-drug or combination-disease-modifying antirheumatic drug therapy in early rheumatoid arthritis. Arthritis Rheum 46:894-898

106. Soderlin MK, Bergman S (2011) Absent "window of opportunity" in smokers with short disease duration. Data from barfot, a multicenter study of early rheumatoid arthritis. J Rheumatol 38:2160-2168

107. Monti S, Montecucco C, Bugatti S, Caporali R(2015) Rheumatoid arthritis treatment: the earlier the better to prevent joint damage. RMD Open 1:e57

108. Markusse IM, Akdemir G, Dirven L, GoekoopRuiterman YP, Groenendael JH, Han KH et al (2016) Long-term outcomes of patients with recentonset rheumatoid arthritis after 10 years of tight controlled treatment: a randomized trial. Ann 
Intern Med 164(8):523-531. (http://onlinelibrary. wiley.com/o/cochrane/clcentral/articles/283/CN01153283/frame.html)

109. van der Woude D, Young A, Jayakumar K, Mertens BJ, Toes REM, van der Heijde $D$ et al (2009) Prevalence of and predictive factors for sustained disease-modifying antirheumatic drugfree remission in rheumatoid arthritis: results from two large early arthritis cohorts. Arthritis Rheum 60:2262-2271

110. Burgers LE, Allaart CF, Huizinga TWJ, Helm-van Mil AHM (2017) Clinical trials aiming to prevent the development of rheumatoid arthritis cannot detect prevention without adequate risk stratification; a trial performed in uapatients as example. Arthritis Rheumatol 69(5):926-931 (http:// onlinelibrary.wiley.com/o/cochrane/clcentral/ articles/881/CN-01292881/frame.html)

111. van Dongen $H$, van Aken J, Lard LR, Visser $K$, Ronday HK, Hulsmans HMJ et al (2007) Efficacy of methotrexate treatment in patients with probable rheumatoid arthritis: A double-blind, randomized, placebo-controlled trial. Arthritis Rheum 56:1424-1432

112. Peltomaa $R$, Paimela L, Kautiainen $H$, Leirisalo-Repo M (2002) Mortality in patients with rheumatoid arthritis treated actively from the time of diagnosis. Ann Rheum Dis 61:889-894

113. van Jaarsveld $C H$, Jacobs JW, van der Veen $M J$, Blaauw AA, Kruize AA, Hofman DM et al (2000) Aggressive treatment in early rheumatoid arthritis: A randomised controlled trial. On behalf of the rheumatic research foundation utrecht, the netherlands. Ann Rheum Dis 59:468-477

114. Smolen JS, Breedveld FC, Burmester GR, Bykerk V, Dougados M, Emery P et al (2016) Treating rheumatoid arthritis to target: 2014 update of the recommendations of an international task force. Ann Rheum Dis 75:3-15

115. Möttönen T, Paimela L, Ahonen J, Helve T, Hannonen P, Leirisalo-Repo M (1996) Outcome in patients with early rheumatoid arthritis treated according to the "sawtooth" strategy. Arthritis Rheum 39:996-1005

116. Fries JF, Williams CA, Ramey D, Bloch DA (1993) The relative toxicity of disease-modifying antirheumatic drugs. Arthritis Rheum 36:297-306

117. Tijhuis GJ, Zwinderman AH, Hazes JMW, Van Den Hout WB, Breedveld FC, Vliet Vlieland TPM (2002) A randomized comparison of care provided by a clinical nurse specialist, an inpatient team, and a day patient team in rheumatoid arthritis. Arthritis Rheum 47:525-531

118. Vliet Vlieland TP, Zwinderman AH, Vandenbroucke JP, Breedveld FC, Hazes JM (1996) A randomized clinical trial of in-patient multidisciplinary treatment versus routine out-patient care in active rheumatoid arthritis. Br JRheumatol 35:475-482

119. Vliet Vlieland TP, Breedveld FC, Hazes JM (1997) The two-year follow-up of a randomized comparison of in-patient multidisciplinary team care and routine out-patient care for active rheumatoid arthritis. $\mathrm{Br}$ JRheumatol 36:82-85

120. Helewa A, Bombardier C, Goldsmith $\mathrm{CH}$, Menchions B, Smythe HA (1989) Cost-effectiveness of inpatient and intensive outpatient treatment of rheumatoid arthritis. A randomized, controlled trial. Arthritis Rheum 32:1505-1514

121. Lambert CM, Hurst NP, Forbes JF, Lochhead $A$, Macleod M, Nuki G (1998) Is day care equivalent to inpatient care for active rheumatoid arthritis? Randomised controlled clinical and economic evaluation. BMJ316:965-969
122. Ayhan F (2011) Long-term effects of comprehensive inpatient rehabilitation on function and disease activity in patients with chronic rheumatoid arthritis and ankylosing spondylitis. Turk J Rheumatol 26:135-144

123. Bearne LM, Byrne A-M, Segrave $H$, White CM (2016) Multidisciplinary team care for people with rheumatoid arthritis: a systematic review and meta-analysis. Rheumatol Int 36:311-324

124. van den Hout WB, Tijhuis GJ, Hazes JMW, Breedveld FC, Vliet Vlieland TPM (2003) Cost effectiveness and cost utility analysis of multidisciplinary care in patients with rheumatoid arthritis: A randomised comparison of clinical nurse specialist care, inpatient team care, and day patient team care. Ann Rheum Dis 62:308-315

125. de Buck PDM, Schoones JW, Allaire SH, Vliet Vlieland TPM (2002) Vocational rehabilitation in patients with chronic rheumatic diseases: a systematic literature review. Semin Arthritis Rheum 32:196-203

126. Felson DT, Smolen JS, Wells G, Zhang B, van Tuyl LH, Funovits J et al (2011) American college of rheumatology/european league against rheumatism provisional definition of remission in rheumatoid arthritis for clinical trials. Ann Rheum Dis 70:404-413

127. Goekoop-Ruiterman YPM, de Vries-Bouwstra JK, Allaart CF, van Zeben D, Kerstens PJSM, Hazes JMW et al (2007) Comparison of treatment strategies in early rheumatoid arthritis: A randomized trial. Ann Intern Med 146:406-415

128. Grigor C, Capell H, Stirling A, McMahon AD, Lock P, Vallance Ret al (2004) Effect of a treatment strategy of tight control for rheumatoid arthritis (the ticora study): A single-blind randomised controlled trial. Lancet 364:263-269

129. Aletaha D, Funovits J, Breedveld FC, Sharp J, Segurado O, Smolen JS (2009) Rheumatoid arthritis joint progression in sustained remission is determined by disease activity levels preceding the period of radiographic assessment. Arthritis Rheum 60(5):1242-1249. (http://onlinelibrary. wiley.com/o/cochrane/clcentral/articles/230/CN00700230/frame.html)

130. Kaneko Y, Kondo H, Takeuchi T (2013) American college of rheumatology/european league against rheumatism remission criteria for rheumatoid arthritis maintain reliable performance when evaluated in 44 joints. J Rheumatol 40:1254-1258

131. Lillegraven S, Prince FH, ShadickNA, BykerkVP, LuB, Frits ML et al (2012) Remission and radiographic outcome in rheumatoid arthritis: Application of the $2011 \mathrm{acr} / \mathrm{eular}$ remission criteria in an observational cohort. Ann Rheum Dis 71:681-686

132. Balsa A, de Miguel E, Castillo C, Peiteado D, MartinMola E (2010) Superiority of sdai over das-28 in assessment of remission in rheumatoid arthritis patients using power doppler ultrasonography as a gold standard. Rheumatology 49:683-690

133. Sakellariou G, Scire CA, Verstappen SM, Montecucco C, Caporali R (2013) In patients with early rheumatoid arthritis, the new acr/eular definition of remission identifies patients with persistent absence of functional disability and suppression of ultrasonographic synovitis. Ann Rheum Dis 72:245-249

134. Kommission bildgebende verfahren der dgrh (2007) Bildgebende verfahren in der rheumatologie. Steinkopff, Darmstadt

135. Bijlsma JW, Welsing PM, Woodworth TG, Middelink LM, Petho-Schramm A, Bernasconi $C$ et al (2016) Early rheumatoid arthritis treated with tocilizumab, methotrexate, or their combination (u-act-early): A multicentre, randomised, double-blind, double-dummy, strategy trial. Lancet 388:343-355

136. Dale J, Stirling A, Zhang R, Purves D, Foley J, Sambrook M et al (2016) Targeting ultrasound remission in early rheumatoid arthritis: The results of the taser study, a randomised clinical trial. Ann Rheum Dis 75(6):1043-1050. (http://onlinelibrary. wiley.com/o/cochrane/clcentral/articles/660/CN01158660/frame.html.)

137. Montecucco C, Todoerti M, Sakellariou G, Scirè CA, Caporali R (2012) Low-dose oral prednisone improves clinical and ultrasonographic remission rates in early rheumatoid arthritis: Results of a 12 month open-label randomised study. Arthritis Res Ther 14(3):R112 (http://onlinelibrary.wiley.com/ o/cochrane/clcentral/articles/918/CN-00864918/ frame.html.)

138. Horslev-Petersen $\mathrm{K}$, Hetland ML, Junker P, Podenphant J, Ellingsen T, Ahlquist $P$ et al (2014) Adalimumab added to a treat-to-target strategy with methotrexate and intra-articular triamcinolone in early rheumatoid arthritis increased remission rates, function and quality of life. The opera study: An investigator-initiated, randomised, double-blind, parallel-group, placebocontrolled trial. Ann Rheum Dis 73:654-661

139. Smolen JS, Emery P, Fleischmann R, van Vollenhoven RF, Pavelka K, Durez P et al (2014) Adjustment of therapy in rheumatoid arthritis on the basis of achievement of stable low disease activity with adalimumab plus methotrexate or methotrexate alone: The randomised controlled optima trial. Lancet 383:321-332

140. Nam JL, Villeneuve E, Hensor EM, Conaghan PG, Keen HI, Buch MH et al (2014) Remission induction comparing infliximab and high-dose intravenous steroid, followed by treat-to-target: A doubleblind, randomised, controlled trial in new-onset, treatment-naive, rheumatoid arthritis (the idea study). Ann Rheum Dis 73(1):75-85 (http:// onlinelibrary.wiley.com/o/cochrane/clcentral/ articles/184/CN-00961184/frame.html)

141. Gøtzsche PC, Hansen M, Stoltenberg M, Svendsen A, Beier J, Faarvang KLetal (1996) Randomized, placebo controlled trial of withdrawal of slowacting antirheumatic drugs and of observer bias in rheumatoid arthritis. Scand J Rheumatol 25:194-199

142. ten Wolde S, Breedveld FC, Hermans J, Vandenbroucke JP, van de Laar MA, Markusse HM et al (1996) Randomised placebo-controlled study of stopping second-line drugs in rheumatoid arthritis. Lancet 347:347-352

143. Felson DT, Anderson JJ, Meenan RF (1990) The comparative efficacy and toxicity of second-line drugs in rheumatoid arthritis. Results of two metaanalyses. Arthritis Rheum 33:1449-1461

144. Sokka T, Hannonen P (1999) Utility of disease modifying antirheumatic drugs in "sawtooth" strategy. A prospective study of early rheumatoid arthritis patients up to 15 years. Ann Rheum Dis 58:618-622

145. Capell HA, Murphy EA, Hunter JA (1991) Rheumatoid arthritis: workload and outcome over 10 years. Q J Med 79:461-476

146. Strangfeld A, Eveslage M, Schneider M, Bergerhausen HJ, Klopsch T, Zink A et al (2011) Treatment benefit or survival of the fittest: What drives the time-dependent decrease in serious infection rates under tnf inhibition and what does this imply for the individual patient? Ann Rheum Dis 70(11):1914-1920. (http://onlinelibrary. 
wiley.com/o/cochrane/clcentral/articles/866/CN00890866/frame.html.)

147. NortonS, KoduriG, Nikiphorou E, Dixey J, WilliamsP, Young A (2013) A study of baseline prevalence and cumulative incidence of comorbidity and extraarticular manifestations in ra and their impact on outcome. Rheumatology 52:99-110

148. Kleinert S, Krueger K (2011) Kardiovaskuläre komorbidität und ihre risikofaktoren bei rheumatoider arthritis. ZRheumatol 70:464-472

149. Cavagna L, Monti S, Grosso V, Boffini N, Scorletti E, Crepaldi $\mathrm{G}$ et al (2013) The multifaceted aspects of interstitial lung disease in rheumatoid arthritis. Biomed Res Int 2013:759760

150. Ogdie A, Yu Y, Haynes K, Love TJ, Maliha S, Jiang Y et al (2015) Risk of major cardiovascular events in patients with psoriatic arthritis, psoriasis and rheumatoid arthritis: A population-based cohort study. Ann Rheum Dis 74:326-332

151. Choy EH, Scott DL, Kingsley GH, Williams P, Wojtulewski J, Papasavvas G et al (2002) Treating rheumatoid arthritis early with disease modifying drugs reduces joint damage: A randomised double blind trial of sulphasalazine vs diclofenac sodium. Clin Exp Rheumatol 20:351-358

152. Westhovens R, Robles $M$, Ximenes AC, Nayiager $S$, Wollenhaupt J, Durez P et al (2009) Clinical efficacy and safety of abatacept in methotrexate-naive patients with early rheumatoid arthritis and poor prognostic factors. Ann Rheum Dis 68:1870-1877

153. Emery P, Burmester GR, Bykerk VP, Combe BG, Furst DE, Barré E et al (2015) Evaluating drugfree remission with abatacept in early rheumatoid arthritis: Results from the phase $3 \mathrm{~b}$, multicentre, randomised, active-controlled avert study of 24 months, with a 12-month, double-blind treatment period. Ann Rheum Dis 74:19-26

154. Breedveld FC, Weisman MH, Kavanaugh AF, Cohen SB, Pavelka K, van Vollenhoven Retal (2006) The premier study: a multicenter, randomized, double-blind clinical trial of combination therapy with adalimumab plus methotrexate versus methotrexate alone or adalimumab alone in patients with early, aggressive rheumatoid arthritis who had not had previous methotrexate treatment Arthritis Rheum 54:26-37

155. Bejarano V, Quinn M, Conaghan PG, Reece $R$, Keenan A-M, Walker D et al (2008) Effect of the early use of the anti-tumor necrosis factor adalimumab on the prevention of job loss in patients with early rheumatoid arthritis. Arthritis Rheum 59:1467-1474

156. Takeuchi T, Yamanaka H, Ishiguro N, Miyasaka N, Mukai M, Matsubara T et al (2014) Adalimumab, a human anti-tnf monoclonal antibody, outcome study for the prevention of joint damage in japanese patients with early rheumatoid arthritis: The hopeful 1 study. Ann Rheum Dis 73:536-543

157. Atsumi T, Yamamoto $\mathrm{K}$, Takeuchi T, Yamanaka $\mathrm{H}$, Ishiguro N, Tanaka Y et al (2016) The first doubleblind, randomised, parallel-group certolizumab pegol study in methotrexate-naive early rheumatoid arthritis patients with poor prognostic factors, c-opera, shows inhibition of radiographic progression. Ann Rheum Dis 75(1):75-83 (http:// onlinelibrary.wiley.com/o/cochrane/clcentral/ articles/323/CN-01134323/frame.html)

158. Emery P, Bingham CO, Burmester GR, Bykerk VP, Furst DE, Mariette X et al (2017) Certolizumab pegol in combination with dose-optimised methotrexate in dmard-naïve patients with early, active rheumatoid arthritis with poor prognostic factors: 1-year results from c-early, a randomised, double-blind, placebo-controlled phase iii study. Ann Rheum Dis 76:96-104

159. Bathon JM, Martin RW, Fleischmann RM, Tesser JR, SchiffMH, Keystone EC et al (2000) A comparison of etanercept and methotrexate in patients with early rheumatoid arthritis. N Engl J Med 343:1586-1593

160. Emery P, Breedveld FC, Hall S, Durez P, Chang DJ, Robertson D et al (2008) Comparison of methotrexate monotherapy with a combination of methotrexate and etanercept in active, early, moderate to severe rheumatoid arthritis (comet): $\mathrm{A}$ randomised, double-blind, parallel treatment trial. Lancet 372:375-382

161. Emery P, Fleischmann RM, Moreland LW, Hsia EC, Strusberg I, Durez P et al (2009) Golimumab, a hu man anti-tumor necrosis factor alpha monoclonal antibody, injected subcutaneously every four weeks in methotrexate-naive patients with active rheumatoid arthritis: Twenty-four-week results of a phase iii, multicenter, randomized, doubleblind, placebo-controlled study of golimumab before methotrexate as first-line therapy for early-onset rheumatoid arthritis. Arthritis Rheum 60:2272-2283

162. St Clair EW, van der Heijde DMFM, Smolen JS, Maini RN, Bathon JM, Emery P et al (2004) Combination of infliximab and methotrexate therapy for early rheumatoid arthritis: a randomized, controlled trial. Arthritis Rheum 50:3432-3443

163. Tak PP, Rigby WF, Rubbert-Roth A, Peterfy CG, Vollenhoven RF, Stohl W et al (2011) Inhibition of joint damage and improved clinical outcomes with rituximab plus methotrexate in early active rheumatoid arthritis: the image trial. Ann Rheum Dis 70(1):39-46 (http://onlinelibrary.wiley.com/ o/cochrane/clcentral/articles/054/CN-00779054/ frame.html.)

164. Burmester GR, Rigby WF, van Vollenhoven RF, Kay J, Rubbert-Roth A, Kelman A et al (2016) Tocilizumab in early progressive rheumatoid arthritis: function, a randomised controlled trial. Ann Rheum Dis 75:1081-1091

165. Hetland ML, Stengaard-Pedersen K, Junker $P$ Lottenburger T, Ellingsen T, Andersen LS et al (2006) Combination treatment with methotrexate, cyclosporine, and intraarticular betamethasone compared with methotrexate and intraarticular betamethasone in early active rheumatoid arthritis: An investigator-initiated, multicenter, randomized, double-blind, parallel-group, placebocontrolled study. Arthritis Rheum 54:1401-1409

166. Hetland ML, Stengaard-Pedersen $K$, Junker $P$ Lottenburger T, Hansen I, Andersen LS et al (2008) Aggressive combination therapy with intra-articular glucocorticoid injections and conventional disease-modifying anti-rheumatic drugs in early rheumatoid arthritis: Second-year clinical and radiographic results from the cimestra study. Ann Rheum Dis 67:815-822

167. van der Heijde DM, van Riel PL, Nuver-Zwart IH, Gribnau FW, vad de Putte LB (1989) Effects of hydroxychloroquine and sulphasalazine on progression of joint damage in rheumatoid arthritis. Lancet 1:1036-1038

168. Möttönen T, Hannonen P, Leirisalo-Repo $M$, Nissilä M, Kautiainen H, Korpela M et al (1999) Comparison of combination therapy with singledrug therapy in early rheumatoid arthritis: A randomised trial. Fin-raco trial group. Lancet 353:1568-1573

169. Landewé RB, Goei Thè HS, van Rijthoven AW, Breedveld FC, Dijkmans BA (1994) A randomized double-blind, 24-week controlled study of low- dose cyclosporine versus chloroquine for early rheumatoid arthritis. Arthritis Rheum 37:637-643

170. Proudman SM, Conaghan PG, Richardson C, Griffiths B, Green MJ, McGonagle D et al (2000) Treatment of poor-prognosis early rheumatoid arthritis. A randomized study of treatment with methotrexate, cyclosporin a, and intraarticular corticosteroids compared with sulfasalazine alone. Arthritis Rheum 43:1809-1819

171. Haagsma $C J$, van Riel $P L$, de Jong $A J$, van de Putte LB (1997) Combination of sulphasalazine and methotrexate versus the single components in early rheumatoid arthritis: A randomized, controlled, double-blind, 52 week clinical trial. $\mathrm{Br}$ J Rheumatol 36:1082-1088

172. Dougados $M$, Combe B, Cantagrel A, Goupille $P$ Olive P, Schattenkirchner M et al (1999) Combination therapy in early rheumatoid arthritis: $A$ randomised, controlled, double blind 52 week clinical trial of sulphasalazine and methotrexate compared with the single components. Ann Rheum Dis 58:220-225

173. Boers M, Verhoeven AC, Markusse HM, van de Laar MA, Westhovens R, van Denderen JC et al (1997) Randomised comparison of combined step-down prednisolone, methotrexate and sulphasalazine with sulphasalazine alone in early rheumatoid arthritis. Lancet 350:309-318

174. van Vollenhoven RF, Ernestam S, Geborek $P$, Petersson IF, Cöster L, Waltbrand E et al (2009) Addition of infliximab compared with addition of sulfasalazine and hydroxychloroquine to methotrexate in patients with early rheumatoid arthritis (swefot trial): 1-year results of a randomised trial. Lancet 374:459-466

175. Hannonen P, Möttönen T, Hakola M, Oka M (1993) Sulfasalazine in early rheumatoid arthritis. A 48-week double-blind, prospective, placebocontrolled study. Arthritis Rheum 36:1501-1509

176. Fleischmann $R$, Schiff $M$, van der Heijde $D$, Ramos-Remus C, Spindler A, Stanislav M et al (2017) Baricitinib, methotrexate, or combination in patients with rheumatoid arthritis and no or limited prior disease-modifying antirheumatic drug treatment. Arthritis Rheumatol 69:506-517

177. Fleischmann RM, Huizinga TWJ, Kavanaugh AF, Wilkinson B, Kwok K, DeMasi R et al (2016) Efficacy of tofacitinib monotherapy in methotrexate-naive patients with early or established rheumatoid arthritis. RMD Open 2:e262

178. Lee EB, Fleischmann R, Hall S, Wilkinson B, Bradley JD, Gruben D et al (2014) Tofacitinib versus methotrexate in rheumatoid arthritis. N Engl J Med 370:2377-2386

179. Clark P, Tugwell P, Bennet K, Bombardier C, Shea B, Wells G et al (2000) Injectable gold for rheumatoid arthritis. Cochrane Database Syst Rev. https://doi. org/10.1002/14651858.CD000520

180. Suarez-Almazor ME, Belseck E, Shea B, Homik J, Wells G, Tugwell P (2000) Antimalarials for treating rheumatoid arthritis. Cochrane Database Syst Rev. https://doi.org/10.1002/14651858.CD000959

181. Suarez-Almazor ME, Belseck E, Shea B, Wells G, Tugwell P (2000) Methotrexate for rheumatoid arthritis. Cochrane Database Syst Rev. https://doi. org/10.1002/14651858.CD000957

182. Suarez-Almazor ME, Belseck E, Shea B, Wells G, Tugwell P (2000) Sulfasalazine for rheumatoid arthritis. Cochrane Database Syst Rev. https://doi. org/10.1002/14651858.CD000958

183. Suarez-Almazor ME, Spooner C, Belseck E (2000) Azathioprine for treating rheumatoid arthritis. Cochrane Database Syst Rev. https://doi.org/10 1002/14651858.CD001461 
184. Suarez-Almazor ME, Spooner C, Belseck E (2000) Penicillamine for treating rheumatoid arthritis. Cochrane Database Syst Rev. https://doi.org/10. 1002/14651858.CD001460

185. Suarez-Almazor ME, Spooner CH, BelseckE, Shea B (2000) Auranofin versus placebo in rheumatoid arthritis. Cochrane Database Syst Rev. https://doi. org/10.1002/14651858.CD002048

186. Wells G, HaguenauerD, SheaB, Suarez-Almazor ME, Welch VA, Tugwell P (2000) Cyclosporine for rheumatoid arthritis. Cochrane Database Syst Rev. https://doi.org/10.1002/14651858.CD001083

187. Fries JF, Williams CA, Morfeld D, Singh G, Sibley J (1996) Reduction in long-term disability in patients with rheumatoid arthritis by disease-modifying antirheumatic drug-based treatment strategies. Arthritis Rheum 39:616-622

188. Choi HK, Hernán MA, Seeger JD, Robins JM, Wolfe F (2002) Methotrexate and mortality in patients with rheumatoid arthritis: A prospective study. Lancet 359:1173-1177

189. Krause D, Schleusser B, Herborn G, Rau R (2000) Response to methotrexate treatment is associated with reduced mortality in patients with severe rheumatoid arthritis. Arthritis Rheum 43:14-21

190. Ferraccioli GF, Gremese E, Tomietto P, Favret G, Damato R, Di Poi E (2002) Analysis of improvements, full responses, remission and toxicity in rheumatoid patients treated with step-up combination therapy (methotrexate, cyclosporin a, sulphasalazine) or monotherapy for three years. Rheumatology 41:892-898

191. Menninger H, Herborn G, Sander O, Blechschmidt J, Rau R (1998) A 36 month comparative trial of methotrexate and gold sodium thiomalate in the treatment of early active and erosive rheumatoid arthritis. Br JRheumatol 37:1060-1068

192. Rau R, Herborn G, Menninger H, Sangha O (2002) Radiographic outcome after three years of patients with early erosive rheumatoid arthritis treated with intramuscular methotrexate or parenteral gold. Extension of a one-year double-blind study in 174 patients. Rheumatology 41:196-204

193. Verschueren P, De Cock D, Corluy L, Joos R, Langenaken C, Taelman Vetal (2017) Effectiveness of methotrexate with step-down glucocorticoid remission induction (cobra slim) versus other intensive treatmentstrategies for early rheumatoid arthritis in a treat-to-target approach: 1-year results of carera, a randomised pragmatic openlabel superiority trial. Ann Rheum Dis 76:511-520

194. Emery P, Breedveld FC, Lemmel EM, Kaltwasser JP, Dawes PT, Gömör B et al (2000) A comparison of the efficacy and safety of leflunomide and methotrexate for the treatment of rheumatoid arthritis. Rheumatology 39:655-665

195. Kremer JM, Genovese MC, Cannon GW, Caldwell JR, Cush JJ, Furst DE et al (2002) Concomitant leflunomide therapy in patients with active rheumatoid arthritis despite stable doses of methotrexate. A randomized, double-blind, placebo-controlled trial. Ann Intern Med 137:726-733

196. Smolen JS, Kalden JR, Scott DL, Rozman B, Kvien TK, Larsen A et al (1999) Efficacy and safety of leflunomide compared with placebo and sulphasalazine in active rheumatoid arthritis: A double-blind, randomised, multicentre trial. European leflunomide study group. Lancet 353:259-266

197. Strand V, Cohen S, Schiff M, Weaver A, Fleischmann R, Cannon G et al (1999) Treatment of active rheumatoid arthritis with leflunomide compared with placebo and methotrexate. Leflunomide rheumatoid arthritis investigators group. Arch Intern Med 159:2542-2550

198. Genovese MC, Bathon JM, Martin RW, Fleischmann RM, Tesser JR, Schiff MH et al (2002) Etanercept versus methotrexate in patients with early rheumatoid arthritis: Two-year radiographic and clinical outcomes. Arthritis Rheum 46:1443-1450

199. Kimel M, Cifaldi M, Chen N, Revicki D (2008) Adalimumab plus methotrexate improved sf-36 scores and reduced the effect of rheumatoid arthritis ( $\mathrm{ra}$ ) on work activity for patients with early ra.J Rheumatol 35:206-215

200. Donahue KE, Gartlehner G, Jonas DE, Lux LJ, Thieda P, Jonas BL et al (2008) Systematic review: comparative effectiveness and harms of diseasemodifying medications for rheumatoid arthritis. Ann Intern Med 148:124-134

201. Sarzi-Puttini $P, D^{\prime}$ Ingianna $E$, Fumagalli $M$, Scarpellini M, Fiorini T, Cherie-Ligniere EL et al (2005) An open, randomized comparison study of cyclosporine a, cyclosporine $a+$ methotrexate and cyclosporine $\mathrm{a}+$ hydroxychloroquine in the treatment of early severe rheumatoid arthritis. Rheumatol Int 25:15-22

202. Gerards AH, Landewé RBM, Prins APA, Bruyn GW Goei Thé HS, Laan RFJM et al (2003) Cyclosporin a monotherapy versus cyclosporin a and methotrexate combination therapy in patients with early rheumatoid arthritis: a double blind randomised placebo controlled trial. Ann Rheum Dis 62:291-296

203. Marchesoni A, Battafarano N, Arreghini M, Panni B Gallazzi M, Tosi S (2003) Radiographic progression in early rheumatoid arthritis: A 12-month randomized controlled study comparing the combination of cyclosporin and methotrexate with methotrexate alone. Rheumatology 42:1545-1549

204. Durez P, Malghem J, Nzeusseu Toukap A, Depresseux G, Lauwerys BR, Westhovens $R$ et al (2007) Treatment of early rheumatoid arthritis: A randomized magnetic resonance imaging study comparing the effects of methotrexate alone, methotrexate in combination with infliximab, and methotrexate in combination with intravenous pulse methylprednisolone. Arthritis Rheum 56:3919-3927

205. Smolen JS, Han C, van der Heijde D, Emery P, Bathon JM, Keystone E et al (2006) Infliximab treatment maintains employability in patients with early rheumatoid arthritis. Arthritis Rheum 54:716-722

206. Kekow J, Moots RJ, Emery P, Durez P, Koenig A, Singh A et al (2010) Patient-reported outcomes improve with etanercept plus methotrexate in active early rheumatoid arthritis and the improvement is strongly associated with remission: The comet trial. Ann Rheum Dis 69:222-225

207. Ma MH, Kingsley GH, Scott DL (2010) A systematic comparison of combination dmard therapy and tumour necrosis inhibitor therapy with methotrexate in patients with early rheumatoid arthritis. Rheumatology 49:91-98

208. Katchamart W, Trudeau J, Phumethum V, Bombardier C (2009) Efficacy and toxicity of methotrexate $(\mathrm{mtx})$ monotherapy versus $\mathrm{mtx}$ combination therapy with non-biological disease-modifying antirheumatic drugs in rheumatoid arthritis: $A$ systematic review and meta-analysis. Ann Rheum Dis 68:1105-1112

209. Singh JA, Hossain A, Tanjong Ghogomu E, Kotb A, Christensen R, Mudano AS et al (2016) Biologics or tofacitinib for rheumatoid arthritis in incomplete responders to methotrexate or other traditional disease-modifying anti-rheumatic drugs: A systematic review and network metaanalysis. Cochrane Database Syst Rev. https://doi. org/10.1002/14651858.CD012183

210. Saunders SA, Capell HA, Stirling A, Vallance R, Kincaid W, McMahon AD et al (2008) Triple therapy in early active rheumatoid arthritis: A randomized single-blind, controlled trial comparing step-up and parallel treatment strategies. Arthritis Rheum 58:1310-1317

211. Capell HA, Madhok R, Porter DR, Munro RA, McInnes IB, Hunter JA et al (2007) Combination therapy with sulfasalazine and methotrexate is more effective than either drug alone in patients with rheumatoid arthritis with a suboptimal response to sulfasalazine: results from the doubleblind placebo-controlled mascot study. Ann Rheum Dis 66:235-241

212. Choy EH, Smith CM, Farewell V, Walker D, Hassell A, Chau L et al (2008) Factorial randomised controlled trial of glucocorticoids and combination disease modifying drugs in early rheumatoid arthritis. Ann Rheum Dis 67:656-663

213. Le Loet X, Berthelot JM, Cantagrel A, Combe B, De Bandt M, Fautrel B et al (2006) Clinical practice decision tree for the choice of the first disease modifying antirheumatic drug for very early rheumatoid arthritis: A 2004 proposal of the french society of rheumatology. Ann Rheum Dis 65:45-50

214. Lopez-Olivo Maria A, Siddhanamatha Harish $R$ Shea B, Tugwell P, Wells GA, Suarez-Almazor ME (2014) Methotrexate for treating rheumatoid arthritis. Cochrane Database Syst Rev 2014(6):CD000957 (http://onlinelibrary.wiley. com/doi/10.1002/14651858.CD000957.pub2/ abstract)

215. Hider SL, Silman A, Bunn D, Manning S, Symmons D, Lunt M (2006) Comparing the long-term clinical outcome of treatment with methotrexate or sulfasalazine prescribed as the first diseasemodifying antirheumatic drug in patients with inflammatory polyarthritis. Ann Rheum Dis 65:1449-1455

216. Fiehn C, Holle J, Iking-Konert C, Leipe J, Weseloh C, FrerixMetal (2018)S2e-leitlinie:Therapie der rheumatoiden arthritis mit krankheitsmodifizierenden medikamenten. ZRheumatol 77:35-53

217. Felson DT, Anderson JJ, Meenan RF (1992) Use of short-term efficacy/toxicity tradeoffs to select second-line drugs in rheumatoid arthritis. A metaanalysis of published clinical trials. Arthritis Rheum 35:1117-1125

218. van Ede AE, Laan RF, Rood MJ, Huizinga TW, van de Laar MA, van Denderen CJ et al (2001) Effect of folic or folinic acid supplementation on the toxicity and efficacy of methotrexate in rheumatoid arthritis: A forty-eight week, multicenter, randomized, double-blind, placebo-controlled study. Arthritis Rheum 44:1515-1524

219. Shea B, Swinden Michael V, Tanjong Ghogomu E, Ortiz Z, Katchamart W, Rader T et al (2013) Folic acid and folinic acid for reducing side effects in patients receiving methotrexate for rheumatoid arthritis. Cochrane Database Syst Rev 2013(5):CD000951 (http://onlinelibrary.wiley com/doi/10.1002/14651858.CD000951.pub2/ abstract.)

220. Alfaro-Lara R, Espinosa-Ortega HF, Arce-Salinas CA (2017) Systematic review and meta-analysis of the efficacy and safety of leflunomide and methotrexate in the treatment of rheumatoid arthritis. Reumatol Clin 15(3):133-139

221. Bongartz T, Sutton AJ, Sweeting MJ, Buchan I, Matteson EL, Montori V (2006) Anti-tnf antibody 
therapy in rheumatoid arthritis and the risk of serious infections and malignancies: Systematic review and meta-analysis of rare harmful effects in randomized controlled trials. JAMA 295:2275-2285

222. Ramiro S, Sepriano A, Chatzidionysiou K, Nam JL, Smolen JS, van der Heijde D et al (2017) Safety of synthetic and biological dmards: A systematic literature review informing the 2016 update of the eular recommendations for management of rheumatoid arthritis. Ann Rheum Dis 76:1101-1136

223. Strangfeld A, Richter A, Siegmund B, Herzer $P$, Rockwitz K, Demary W et al (2017) Risk for lower intestinal perforations in patients with rheumatoid arthritis treated with tocilizumab in comparison to treatment with other biologic or conventional synthetic dmards. Ann Rheum Dis 76:504-510

224. Krüger K, Albrecht K, Rehart S, Scholz R, der Kommission Pharmakotherapie D (2014) Recommendations of the german society for rheumatology on the perioperative approach under therapy with dmards and biologicals in inflammatory rheumatic diseases. ZRheumatol 73:77-84

225. Asten P, Barrett J, Symmons D (1999) Risk of developing certain malignancies is related to duration of immunosuppressive drug exposure in patients with rheumatic diseases. J Rheumatol 26:1705-1714

226. Baecklund E, Ekbom A, Sparén P, Feltelius N, Klareskog $L$ (1998) Disease activity and risk of lymphoma in patients with rheumatoid arthritis: Nested case-control study. BMJ 317:180-181

227. Beauparlant P, Papp K, Haraoui B (1999) The incidence of cancer associated with the treatment of rheumatoid arthritis. Semin Arthritis Rheum 29:148-158

228. Baecklund E, Iliadou A, Askling J, Ekbom A, Backlin C, Granath F et al (2006) Association of chronic inflammation, not its treatment, with increased lymphoma risk in rheumatoid arthritis. Arthritis Rheum 54:692-701

229. Maneiro JR, Souto A, Gomez-Reino JJ(2017)Risks of malignancies related to tofacitinib and biological drugs in rheumatoid arthritis: Systematic review, meta-analysis, and network meta-analysis. Semin Arthritis Rheum 47:149-156

230. Askling J, van Vollenhoven RF, Granath F, Raaschou P, Fored CM, Baecklund E et al (2009) Cancer risk in patients with rheumatoid arthritis treated with anti-tumor necrosis factor alpha therapies: Does the risk change with the time since start of treatment? Arthritis Rheum 60:3180-3189

231. Wadström $H$, Frisell T, Askling J, The AntiRheumatic Therapy in Sweden Study G (2017) Malignant neoplasms in patients with rheumatoid arthritis treated with tumor necrosis factor inhibitors, tocilizumab, abatacept, or rituximab in clinical practice: A nationwide cohort study from sweden. JAMA Intern Med 177:1605

232. Laan RF, Jansen TL, van Riel PL (1999) Glucocorticosteroids in the management of rheumatoid arthritis. Rheumatology 38:6-12

233. Gotzsche PC, Johansen HK (1998) Meta-analysis of short-term low dose prednisolone versus placebo and non-steroidal anti-inflammatory drugs in rheumatoid arthritis. BMJ316:811-818

234. Gotzsche PC, Johansen HK (2003) Short-term lowdose corticosteroids vs placebo and nonsteroidal antiinflammatory drugs in rheumatoid arthritis. Cochrane Database Syst Rev. https://doi.org/10. 1002/14651858.CD000189

235. ter Wee MM, den Uyl D, Boers $M$, Kerstens $P$, Nurmohamed $M$, van Schaardenburg $D$ et al (2015) Intensive combination treatment regimens, including prednisolone, are effective in treating patients with early rheumatoid arthritis regardless of additional etanercept: 1-year results of the cobra-light open-label, randomised, noninferiority trial. Ann Rheum Dis 74:1233-1240

236. Buttgereit F, Doering G, Schaeffler A, Witte S, Sierakowski S, Gromnica-Ihle E et al (2008) Efficacy of modified-release versus standard prednisone to reduce duration of morning stiffness of the joints in rheumatoid arthritis (capra-1): A double-blind randomised controlled trial. Lancet 371:205-214

237. Gestel AMV, Laan RFJM, Haagsma CJ, Van De Putte LBA, Van Riel PLCM (1995) Oral steroids as bridge therapy in rheumatoid arthritis patients starting with parenteral gold. A randomized double-blind placebo-controlled trial. Baillieres Clin Rheumatol 34:347-351

238. Million R, Kellgren JH, Poole P, Jayson MI (1984) Long-term study of management of rheumatoid arthritis. Lancet 1:812-816

239. Kirwan JR, Reeback JS (1986) Stanford health assessment questionnaire modified to assess disability in british patients with rheumatoid arthritis. Br JRheumatol 25:206-209

240. Kirwan JR (1995) The effect of glucocorticoids on joint destruction in rheumatoid arthritis. The arthritis and rheumatism council lowdose glucocorticoid study group. N Engl J Med 333:142-146

241. Smolen JS, Landewé R, Bijlsma J, Burmester G, Chatzidionysiou K, Dougados M et al (2017) Eular recommendations for the management of rheumatoid arthritis with synthetic and biological disease-modifying antirheumatic drugs: 2016 update. Ann Rheum Dis 76:960-977

242. Hickling P, Jacoby RK, Kirwan JR (1998) Joint destruction after glucocorticoids are withdrawn in early rheumatoid arthritis. Arthritis and rheumatism council low dose glucocorticoid study group. Br JRheumatol 37:930-936

243. Kirwan JR, Bijlsma JW, Boers M, Shea BJ (2007) Effects of glucocorticoids on radiological progres sion in rheumatoid arthritis. Cochrane Database Syst Rev. https://doi.org/10.1002/14651858. CD006356

244. van Everdingen AA, Jacobs JW, Siewertsz Van Reesema DR, Bijlsma JW (2002) Low-dose prednisone therapy for patients with early active rheumatoid arthritis: Clinical efficacy, disease-modifying properties, and side effects: A randomized, double-blind, placebo-controlled clinical trial. Ann Intern Med 136:1-12

245. Bakker MF, Jacobs JW, Welsing PM, Verstappen SM, Tekstra J, Ton E et al (2012) Low-dose prednisone inclusion in a methotrexate-based, tight control strategy for early rheumatoid arthritis: a randomized trial. Ann Intern Med 156:329-339

246. McDougall R, Sibley J, Haga M, Russell A (1994) Outcome in patients with rheumatoid arthritis receiving prednisone compared to matched controls. JRheumatol 21:1207-1213

247. Saag KG (1997) Low-dose corticosteroid therapy in rheumatoid arthritis: Balancing the evidence. Am J Med 103:31S-39S

248. Saag KG, Koehnke R, Caldwell JR, Brasington R, Burmeister LF, Zimmerman B et al (1994) Low dose long-term corticosteroid therapy in rheumatoid arthritis: an analysis of serious adverse events. Am J Med 96:115-123

249. Wolfe F, Mitchell DM, Sibley JT, Fries JF, Bloch DA, Williams CA et al (1994) The mortality of rheumatoid arthritis. Arthritis Rheum 37:481-494
250. Strehl C, Bijlsma JW, de Wit M, Boers M, Caeyers N Cutolo $M$ et al (2016) Defining conditions where long-term glucocorticoid treatment has an acceptably low level of harm to facilitate implementation of existing recommendations: Viewpoints from an eular task force. Ann Rheum Dis 75:952-957

251. Seror $P$, Pluvinage $P$, d'Andre FL, Benamou $P$, Attuil G (1999) Frequency of sepsis after local corticosteroid injection (an inquiry on 1160000 injections in rheumatological private practice in france). Rheumatology 38:1272-1274

252. Weitoft T, Uddenfeldt $P$ (2000) Importance of synovial fluid aspiration when injecting intra-articular corticosteroids. Ann Rheum Dis 59:233-235

253. Chakravarty K, Pharoah PD, Scott DG (1994) A randomized controlled study of post-injection rest following intra-articular steroid therapy for knee synovitis. Br JRheumatol 33:464-468

254. Wallen M, Gillies D (2006) Intra-articular steroids and splints/rest for children with juvenile idiopathic arthritis and adults with rheumatoid arthritis. Cochrane Database Syst Rev. https://doi.org/10. 1002/14651858.CD002824.pub2

255. Brooks PM, Day RO (1991) Nonsteroidal antiinflammatory drugs - differences and similarities. N Engl JMed 324:1716-1725

256. Furst DE (1994) Are there differences among nonsteroidal antiinflammatory drugs? Comparing acetylated salicylates, nonacetylated salicylates, and nonacetylated nonsteroidal antiinflammatory drugs. Arthritis Rheum 37:1-9

257. van Walsem A, Pandhi S, Nixon RM, Guyot $P_{\text {, }}$ Karabis A, Moore RA (2015) Relative benefitrisk comparing diclofenac to other traditional non-steroidal anti-inflammatory drugs and cyclooxygenase-2 inhibitors in patients with osteoarthritis or rheumatoid arthritis: A network meta-analysis. Arthritis Res Ther 17:66

258. Colebatch AN, Marks JL, Edwards CJ (2011) Safety of non-steroidal anti-inflammatory drugs, including aspirin and paracetamol (acetaminophen) in people receiving methotrexate for inflammatory arthritis (rheumatoid arthritis, ankylosing spondylitis, psoriatic arthritis, other spondyloarthritis). Cochrane Database Syst Rev. https://doi.org/10. 1002/14651858.CD008872.pub2

259. Nsaids GPC (2010) BMJ clinical evidence 2010

260. Hardin JG Jr., Kirk KA (1979) Comparative effectiveness of five analgesics for the pain of rheumatoid synovitis. JRheumatol 6:405-412

261. Huskisson EC (1974) Simple analgesics for arthritis. BrMed J 4:196-200

262. Seideman P, Melander A (1988) Equianalgesic effects of paracetamol and indomethacin in rheumatoid arthritis. Br JRheumatol 27:117-122

263. Wienecke T, Gotzsche PC (2004) Paracetamol versus nonsteroidal anti-inflammatory drugs for rheumatoid arthritis. Cochrane Database Syst Rev. https://doi.org/10.1002/14651858.CD003789. pub2

264. Moore RA, Derry S, Wiffen PJ, Straube S, Aldington DJ (2015) Overview review: Comparative efficacy of oral ibuprofen and paracetamol (acetaminophen) across acute and chronic pain conditions. Eur JPain 19:1213-1223

265. Whittle S, Richards B, Buchbinder R (2011) The efficacy and safety of opioids in rheumatoid arthritis: A cochrane systematic review. Cochrane Database Syst Rev 41(11):CD003113 (http:// onlinelibrary.wiley.com/o/cochrane/clcentral/ articles/419/CN-01003419/frame.html.) 
266. Chandanwale AS, Sundar S, Latchoumibady K Biswas S, Gabhane M, Naik M et al (2014) Efficacy and safety profile of combination of tramadol-diclofenac versus tramadol-paracetamol in patients with acute musculoskeletal conditions, postoperative pain, and acute flare of osteoarthritis and rheumatoid arthritis: A phase iii, 5-day open-label study. J Pain Res 7:455-463. (http://onlinelibrary. wiley.com/o/cochrane/clcentral/articles/394/CN01002394/frame.html.)

267. Furlan AD, Sandoval JA, Mailis-Gagnon A, Tunks E (2006) Opioids for chronic noncancer pain: a metaanalysis of effectiveness and side effects. CMAJ 174:1589-1594

268. Bell MJ, Lineker SC, Wilkins AL, Goldsmith CH, Badley EM (1998) A randomized controlled trial to evaluate the efficacy of community based physical therapy in the treatment of people with rheumatoid arthritis. J Rheumatol 25:231-237

269. Mayoux Benhamou MA (2007) Reconditioning in patients with rheumatoid arthritis. Ann Readapt Med Phys 50:382-5, 77-81

270. Metsios GS, Stavropoulos-Kalinoglou A, Veldhuijzen van Zanten JJ, Treharne GJ, Panoulas VF, Douglas KM et al (2008) Rheumatoid arthritis, cardiovascular disease and physical exercise: a systematic review. Rheumatology 47:239-248

271. Neill J, Belan I, Ried K (2006) Effectiveness of non-pharmacological interventions for fatigue in adults with multiple sclerosis, rheumatoid arthritis, or systemic lupus erythematosus: A systematic review. J Adv Nurs 56:617-635

272. Wessel J (2004) The effectiveness of hand exercises for persons with rheumatoid arthritis: a systematic review. JHand Ther 17:174-180

273. Eversden L, Maggs F, Nightingale $P$, Jobanputra $P$ (2007) A pragmatic randomised controlled trial of hydrotherapy and land exercises on overall well being and quality of life in rheumatoid arthritis. BMC Musculoskelet Disord 8:23

274. Baillet A, Vaillant M, Guinot $M$, Juvin $R$, Gaudin P (2012) Efficacy of resistance exercises in rheumatoidarthritis:Meta-analysis of randomized controlled trials (structured abstract). Rheumatology (Oxford) 51(3):519-527. (http://onlinelibrary.wiley.com/ o/cochrane/cldare/articles/DARE-12012014201/ frame.html.)

275. Baillet A, Zeboulon N, Gossec L, Combescure C, Bodin LA, Juvin R et al (2010) Efficacy of cardiorespiratory aerobic exercise in rheumatoid arthritis: meta-analysis of randomized controlled trials. Arthritis Care Res 62:984-992

276. Bulthuis Y, Drossaers-Bakker KW, Taal E, Rasker J, Oostveen J, van't Pad Bosch P et al (2007) Arthritis patients show long-term benefits from 3 weeks intensive exercise training directly following hospital discharge. Baillieres Clin Rheumatol 46:1712-1717

277. Bulthuis $Y$, Mohammad S, Braakman-Jansen LM, Drossaers-Bakker KW, van de Laar MA (2008) Cost-effectiveness of intensive exercise therapy directly following hospital discharge in patients with arthritis: Results of a randomized controlled clinical trial. Arthritis Rheum 59:247-254

278. Gaudin P, Leguen-Guegan S, Allenet B, Baillet A, Grange L, Juvin R (2008) Is dynamic exercise beneficial in patients with rheumatoid arthritis? Joint Bone Spine 75:11-17

279. Neuberger GB, Aaronson LS, Gajewski B, Embretson SE, Cagle PE, Loudon JK et al (2007) Predictors of exercise and effects of exercise on symptoms, function, aerobic fitness, and disease outcomes of rheumatoid arthritis. Arthritis Rheum 57:943-952
280. Plasqui G (2008) The role of physical activity in rheumatoid arthritis. Physiol Behav 94:270-275

281. Cairns AP, McVeigh JG (2009) A systematic review of the effects of dynamic exercise in rheumatoid arthritis. Rheumatol Int 30:147-158

282. Hsieh LF, Chen SC, Chuang CC, Chai HM, Chen WS, He YC (2009) Supervised aerobic exercise is more effective than home aerobic exercise in female chinese patients with rheumatoid arthritis. JRehabil Med 41:332-337

283. Hurkmans E, van der Giesen FJ, Vliet Vlieland TPM, Schoones J, Van den Ende Els CHM (2009) Dynamic exercise programs (aerobic capacity and/or muscle strength training) in patients with rheumatoid arthritis. Cochrane Database Syst Rev 2009 (4):CD006853. https://doi.org/10.1002/14651858. CD006853.pub2

284. Balsamo S, Diniz LR, dos Santos-Neto LL, da Mota LM (2014) Exercise and fatigue in rheumatoid arthritis. Isr Med Assoc J 16:57-60

285. Cramp F, Berry J, Gardiner M, Smith F, Stephens D (2013) Health behaviour change interventions for the promotion of physical activity in rheumatoid arthritis: A systematic review. Musculoskelet Care 11:238-247

286. Durcan L, Wilson F, Cunnane G (2014) The effect of exercise on sleep and fatigue in rheumatoid arthritis: a randomised controlled study. J Rheumatol 41(10):1966-1973. (http:// onlinelibrary.wiley.com/o/cochrane/clcentral/ articles/040/CN-01050040/frame.html)

287. Feldthusen $C$, Dean E, Forsblad-d'Elia H, Mannerkorpi K (2016) Effects of person-centered physical therapy on fatigue-related variables in persons with rheumatoid arthritis: A randomized controlled trial. Arch Phys Med Rehabil 97(1):26-36 (http://onlinelibrary.wiley.com/o/ cochrane/clcentral/articles/299/CN-01133299/ frame.html.)

288. de Jong Z, Munneke M, Zwinderman AH, Kroon HM, Jansen A, Ronday KH et al (2003) Is a long-term high-intensity exercise program effective and safe in patients with rheumatoid arthritis? Results of a randomized controlled trial. Arthritis Rheum 48:2415-2424

289. van den Berg MH, Ronday HK, Peeters AJ, le CessieS, van derGiesen FJ, Breedveld FCetal (2006) Using internet technology to deliver a home-based physical activity intervention for patients with rheumatoid arthritis: a randomized controlled trial. Arthritis Rheum 55:935-945

290. Santos I, Cantista P, Vasconcelos C, Amado J (2016) Balneotherapy and rheumatoid arthritis: a randomized control trial. Int J Biometeorol 60(8):1287-1301. (http://onlinelibrary.wiley.com/ o/cochrane/clcentral/articles/620/CN-01211620/ frame.html)

291. Verhagen AP, Bierma-Zeinstra SM, Boers $M$, Cardoso JR, Lambeck J, De Bie R et al (2015) Balneotherapy (or spa therapy) for rheumatoid arthritis. An abridged version of cochrane systematic review. Eur J Phys Rehabil Med 51:833-847

292. FieldT, Diego M, Delgado J,Garcia D, FunkCG (2013) Rheumatoid arthritis in upper limbs benefits from moderate pressure massage therapy. Complement Ther Clin Pract 19(2):101-103. (http:// onlinelibrary.wiley.com/o/cochrane/clcentral/ articles/678/CN-00913678/frame.html.)

293. Robinson V, Brosseau L, Casimiro L, Judd M, Shea B, Wells $G$ et al (2002) Thermotherapy for treating rheumatoid arthritis. Cochrane Database Syst Rev. https://doi.org/10.1002/14651858.CD002826
294. Hirvonen HE, Mikkelsson MK, Kautiainen H, Pohjolainen TH, Leirisalo-Repo M (2006) Effectiveness of different cryotherapies on pain and disease activity in active rheumatoid arthritis. A randomised single blinded controlled trial. Clin Exp Rheumatol 24:295-301

295. Brosseau L, Judd MG, Marchand S, Robinson VA, Tugwell P, Wells G et al (2003) Transcutaneous electrical nervestimulation (tens) for the treatment of rheumatoid arthritis in the hand. Cochrane Database Syst Rev. https://doi.org/10.1002/ 14651858.CD004287

296. Brosseau L, Robinson V, Wells G, Debie R, Gam A, Harman K et al (2005) Low level laser therapy (classes i, ii and iii) for treating rheumatoid arthritis. Cochrane Database Syst Rev. https://doi.org/10. 1002/14651858.CD002049.pub2

297. Meireles $S M$, Jones $A$, Jennings $F$, Suda $A L$, Parizotto NA, Natour J (2010) Assessment of the effectiveness of low-level laser therapy on the hands of patients with rheumatoid arthritis: A randomized double-blind controlled trial. Clin Rheumatol 29:501-509

298. Casimiro L, Brosseau L, Robinson V, MilneS, Judd M, Well G et al (2002) Therapeutic ultrasound for the treatment of rheumatoid arthritis. Cochrane Database Syst Rev. https://doi.org/10.1002/ 14651858.CD003787

299. Kelley GA, Kelley KS, Hootman JM, Jones DL (2011) Effects of community-deliverable exercise on pain and physical function in adults with arthritis and other rheumatic diseases: A meta-analysis (structured abstract). Arthritis Care Res (Hoboken) 63(1):79-93 (http://onlinelibrary.wiley.com/o/ cochrane/cldare/articles/DARE-12011001218/ frame.html.)

300. Evans S, Moieni M, Lung K, Tsao J, Sternlieb B, Taylor $M$ et al (2013) Impact of iyengar yoga on quality of life in young women with rheumatoid arthritis. Clin JPain 29:988-997

301. Moonaz SH, Bingham CO, Wissow L, Bartlett SJ (2015) Yoga in sedentary adults with arthritis: Effects of a randomized controlled pragmatic trial. J Rheumatol42(7):1194-1202.(http://onlinelibrary. wiley.com/o/cochrane/clcentral/articles/993/CN01097993/frame.html)

302. Singh VK, Bhandari RB, Rana BB (2011) Effect of yogic package on rheumatoid arthritis. Indian J Physiol Pharmacol 55(4):329-335. (http:// onlinelibrary.wiley.com/o/cochrane/clcentral/ articles/470/CN-00868470/frame.html)

303. Han A, Robinson V, Judd M, Taixiang W, Wells G, Tugwell P (2004) Tai chi for treating rheumatoid arthritis. Cochrane Database Syst Rev. https://doi. org/10.1002/14651858.CD004849

304. Lee MS, Pittler MH, Ernst E (2007) Tai chi for rheumatoid arthritis: Systematic review. Rheumatology 46:1648-1651

305. Steultjens EM, Dekker J, Bouter LM, Leemrijse CJ, van den Ende CH (2005) Evidence of the efficacy of occupational therapy in different conditions: an overview of systematic reviews. Clin Rehabil 19:247-254

306. Steultjens EM, Dekker J, Bouter LM, van Schaardenburg D, van Kuyk MA, van den Ende CH (2002) Occupational therapy for rheumatoid arthritis: a systematic review. Arthritis Rheum 47:672-685

307. Lamb SE, Williamson EM, Heine PJ, Adams J, Dosanjh S, Dritsaki M et al (2015) Exercises to improve function of the rheumatoid hand (sarah): A randomised controlled trial. Lancet 385:421-429

308. Cima SR, Barone A, Porto JM, Abreu DCC (2013) Strengthening exercises to improve hand strength and functionality in rheumatoid arthritis with 
hand deformities: A randomized, controlled trial. Rheumatol Int33(3):725-732 (http://onlinelibrary. wiley.com/o/cochrane/clcentral/articles/754/CN00904754/frame.html.)

309. Dogu B, Sirzai H, Yilmaz F, Polat B, Kuran B (2013) Effects of isotonic and isometric hand exercises on pain, hand functions, dexterity and quality of life in women with rheumatoid arthritis. Rheumatol Int 33(10):2625-2630. (http:// onlinelibrary.wiley.com/o/cochrane/clcentral/ articles/877/CN-00913877/frame.html)

310. Egan M, Brosseau L, Farmer M, Ouimet MA, Rees S, Wells G et al (2003) Splints/orthoses in the treatment of rheumatoid arthritis. Cochrane Database Syst Rev. https://doi.org/10.1002/ 14651858.CD004018

311. Baldwin D, Johnstone B, Ge B, Hewett J, Smith M, Sharp G (2012) Randomized prospective study of a work place ergonomic intervention for individuals with rheumatoid arthritis and osteoarthritis. Arthritis Care Res 64:1527-1535

312. Macedo AM, Oakley SP, Panayi GS, Kirkham BW (2009) Functional and work outcomes improve in patients with rheumatoid arthritis who receive targeted, comprehensive occupational therapy. Arthritis Rheum 61(11):1522-1530. (http:// onlinelibrary.wiley.com/o/cochrane/clcentral/ articles/390/CN-00728390/frame.html)

313. Conceicao CS, Gomes Neto M, Mendes SM, Sa KN, Baptista AF (2015) Systematic review and metaanalysis of effects of foot orthoses on pain and disability in rheumatoid arthritis patients. Disabil Rehabil 37:1209-1213

314. Gibson KS, Woodburn J, Porter D, Telfer S (2014) Functionally optimized orthoses for early rheumatoid arthritis foot disease: A study of mechanisms and patient experience. Arthritis Care Res (Hoboken) 66(10):1456-1464. (http:// onlinelibrary.wiley.com/o/cochrane/clcentral/ articles/120/CN-01022120/frame.html)

315. Hennessy K, Woodburn J, Steultjens MP (2012) Custom foot orthoses for rheumatoid arthritis: a systematic review. Arthritis Care Res 64:311-320

316. Moreira $E$, Jones $A$, Oliveira $H A$, Jennings $F$, Fernandes ARC, Natour J (2012) Effect of insoles on the rheumatoid foot. Scand J Rheumatol 45(5):363-370. (http://onlinelibrary.wiley.com/ o/cochrane/clcentral/articles/417/CN-01028417/ frame.html)

317. Rome K, Clark H, Gray J, McMeekin P, Plant M, Dixon J (2016) Clinical effectiveness and costeffectiveness of foot orthoses for people with established rheumatoid arthritis: An exploratory clinical trial. Scand J Rheumatol. https://doi.org/ 10.1080/03009742.2016.1196500

318. Novak P, Burger H, Tomsic M, Marincek C, Vidmar G (2009) Influence of foot orthoses on plantar pressures, foot pain and walking ability of rheumatoid arthritis patients—a randomised controlled study. Disabil Rehabil 31(8):638-645. (http:// onlinelibrary.wiley.com/o/cochrane/clcentral/ articles/225/CN-00704225/frame.html.)

319. Astin JA, Beckner W, Soeken K, Hochberg MC Berman B (2002) Psychological interventions for rheumatoid arthritis: a meta-analysis of randomized controlled trials. Arthritis Rheum 47:291-302

320. Dixon KE, Keefe FJ, Scipio CD, Perri LM, Abernethy AP (2007) Psychological interventions for arthritis pain management in adults: A metaanalysis. Health Psychol 26:241-250

321. Evers AW, Kraaimaat FW, van Riel PL, de Jong AJ (2002) Tailored cognitive-behavioral therapy in early rheumatoid arthritis for patients at risk: A randomized controlled trial. Pain 100:141-153

322. Savelkoul M, de Witte L, Post M (2003) Stimulating active coping in patients with rheumatic diseases:a systematic review of controlled group intervention studies. Patient Educ Couns 50:133-143

323. Sharpe L, Allard S, Sensky T (2008) Five-year followup of a cognitive-behavioral intervention for patients with recently-diagnosed rheumatoid arthritis: effects on health care utilization. Arthritis Rheum 59:311-316

324. Sharpe L, Sensky T, Timberlake N, Ryan B, Allard S (2003) Long-term efficacy of a cognitive behavioural treatment from a randomized controlled trial for patients recently diagnosed with rheumatoid arthritis. Rheumatology 42:435-441

325. Barsky AJ, Ahern DK, Orav EJ, Nestoriuc Y, Liang MH, Berman IT et al (2010) A randomized trial of three psychosocial treatments for the symptoms of rheumatoid arthritis. Semin Arthritis Rheum 40(3):222-232. (http://onlinelibrary.wiley.com/ o/cochrane/clcentral/articles/747/CN-00781747/ frame.html)

326. Fogarty FA, Booth RJ, Gamble GD, Dalbeth N, Consedine NS (2015) The effect of mindfulnessbased stress reduction on disease activity in people with rheumatoid arthritis: a randomised controlled trial. Ann Rheum Dis 74(2):472-474. (http:// onlinelibrary.wiley.com/o/cochrane/clcentral/ articles/246/CN-01049246/frame.html)

327. Hewlett S, Ambler N, Almeida C, Cliss A, Hammond A, Kitchen K et al (2011) Self-management of fatigue in rheumatoid arthritis: a randomised controlled trial of group cognitive-behavioural therapy. Ann Rheum Dis 70(6):1060-1067. (http:// onlinelibrary.wiley.com/o/cochrane/clcentral/ articles/651/CN-00788651/frame.html)

328. Knittle K, Maes S, Gucht V (2010) Psychological interventions for rheumatoid arthritis: Examining the role of self-regulation with a systematic review and meta-analysis of randomized controlled trials. Arthritis Care Res (Hoboken) 62(10):1460-1472. (http://onlinelibrary. wiley.com/o/cochrane/clcentral/articles/525/CN00898525/frame.html)

329. Lumley MA, Keefe FJ, Mosley-Williams A, Rice JR, McKeeD, WatersSJetal (2014) The effects of written emotional disclosure and coping skills training in rheumatoid arthritis: A randomized clinical trial. J Consult Clin Psychol 82(4):644-658. (http:// onlinelibrary.wiley.com/o/cochrane/clcentral/ articles/684/CN-00998684/frame.html.)

330. Lee MS, Shin BC, Ernst E (2008) Acupuncture for rheumatoid arthritis: a systematic review. Rheumatology 47:1747-1753

331. Wang C, de Pablo P, Chen X, Schmid C, McAlindon T (2008) Acupuncture for pain relief in patients with rheumatoid arthritis: A systematic review. Arthritis Rheum 59:1249-1256

332. Park J, Ernst E (2005) Ayurvedic medicine for rheumatoid arthritis: A systematic review. Semin Arthritis Rheum 34:705-713

333. Cameron M, Gagnier JJ, Chrubasik S (2011) Herbal therapy for treating rheumatoid arthritis. Cochrane Database Syst Rev. https://doi.org/10. 1002/14651858.CD002948.pub2

334. Macfarlane GJ, El-Metwally A, De Silva V, Ernst E, Dowds GL,MootsRJ(2011)Evidenceforthe efficacy of complementary andalternative medicines in the management of rheumatoid arthritis: A systematic review. Rheumatology 50:1672-1683

335. Wang HL, Jiang Q, Feng XH, Zhang HD, Ge L, Luo CG et al (2016) Tripterygium wilfordii hook $f$ versus conventional synthetic disease-modifying anti- rheumatic drugs as monotherapy for rheumatoid arthritis: A systematic review and network metaanalysis. BMC Complement Altern Med 16:215

336. Wang X, Zu Y, Huang L, Yu J, Zhao H, Wen C et al (2017) Treatment of rheumatoid arthritis with combination of methotrexate and tripterygium wilfordii: a meta-analysis. Life Sci 171:45-50

337. Zhang W, Shi Q, Zhao LD, Li Y, Tang FL, Zhang FC et al (2010) The safety and effectiveness of a chloroform/methanol extract of tripterygium wilfordii hook $\mathrm{f}(\mathrm{t} 2)$ plus methotrexate in treating rheumatoid arthritis. J Clin Rheumatol 16:375-378

338. Brien S, Lachance L, Prescott $P, M c D e r m o t t$ C, Lewith G (2011) Homeopathy has clinical benefits in rheumatoid arthritis patients that are attributable to the consultation process but not the homeopathic remedy: A randomized controlled clinical trial. Rheumatology (Oxford) 50(6):1070-1082. (http://onlinelibrary.wiley.com/ o/cochrane/clcentral/articles/373/CN-00802373/ frame.html)

339. Kåre HB, Byfuglien Marte G, Falzon L, Olsen Sissel U, Smedslund G (2009) Dietary interventions for rheumatoid arthritis. Cochrane Database Syst Rev. https://doi.org/10.1002/14651858.CD006400. pub2

340. Jiang J, LiK, Wang F, Yang B, Fu Y, Zheng Jetal (2016) Effect of marine-derived $n-3$ polyunsaturated fatty acids on major eicosanoids: a systematic review and meta-analysis from 18 randomized controlled trials. PLoS ONE 11:e147351

341. Miles EA, Calder PC (2012) Influence of marine $n-3$ polyunsaturated fatty acids on immune function and a systematic review of their effects on clinical outcomes in rheumatoid arthritis (provisional abstract). Br J Nutr 107(Suppl 2):S171-184 (http://onlinelibrary.wiley.com/o/ cochrane/cldare/articles/DARE-12012029080/ frame.html.)

342. Olendzki BC, Leung K, Buskirk S, Reed G, Zurier RB (2011) Treatment of rheumatoid arthritis with marine and botanical oils: Influence on serum lipids. Evid Based Complement Alternat Med 2011:827286 (http://onlinelibrary.wiley.com/o/ cochrane/clcentral/articles/291/CN-00898291/ frame.html)

343. Proudman SM, Cleland LG, Metcalf RG, Sullivan TR, Spargo LD, James MJ (2015) Plasma n-3 fatty acids and clinical outcomes in recent-onset rheumatoid arthritis. Br J Nutr 114(6):885-890. (http:// onlinelibrary.wiley.com/o/cochrane/clcentral/ articles/460/CN-01097460/frame.html)

344. Proudman SM, James MJ, Spargo LD, Metcalf RG, Sullivan TR, Rischmueller M et al (2015) Fish oil in recent onset rheumatoid arthritis: A randomised, double-blind controlled trial within algorithmbased drug use. Ann Rheum Dis 74:89-95

345. Prevoo ML, van't Hof MA, Kuper HH, van Leeuwen MA, van de Putte LB, van Riel PL (1995) Modified disease activity scores that include twenty-eight-joint counts. Development and validation in a prospective longitudinal study of patients with rheumatoidarthritis. Arthritis Rheum 38:44-48

346. Smolen JS, Breedveld FC, Schiff MH, Kalden JR, Emery P, Eberl G et al (2003) A simplified disease activity index for rheumatoid arthritis for use in clinical practice. Rheumatology 42:244-257

347. Aletaha D, Smolen J (2005) The simplified disease activity index (sdai) and the clinical disease activity index (cdai): A review of their usefulness and validity in rheumatoid arthritis. Clin Exp Rheumatol 23:S100-S108 